Quarterly Progress Report

\title{
Research and Development
}

Activities

Waste Fixation Program

January through March 1975

June 1975

Prepared for the U.S. Energy

Research and Development Administration under Contract AT(45-1):1830 
NOTICE

This report was prepared as an account of work sponsored by the United States Government. Neither the United States nor the United States Energy Research and Development Administration, nor any of their employees, nor any of their contractors, subcontractors, or their employees, makes any warranty, express or implied, or assumes any legal liability or responsibility for the accuracy, completeness or usefulness of any information. apparatus, product or process disclosed, or represents that its use would not infringe privately owned rights.

\section{PACIFIC NORTHWEST LABORATORY}

operated by

BATTELLE

for the

U.S. ENERGY RESEARCH AND DEVELOPMENT ADMINISTRATION

Under Contract $E(45-1)-1830$ 
BNWL- 1908

UC-70

Waste Disposal

and Processing

QUARTERLY PROGRESS REPORT

RESEARCH AND DEVELOPMENT ACTIVITIES

WASTE FIXATION PROGRAM

JANUARY THROUGH MARCH 1975

Compiled by

J. L. McElroy

Chemical Technology Department

June 1975

On January 19, 1975, research and development programs of the U.S. Atomic Energy Commission (AEC) became part of the newly formed Energy Research and Development Administration (ERDA). In this report, since it refers to work done in 1974, most references are to AEC programs.

Battelle

Pacific Northwest Laboratories

Richland, Washington 99352 
LIST OF FIGURES • • • • • • • • • • • • • • • • • •

LIST OF TABLES • • • • • • • • • • • • • • • • • •

INTRODUCTION • • • • • • • • • • • • • • • • • • • 1

SUMMARY • • • • • • • • • • • • • • • • • • • • 1

COMMERCIAL WASTE FIXATION • • • • • • • • • • • • • • 5

In-Can Melting • • • • • • • • • • • • • • • • 5

Joule-Heated Ceramic Melter . . . . . • . . . . 15

Fluidized Bed Calciner . . . . . . . . . . . 20

Wiped Film Evaporator . • • • . • • . • • . . . 30

WASTE FORM CHARACTERIZATION • • • • • • • • • • • • • • 33

Commercial Radioactive Waste Compositions Used in the Waste Fixation Program . • . . . . . . . . . 33

Glass Composition Development • . • • • • • • • . 35

Stored Energy Measurements . • . • • • • . • • . 40

Helium in Glass . • • • • • • • • • • • • • • 41

Radiolytic Gas Generation . . . . . . . . . . . 46

Full-Level Radioactive Tests . . . . • . • . . . . 48

SS-9 Canister Evaluation Status . • • • • • • . • . 48

Impact Testing of Vitreous Simulated High-Level 49

Waste in Canisters . • • . • • • • • • • . • • . 49

Thermal Properties of Waste Forms . . . . . . . . . 49

ALTERNATIVE WASTE FIXATION PROCESSES • • • • • • • • • • • 51

Glass Sintering • • • • • • • • • • • • • • • 51

Plasma Spray System • • • • • • • • • • • • • 53

Advanced Product Forms Research and Development . . . . . 56

Silica Matrix Isolation by Hot Pressing . . . . . • . . 57

Supercalcine . • • • • • • • • • . • • • 61

Cs Fixation . . . . . . . . . • • . • • . 62

Formulations . . . . . . . . . . • . . . . 63

SYSTEMS EVALUATION • • • • • • • • • • • • • • • • • 65

Summary • • • • • • • • • • • • • • • • • • 65 
Page

Fault Tree Evaluation Methodology . . . . . . . 65

Transportation of Solidified High-Level Waste . . . . . 66

Liquid Storage and Transfer . . . . . . . . . 68

Migration of Radioactive Elements Through Subsoils . • • 68

Consequences of Resuspension of an Airborne Release . • • . 72

DISTRIBUTION . • • . . . • • • • • • • • • • 73 


\section{LIST OF FIGURES}

Page

1 Melting Rate as a Function of Surface Temperatures for a 12-in. Diam Canister . . . . . . . . . 8

2 Cooling of Canister Surfaces and Product During Selected In-Can Melting Runs . . . . . . . . . . 9

3 Product of ICM-4 . . . . . . . . . . . . 13

4 Corrosion Rate of 304L Stainless Steel in Simulated HLW Glass Melt • • • • • • • • • • • • • 14

5 Temperatures in Melter While Idling . . . . . . . 16

6 Temperature/Power History During Batch Melting . . . . . . 19

7 Fluidized Bed Calciner Coupled to the In-Can Melter . • . - 21

8 Run Data FBC-5 • . • . • • • • • • • • • • 23

9 Distribution of Overhead Fines FBC-5 . • • • • • • • • 24

10 Viscosity of Zinc Borosilicate Glasses Containing AGNS-Type High-Level Waste . . . . . • . . . 37

11 Effect of Fission Product and Sodium Content on Leach Rate and Molybdenum Phase Separation . . . . . . 38

12 Onset Temperature of Energy Release . • . . . • • • 41

13 Quantity of Stored Energy Released as Function of Storage Temperature • • • . . • . • • . . . 4.1

14 Isotherma] Helium Release After 168 Days' Ingrowth for Sample A-23-1, Plotted as cc/sec Versus Time . . . . . 42

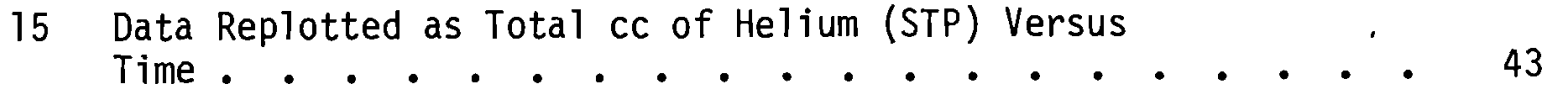

16. Isotherm at $351^{\circ} \mathrm{C}$ Plotted as Fractional Release
Versus Time and Compared to Theoretical Curves . . . . . . 44

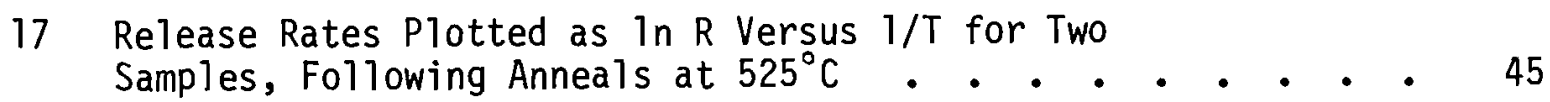

$18 \mathrm{CO}_{2}$ Adsorption of PW-7 Nuclear Waste . • • • • • • • • 47 
Page

19 Heat Capacity of PW-4b-2 Calcine . • • • • • • • . 50

20 Heat Capacity of 72-68 Glass . . . . . . . . . . 50

21 Characteristics of High-Calcine Content Pellets

Formed with PW-4b-2 Calcine and 75-10 Frit at $875^{\circ} \mathrm{C}$. . . . 52

22 50X Photomicrograph of Pellet of 65 wt\% PW-4b-2

Calcine and 35 wt\% 75-10 Frit Sintered at $900^{\circ} \mathrm{C}$

for $2 \mathrm{hr}$

23 1000X SEM Micrograph of Above Pellet . • • • • • • • 54

24 SEM Secondary Electron Photomicrographs of HP-41 at

100X and $3000 \mathrm{X}$. . . . . . . . . . . . . 58

25 Top Levels of the Rail Transportation Fault Tree • • • • • 67

26 Example of the Use of Inhibit Gates in the Rail

Transportation Fault Tree . . . . . . . • . . . . . 67

27 Fault Tree for High Level Liquid Storage Facility . • • • • 69

\section{LIST OF TABLES}

1 Summary of Data for Runs ICM-3 Through 7 . . . . . . . 7

2 Results of Huey Tests Performed on Samples from

ICM-3 and ICM-4 Canisters . . . . . . . . . . . . . 9

3 Canister Diameter Changes as a Result of the

In-Can Melting Process . . . . . . . . . . 10

4 Some Characteristics of Products of ICM-1

Through 7 . . • . • • . • • . • • . . . 12

5 Test Results of Scouting Run • • • • • • • • • • • • 19

6 88-hr PW-7 Run Operating Conditions . • • • • • • • • 22

7 Bed and Overhead Product Characteristics . . . . . . . . 24 
Page

8 Overhead Fines Size Distribution . . . . . . . . 25

9 FBC-5 Off-Gas Composition . . . . . . . . . . 25

10 Particle Size and Concentration - Fluidized Bed Calciner FBC-5 . . . . . . . . . . . 25

11 Operating Conditions . . . . . . . . . . . . 27

12 Overhead Fines Distribution . . . . . . . . . . 29

13 Bed and Overhead Product Characteristics . . . . . . 29

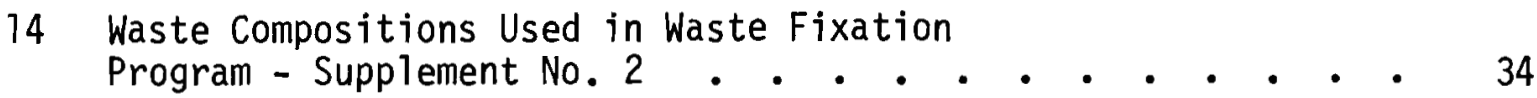

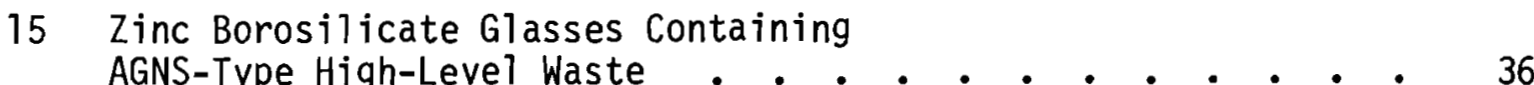

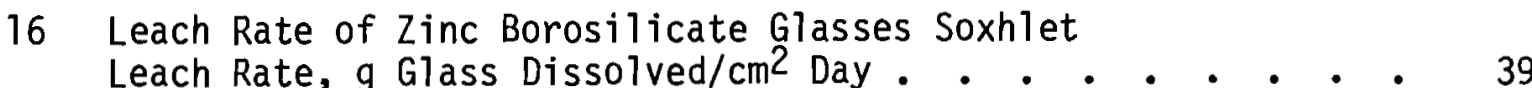

17 Thermal Conductivity of Glass . . . . . . . . . . 49

18 Costs to Spray Coat Waste Containers . . . . . . . . 56

19 Composition and Product Characterization for

20 Estimated Distribution Coefficients for Trace Radionuclides in Southeastern United States Soil . . . . . 71

21 Estimated Composition of Groundwater Below a Typical Southeastern United States Area . . . . . . . 72 


\author{
QUARTERLY PROGRESS REPORT \\ RESEARCH AND DEVELOPMENT ACTIVITIES \\ WASTE FIXATION PROGRAM \\ JANUARY THROUGH MARCH 1975
}

\begin{abstract}
INTRODUCTION
This progress report is the tenth in a series that presents research and development activities in radioactive waste fixation. Previous progress reports were BNWL-1699, 1741, 1761, 1788, 1809, 1826, 1841, 1871 and 1893.
\end{abstract}

\title{
SUMMARY
}

Four engineering-scale in-can melting tests were conducted. One of the tests established the melting rate in a 12 in.-diam canister and three successfully demonstrated direct coupling of the in-can melting system to the spray calciner, the fluid bed calciner, and the wiped film evaporator. Product characteristics and thermal effects on canister and canister materials were investigated.

The joule-heated ceramic melter has been in continuous operation for 70 days. A short-term capacity test indicated an instantaneous melting rate as high as $140 \mathrm{lb} / \mathrm{hr}$.

The fluidized bed calciner was successfully operated during the last report period. Tests included direct coupling to the in-can melter, an 88-hr run using concentrated $\mathrm{PW}-7$ feed and a $14-\mathrm{hr}$ run investigating the attrition-elutriation concept.

The wiped film evaporator was operated directly coupled to a metallictype melter and then to an in-can melting system. Tests with the closecoupled metallic melter continued to reveal problems in discharge plugging 
and solids carry-over in the off-gas system. Tests of the evaporator coupled to the in-can melting system were free of significant problems.

Two new waste compositions were defined representing typical combinations of ILW with the reference AGNS HLW. Iron was added to one of the compositions as an aid to improving fluidized bed calcination.

Laboratory-scale melts were prepared to determine the characteristics of zinc borosilicate glass containing AGNS-type waste aimed toward achieving the maximum fission product loading in glasses containing HLW, combined HLW-ILW, and combined HLW-ILW plus iron. Indications are that the combined compositions will require longer time or higher temperature to achieve homogeneous glasses.

Experiments were conducted to observe the effect of solidified waste temperature on the stored energy behavior. The results indicate that the quantity of stored energy is inversely proportional to the storage temperature and therefore can be limited to some extent by maintaining the solidified waste at a slightly elevated temperature.

Preliminary runs with the new mass spectrometer were made to study helium diffusivity in simulated waste glass.

Failed canister number 36 from the Waste Solidification Engineering Prototype program was overpacked in stainless steel, helium leak checked, and returned to the water test pod. Tests of a stainless steel sample trepanned from the canister showed that the material was fully-sensitized.

Sintered pellets of a calcine and frit mixture were formed, characterized, and coated. Preliminary evaluations indicate that two pellet sizes using different coating methods should be considered: for the larger, about 1-in. in diam, and the smaller, in the 1-mm diam range. Optical and electron microscopy of sintered pellets shows considerable porosity, but indications are that much of the porosity is still closed. Tests showed that highly leach-resistant and impact-resistant frit coatings can be applied to waste pellets. 
At Pennsylvania State University the investigation of advanced solidified waste forms continued. Samples prepared to study silica matrix isolation of waste by hot pressing were subjected to microstructure examination, leach testing, x-ray phase analysis before and after leaching and before and after heat treatment, and tests of thermal stability. Development of supercalcine continued in two areas, 1) identification and characterization of refractory and leach resistant phases which can fix cesium and 2) designing improved formulations. Emphasis has shifted to incorporation of cesium in aluminosilicates.

Computer codes were written to evaluate the probability of previously identified failure sequences, release fractions, and ordered risk measures of the failure sequences. The codes will be used to evaluate the large fault trees developed for the reference high-level waste management system. 


\section{COMMERCIAL WASTE FIXATION}

The purpose of this task is to develop processes and equipment for converting liquid high-level radioactive waste to a stable, relatively nondispersible form for storage and, ultimately, disposal. This objective is generally being accomplished by development of a two-step approach, calcination or concentration, followed by melting to form a silicate glass.

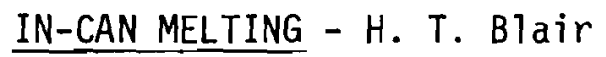

The purpose of this study is to further devezop a method of melting a mixture of nuclear waste calcine and glass former using the storage canister as the melting crucible.

Four engineering-scale tests of in-can melting were made. A melting rate of $17 \mathrm{~kg} / \mathrm{hr}$ was demonstrated for a 12-in. diam canister. Direct coupling of the in-can melting system to the spray calciner, to the fluid bed calciner (FBC) and to the wiped film evaporator (WFE) was successfully demonstrated. Various cooling programs and their effects on canister material sensitization were investigated during the runs, and the residual stress in a canister following a run was measured. Sensitization does not appear to be a problem in canisters of $304 \mathrm{~L}$ stainless steel, but the residual stress was found to be high in both the axial and hoop directions in the canister walls. The product of the in-can melting runs is a heterogenous mixture of various crystalline phases suspended in a glass with some separation of certain species resulting in the accumulation of a $\mathrm{CeO}_{2}$ rich layer on the bottom and a soluble layer of molybdates on the top. Leach resistance of all but the top layer is very satisfactory.

The canisters used for the four in-can melting demonstrations described in this report were suspended in a concentric, resistance-heated, singlezone furnace. Temperatures were monitored with type $K$ thermocouples located down the central axis of the canisters and on the canister exterior walls. For all the runs except that with the WFE, the cans were capped by a coupling section fitted with a 4-in. diam metal bellows, a quartz viewing port, and a 
pressure sensing line. Connection to the batch source was made through the bellows, which accommodates thermal expansion, vibration, and some misalignment. A section of $4-i n$. diam schedule 40 pipe connected the canister cap to the discharge ports of the two calciners. This pipe served as both the canister off-gas and the feed line. The effluent from the canister passed up the pipe and was vented through the calciner exhaust filters while calcine and frit dropped down the pipe into the canister. The pipe was insulated but did not require heating to prevent effluent condensation. The mechanically blended batch for the run with the 12-in. diam canister, and the frit for the runs with the spray calciner and WFE were fed through a port in the side of the connecting pipe.

The canister was coupled to the WFE with an 8-in. diam, heated, thinwalled, stainless steel tube. Concentrate dropped from the discharge spout of the WFE to the canister through this tube without contacting its surface, and the effluents from the drying, denitration, and melting occurring in the canister rose up this tube and were extracted several feet above the canister through a port into the off-gas treatment system.

A summary of the operating parameters and results of the in-can melting runs covered in this report, and for comparison run ICM-3 reported previously,* are presented in Table 1. Run ICM-4 was made to establish the melting capacity of a 12-in. canister. The canister was filled to the 3-ft level with $87.5 \mathrm{~kg}$ of batch and lowered into a furnace preheated to $1000^{\circ} \mathrm{C}$. The melting rate of $17 \mathrm{~kg} / \mathrm{hr}$ is based on the $5.25 \mathrm{hr}$ required to bring the center line temperatures of the initial charge of batch to $1000^{\circ} \mathrm{C}$ but does not include the time required to refine the melt. It may be more correct to state this melting rate as a function of charge height as well as mass because the time required to melt to the center of the mass is only a function of the radius when there is little heating at the ends. Therefore the melting rate would be $5.6 \mathrm{~kg} / \mathrm{ft}-\mathrm{hr}$.

A melting rate of $14.5 \mathrm{~kg} / \mathrm{hr}$ was obtained by feeding the batch at a rate that maintained the melt surface at the $3-\mathrm{ft}$ level. The effects of

* H. T. Blair and R. B. Dakan, Quarterly Progress Report, BNWL-1893, p. 8, February 1975. 
TABLE 1. Summary of Data for Runs ICM-3 Through 7

\begin{tabular}{|c|c|c|c|c|c|}
\hline Run No. & $\mathrm{ICH}-3$ & ICM-4 & ICM-5 & $\mathrm{ICM}-6$ & iCM-7 \\
\hline Date of Run & $12-11-74$ & $1-23-75$ & $2-6-75$ & $2-19-75$ & $2-27-75$ \\
\hline Coupled To & Screw Feeder & Screw feeder & Spray Calciner & Fluid Bed Calciner & W1ped Film Evaporator \\
\hline \multicolumn{6}{|l|}{ Canister } \\
\hline Diameter, in. & $8 \mathrm{SCH} 40$ & 12 & $8 \mathrm{SCH} 40$ & $8 \mathrm{SCH} 40$ & $8 \mathrm{SCH} 40$ \\
\hline Length, in. & 48 & 60 & 48 & 56 & 56 \\
\hline Hall Thickness, in. & 0.32 & 0.41 plate & 0.32 & 0.32 & 0.32 \\
\hline Material & 304L SS & 304L SS & 304L SS & $304 \mathrm{~L}$ SS & $304 \mathrm{~L} 55$ \\
\hline No. of Internal Fins & 8 & None & None & None & 8 \\
\hline \multicolumn{6}{|l|}{ Batch. } \\
\hline Haste Type & PW-4b-2 & $P W-4 b-2$ & PW-7-2 & Cothercial & $\mathrm{PH}-7-2$ \\
\hline Waste Form & Spray Dried & Spray Dried & Spray Dried & Fluid Bed & WFE Concentrate \\
\hline Waste Oxide-to-Frit Ratio & $1: 3$ & $1: 3$ & $1: 1.8$ to $1: 4.6$ & $1: 2.6$ & $1: 2.2$ \\
\hline Frit Type & $73-1$ & $73-1$ & $73-1$ & $73-1$ & $73-1$ \\
\hline Frit Form & $-325 M$ & $-325 \mathrm{M}$ & $-6 /+2014$ & Proprietary & $-6 /+20 \mathrm{H}$ \\
\hline Batch Preparation & Mixed & Mixed & None & Proprietary & None \\
\hline Batch Weight, kg & 68.0 & 220.0 & 64.5 & NA & NA \\
\hline \multicolumn{6}{|l|}{ Operating Parameters } \\
\hline rime at Melt Temperature, $\mathrm{hr}$ & 6.2 & 26.2 & 9.4 & 21.1 & 9.8 \\
\hline Nominal Surface Temperatures, ${ }^{\circ} \mathrm{C}$ & $1025-1075$ & $1020-1050$ & $1020-1050$ & $1000-1060$ & $1035-1075$ \\
\hline Nominal Melt Temperatures, ${ }^{\circ} \mathrm{C}$ & 975 & $1025-1050$ & 1045 & 1050 & NA \\
\hline Feed Method & Continuous & Batch \& Cont. & Continuous & Continuous & Continuous \\
\hline Feed Conditioning & Batched & Batched & Proportiona 1 & Batched & Proportional \\
\hline Waste 0 xide Feed Rate, $\mathrm{kg} / \mathrm{hr}$ & NA & NA & 2.4 to 2.7 & Ma & 11.1 as Concentrate \\
\hline Frit Feed Rate, $\mathrm{kg} / \mathrm{hr}$ & NA & NA & 4.8 to 11.1 & NA & 8.4 \\
\hline Batch Feed Rate, $\mathrm{kg} / \mathrm{hr}$ & $20.4 \& 40.8$ & $6.4,14.5,27.0$ & 7.4 to 13.3 & 9.0 & 12.2 solids \\
\hline Melting Rate, $\mathrm{kg} / \mathrm{hr}$ & 20.4 to 29.5 & 14.5 to 17.0 & $>13.3$ & 29.0 & $<12.2$ \\
\hline Power Consumption, $\mathrm{kW}$ & 14.9 & 17.2 & 14.4 & 14.3 & 21.7 \\
\hline \multicolumn{6}{|l|}{ Cooling Rate, ${ }^{\circ} \mathrm{C} / \mathrm{hr}$} \\
\hline 1025 to $750^{\circ} \mathrm{C}$ & 48 & 157 & 46 & 30 & 48 \\
\hline 750 to $500^{\circ} \mathrm{C}$ & 26 & 294 & 24 & 36 & 22 \\
\hline 500 to $25^{\circ} \mathrm{C}$ & 6 & 8 & 10 & 6 & 6 \\
\hline \multicolumn{6}{|l|}{ Product } \\
\hline Type & PW-4b-2(1:3)73-1 & $P W-4 b-2(1: 3) 73-1$ & $P W-7-2(1: 3) 73-1$ & $(1: 26) 73-1$ & $\mathrm{PW}-7-2(1: 2) 73-1$ \\
\hline Weight, $\mathrm{kg}$ & 65.3 & 216.6 & 57.4 & 93.0 & 49.4 \\
\hline Volume, $\&$ & 19.7 & 74.5 & 19.68 & 27.8 & 15.1 \\
\hline Bulk Density, $g / c c$ & 3.31 & 2.91 & 2.92 & 3.34 & 3.27 \\
\hline Apparent Density, $g / c c$ & 3.32 & 3.34 & 3.25 & 3.43 & 3.44 \\
\hline Weight Lost, $\%$ & 4 & 1.5 & NA & NA & NA \\
\hline Leach Rate, wt\% lost in $72 \mathrm{hr}$ & 0.93 & 0.69 & 0.55 & 0.85 & 0.40 \\
\hline Unfixed Material, $\mathrm{g} / \mathrm{cm}^{2}$ & 0.09 & 0.14 & 0.09 & 0.19 & NA \\
\hline
\end{tabular}

temperature on the constant level melting rate are shown in Figure 1 . The lower surface temperatures at the level where melting is occurring are necessary to maintain safe temperatures at the bottom of the canister when using a single-zone furnace.

Because the cooling process used for previous in-can melting runs was believed to result in sensitization of the 304L stainless steel, an attempt 


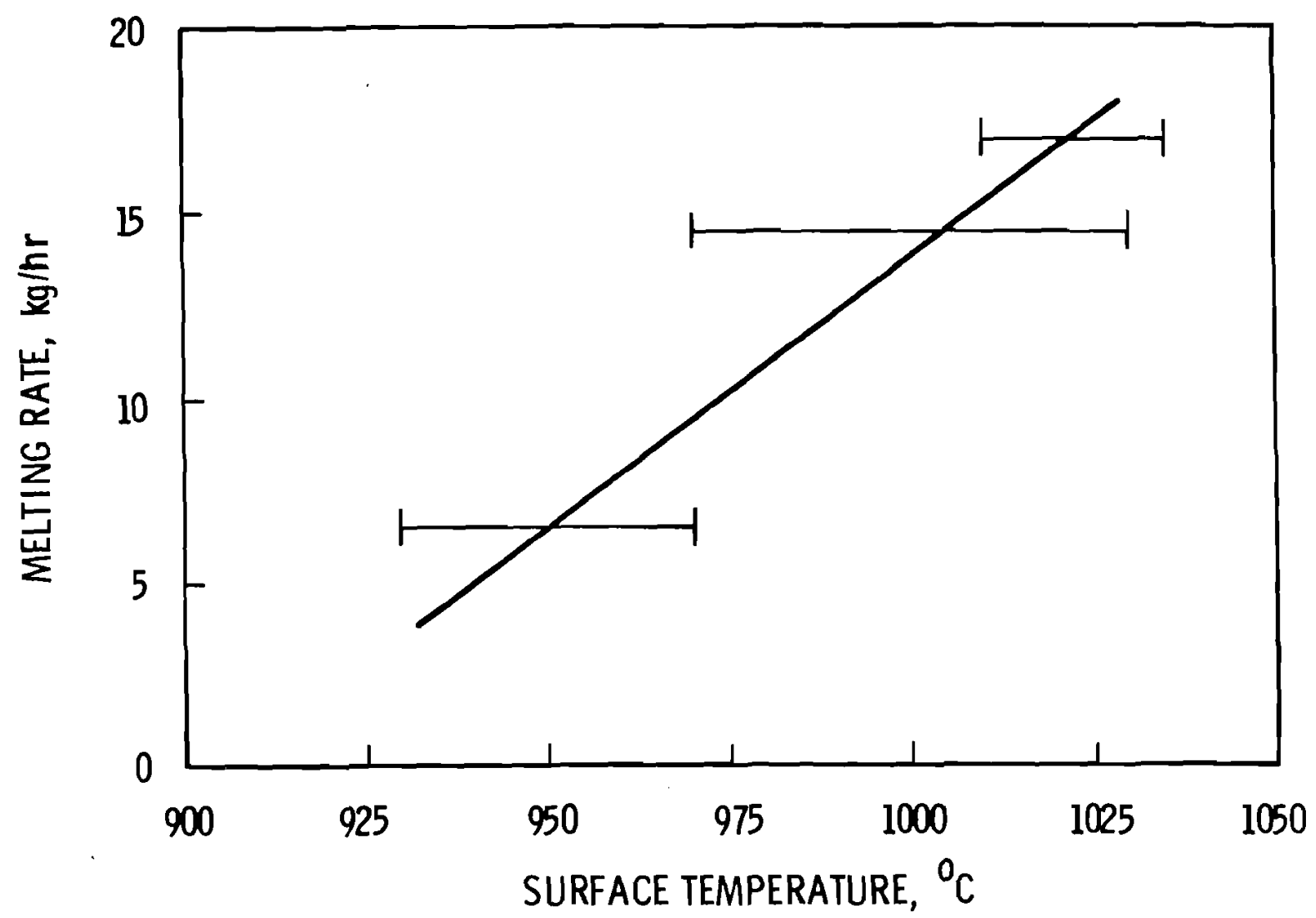

FIGURE 1. Melting Rate as a Function of Surface Temperatures for a 12-in. Diam Canister

was made during the cooling of ICM-4 to rapidly cool the canister between $750^{\circ} \mathrm{C}$ and $480^{\circ} \mathrm{C}$, where sensitization is known to occur. The resulting cooling curve is presented in Figure 2 and compared to the cooling of the canisters of ICM-3 and ICM-6. Samples of steel from the canisters used in ICM-3 and ICM-4 were subjected to Huey tests, and the results are presented in Table 2. In this test a corrosion rate greater than $2 \mathrm{mils} /$ month average indicates significant sensitization of the material. Therefore, sensitization of canisters made with $304 \mathrm{~L}$ stainless steel does not appear to be a problem with the in-can melting process. 


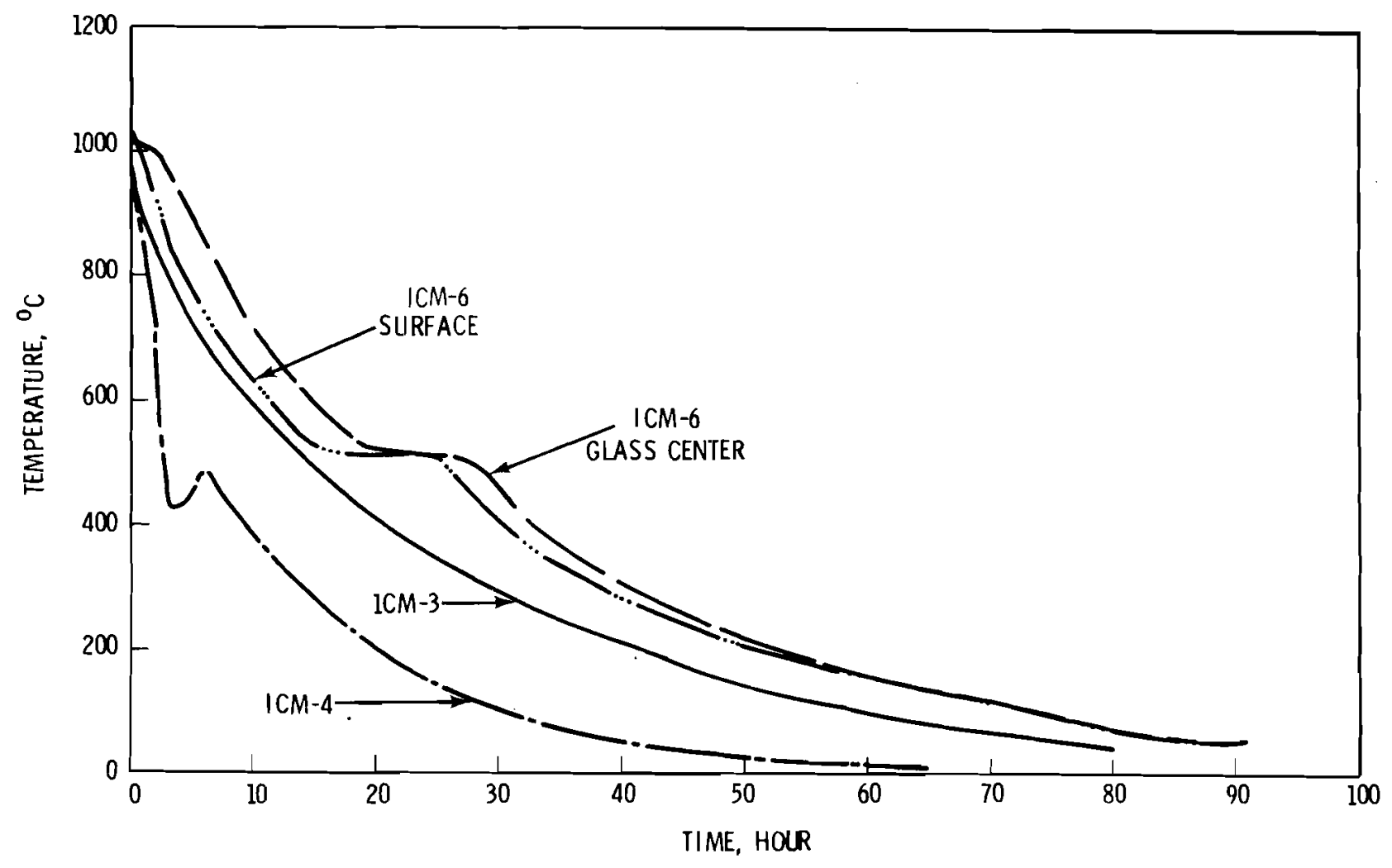

FIGURE 2. Cooling of Canister Surfaces and Product During Selected In-Can Melting Runs

TABLE 2. Results of Huey Tests Performed on Samples from ICM-3 and ICM-4 Canisters

\begin{tabular}{|c|c|c|c|c|}
\hline \multirow[t]{2}{*}{ Period } & \multicolumn{4}{|c|}{ Corrosion Rate, mils/month } \\
\hline & ICM-3 & ICM-4 Top & ICM-4 Middle & ICM-4 Bottom \\
\hline 1 & 0.81 & 0.92 & 0.96 & 1.12 \\
\hline 2 & 0.60 & 0.89 & 0.90 & 0.92 \\
\hline 3 & 0.60 & 0.98 & 0.94 & 0.89 \\
\hline 4 & 0.60 & 1.22 & 1.02 & 0.92 \\
\hline 5 & 0.59 & 1.67 & 1.13 & 0.91 \\
\hline Mean & 0.64 & 1.14 & 0.99 & 0.95 \\
\hline
\end{tabular}


Because increases in the canister diameter below the melt level have been observed for every canister of glass so far prepared, as shown in Table 3, measurements were made of the residual stress in the ICM-4 canister above and below the melt level after it had cooled. The measurements showed that the residual stress below the melt level in the hoop direction was 30,100 psi and in the axial direction was $36,700 \mathrm{psi}$. These stresses are high relative to the typical yield stress value of 35,000 psi for $304 \mathrm{~L}$ stainless steel. Because there is concern that these residual stresses may contribute to stress corrosion cracking of the canisters in water storage, methods to eliminate or at least greatly reduce them are being investigated. These methods include canister designs that will yield to relieve the stress and use of canister alloys with expansion coefficients matching that of the vitrified product.

TABLE 3. Canister Diameter Changes as a Result of the In-Can Melting Process
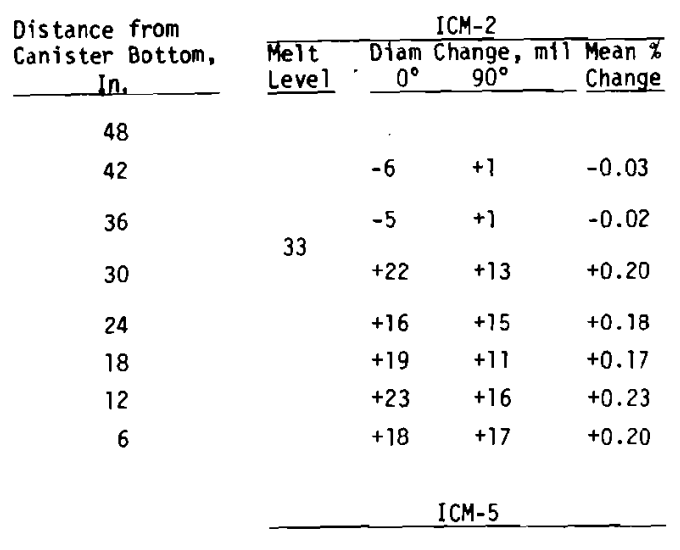

48
42
36
30
24
18
12
6
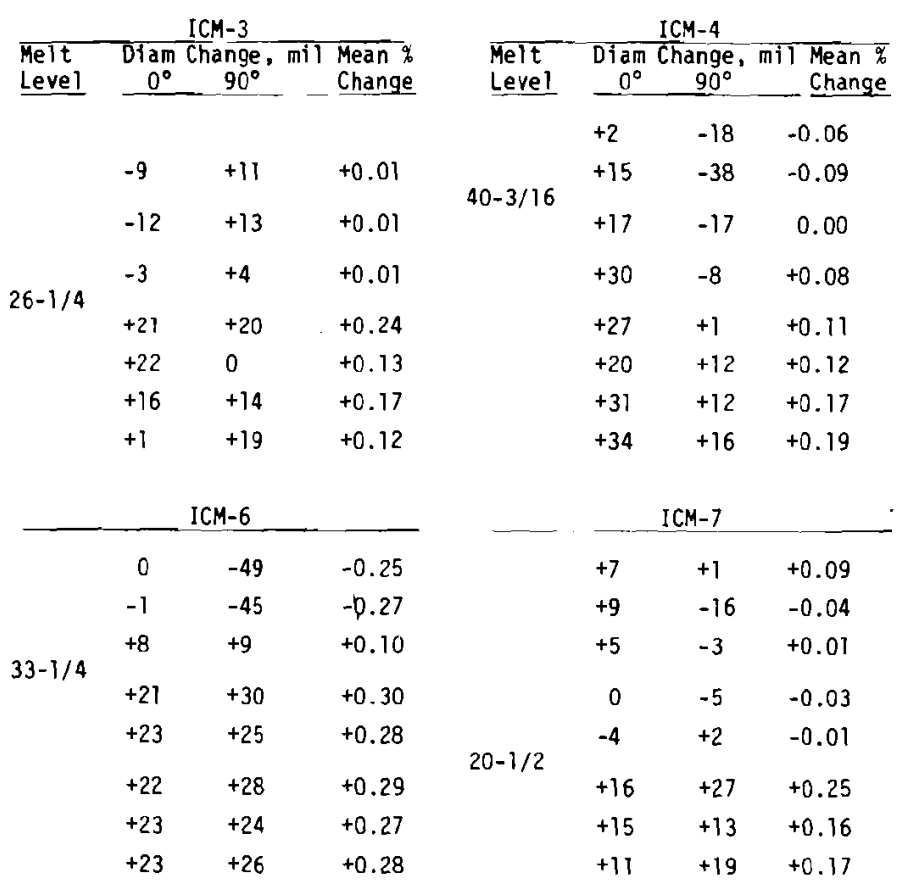
A1though run ICM-5 was made to demonstrate direct coupling of the incan melting system to the spray calciner, several other significant process changes were also successfully demonstrated. Proportional feeding of calcine and frit as two separate streams to the canister and the use of $-6 /+20$ mesh frit were shown to produce a product as good as that produced by mechanically blending calcine and -325 mesh frit before feeding to the canister. Melting of the type PW-7 waste calcine* and of a calcine-to-frit ratio of 1:2 was accomplished on an engineering scale for the first time. A melting capacity of $13.3 \mathrm{~kg} / \mathrm{hr}$ was established for an 8-in. diam canister without fins.

Run ICM- 6 , which demonstrated direct coupling of the in-can melting system to the fluid bed calciner, was routine. The furnace and canister were heated to $1025^{\circ} \mathrm{C}$ before batch from the $\mathrm{FBC}$ was introduced for melting. The batch feed rate never exceeded the melting rate. Because of a failure of the temperature control programmer, the canister of melt was held at $1015^{\circ} \mathrm{C}$ for $10 \mathrm{hr}$ following completion of the melting process. The canister was then cooled as shown in Figure 2. The hold at $510^{\circ} \mathrm{C}$ was to allow the interior glass temperatures to become the same as the exterior temperatures so that during further cooling stress would not build in the glass. However, cooling below $500^{\circ} \mathrm{C}$ was too rapid and a temperature gradient resulted across the glass.

The canister used for ICM-7, which demonstrated direct coupling to the wiped film evaporator, had eight internal fins like those used in ICM-3.** The furnace and canister were heated to $1025^{\circ} \mathrm{C}$ before frit and concentrate were introduced for calcining and melting. Frit was fed at a rate proportional to the feed rate of waste solution to the WFE to give a frit-to-solids ratio of 2.2:1. Thus the canister was fed $8.4 \mathrm{~kg}$ of frit and $11.1 \mathrm{~kg}$ of WFE concentrate per hour. The concentrate had a nominal oxide content of $34.7 \mathrm{wt} \%$.

* J. E. Mende1, Quarter1y Progress Report, BNWL-1871, p. 21 , November 1974.

** H. T. Blair and R. B. Dakan, Quarterly Progress Report, BNWL-1893, p. 8, February 1975. 
After feeding the in-can melting system for approximately $31 / 2 \mathrm{hr}$, the level of material in the canister rose above the top of the fins and formed a complete cold cap with a liquid pool at its center. Two hr were required to melt this material down and eliminate all but the very center of the cold cap so that frit and concentrate could again be fed to the canister. Therefore, the melting capacity of the system for WFE concentrate is less than $12.2 \mathrm{~kg}$ of solids per $\mathrm{hr}$. The limiting factors are the maximum allowable surface temperatures of the 304L canister and the efficiency of transferring heat from the canister surface into the material to be melted.

Table 4 contains some of the product properties of the in-can melting runs completed to date. Figure 3 shows the ICM- 4 canister after being cut open for examination of the product.

TABLE 4. Some Characteristics of Products of ICM-1 Through 7

\begin{tabular}{|c|c|c|c|c|c|c|c|}
\hline \multirow{3}{*}{$\frac{\text { Run No. }}{\text { ICM-1 }}$} & \multirow[b]{2}{*}{ Product Type } & \multirow{3}{*}{$\begin{array}{l}\text { Sample Location } \\
\text { Top } 12 \mathrm{in.}\end{array}$} & \multirow{3}{*}{$\begin{array}{c}\text { Density } \\
g / c c\end{array}$} & \multicolumn{4}{|c|}{ Soxhlet Leach Test, wt\% Lost } \\
\hline & & & & $24 \mathrm{hr}$ & $48 \mathrm{hr}$ & $72 \mathrm{hr}$ & Total \\
\hline & PW-4b-2(1:3) 73-1 & & & & & & \\
\hline & & Middle $21 / 2$ in. & 3.30 & & & & \\
\hline & & Bottom $51 / 2 \mathrm{in.}$ & 3.30 & & & & \\
\hline ICM-2 & PW-4b-2(1:3) 73-1 & Random Sample & 3.11 & 0.57 & 0.31 & 0.29 & 1.17 \\
\hline \multirow[t]{4}{*}{ ICM-3 } & $P W-4 b-2(1: 3) 73-1$ & Scale on Top & -- & 0.94 & 0.21 & 0.61 & 1.76 \\
\hline & & Top 5 in. & 3.29 & 1.30 & 0.52 & 0.84 & 2.66 \\
\hline & & Middle & 3.32 & 0.58 & 0.17 & 0.18 & 0.93 \\
\hline & & Bottom Layer & 3.34 & 0.51 & 0.12 & 0.16 & 0.79 \\
\hline \multirow[t]{4}{*}{ ICM-4 } & $P W-4 b-2(1: 3) 73-1$ & Scale on Top & -- & 0.85 & 0.39 & 1.20 & 2.44 \\
\hline & & Top Frit Cap & 2.96 & 0.34 & 0.37 & 0.72 & 1.43 \\
\hline & & Middle & 3.34 & 0.12 & 0.22 & 0.35 & 0.69 \\
\hline & & Bottom 4 in. & 3.43 & 0.18 & 0.14 & 0.30 & 0.62 \\
\hline \multirow[t]{3}{*}{ ICM- 5} & $\mathrm{PW}-7-2(1: 3) 73-1$ & Top Layer & 3.47 & 0.84 & 0.18 & 0.33 & 1.35 \\
\hline & & Middle & 3.25 & 0.23 & 0.06 & 0.26 & 0.55 \\
\hline & & Bottom Layer & 3.64 & 0.24 & 0.04 & 0.18 & 0.46 \\
\hline \multirow[t]{3}{*}{ ICM- 6} & $\begin{array}{l}\text { Commercial } \\
(1: 2.6) 73-1\end{array}$ & $11 / 2 \mathrm{in}$. from Top & 3.27 & 0.05 & 0.15 & 0.08 & 0.28 \\
\hline & & Middle & 3.38 & 0.35 & 0.23 & 0.27 & 0.85 \\
\hline & & Bottom Layer & 3.67 & 0.77 & 0.22 & 0.25 & 1.24 \\
\hline \multirow[t]{3}{*}{ ICM-7 } & $P W-7-2(1: 2) 73-1$ & Top Layer & 3.66 & 4.7 & 0.63 & 0.58 & 5.91 \\
\hline & & 6 in. from Top & 3.43 & 0.12 & 0.15 & 0.13 & 0.40 \\
\hline & & Bottom & 3.85 & 0.49 & 0.21 & 0.16 & 0.86 \\
\hline
\end{tabular}




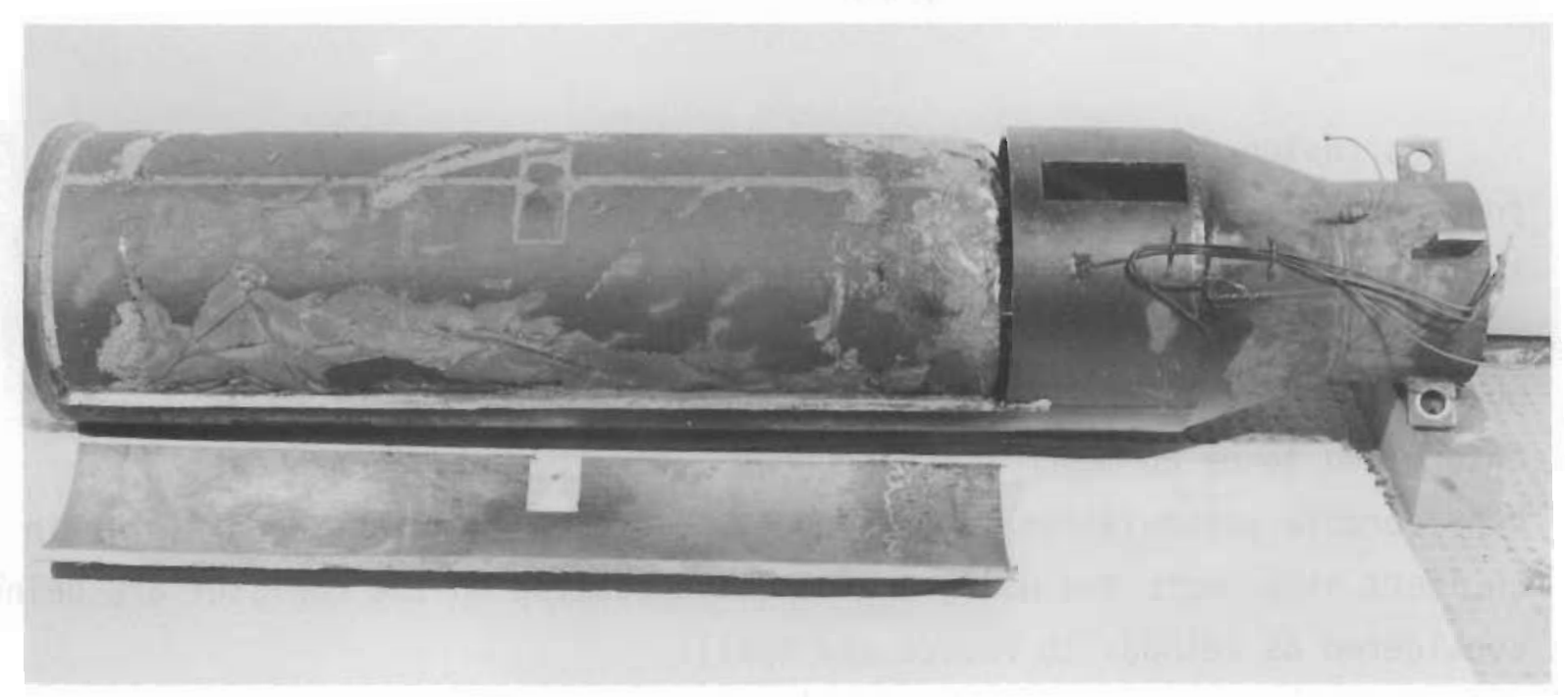

Neg $751022-7 \mathrm{Cn}$

\section{FIGURE 3. Product of ICM-4}

A typical product of the in-can melting process has a 1 - to 5-in. 1ayer of $\mathrm{CeO}_{2}$ rich, vitreous, multiphase material of relatively high density on the bottom. Above this layer the product is black glass full of uniformly sized and distributed crystalline clusters. The glass is sometimes tightly bonded to the canister wall and always highly fractured in a layer about $1 / 2$ in. deep below the wal1. Inside this fractured layer, which may be the result of removing the canister wall for product inspection, the glass is divided into 4- to 10-in.-long chunks by only a few cracks. In the center of the glass in canisters without fins is a $2-i n$. diam column of pores running from $3 \mathrm{in}$. above the bottom to the top. The largest pores are about $1 \mathrm{in.} \mathrm{diam.} \mathrm{There} \mathrm{are} \mathrm{no} \mathrm{pores} \mathrm{in} \mathrm{canisters} \mathrm{having} \mathrm{internal} \mathrm{fins.}$ At the top of the vitreous product is a shrinkage void caused by contraction of the glass as it cools. The glass is capped with a layer as much as $1 / 2$ in. thick of bright yellow crystalline material, identified as a molybdate rich in $\mathrm{Na}, \mathrm{K}, \mathrm{Cs}$, and $\mathrm{Sr}$. On top of this cap are the loose scale and unmelted batch that fall from the sides of the canister and connecting lines during cooling.

Because of the relatively high leach rate of the molybdate and scale, developmental efforts are focusing on their elimination. During runs ICM-4 and ICM-5 frit was dumped in to cap the melt following the completion of the waste batch melting. The molybdates rose through the frit in the time required to melt it. 
Corrosion of the canister by the melt does not appear to be of any consequence. This observation is consistent with the results of corrosion tests reported by Maness* and presented in Figure 4 with additional test results obtained at $1050^{\circ} \mathrm{C}$ and $1100^{\circ} \mathrm{C}$ during the last reporting period. However, the spall from the exterior surfaces of the canister, which was determined to be $80 \mathrm{mg} / \mathrm{cm}^{2}$, is a concern, for it would soon amount to a considerable accumulation in the process furnace. Heating the canister in an inert atmosphere and using a protective coating on the canister are being considered as methods to reduce the spall.

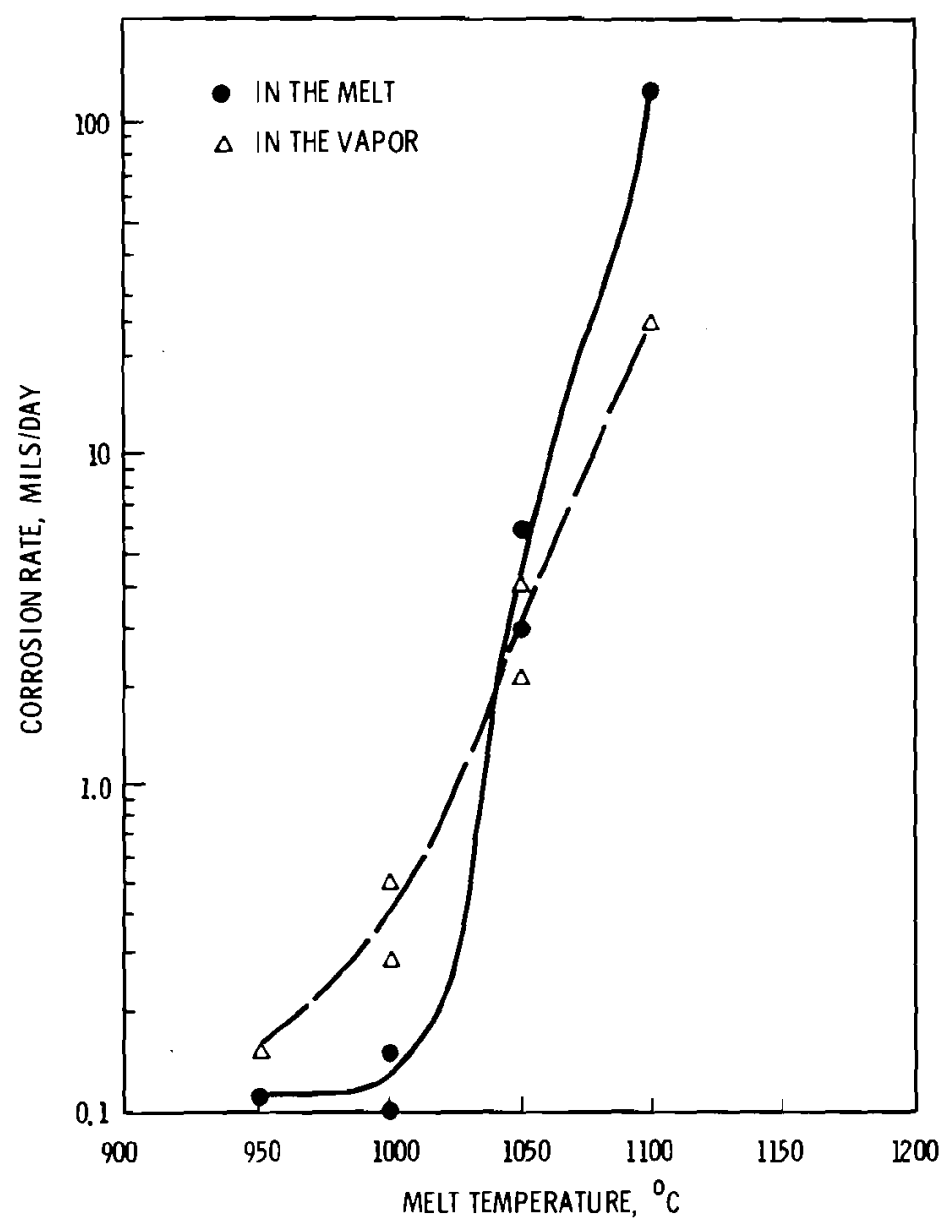

FIGURE 4. Corrosion Rate of 304L Stainless Steel in Simulated HLW Glass Melt

* R. T. Maness, Quarterly Progress Report, BNWL-1893, p. 47, February 1975. 
JOULE-HEATED CERAMIC MELTER - C. C. Chapman

The objective of this work is to develop a reliable ceramic melter design which can be used for converting radioactive waste to a glass.

The joule-heated ceramic melter described earlier* has been started up and, to date, has been in continuous service for 70 days. An anomalous conductive film on the surface of the glass contact refractory has caused delays in the scheduled testing of the system. Due to this extraneous problem, the throughput has been limited to $1000 \mathrm{1b}$. However, a short capacity test was completed and the results were encouraging. An instantaneous melting rate as high as $140 \mathrm{lb} / \mathrm{hr}$ (equivalent to the output of a 9 MTU/day reprocessing plant)** was estimated from an energy balance of the system. Temperature data for the electrode and the molten glass indicate that the life of the electrodes may be longer than expected.

Temperatures in Melter While Idling

During idling of the melter (no throughput of glass), temperatures in the three thermowells and in an electrode were taken. The data are plotted in Figure 5. For clarity, the temperatures at thermowelis 2 and 3 were not plotted because they do not differ by more than $\pm 30^{\circ} \mathrm{C}$. For the electrode the temperatures $4 \mathrm{in}$. in from the side were not plotted because they were typically $20^{\circ} \mathrm{C}$ less than at $1 / 2 \mathrm{in}$. from the side. Examination of Figure 5 shows a number of interesting characteristics. First the glass is far from being at a uniform temperature. The nonsymmetric temperature gradient in the glass indicates that the heat loss through the bottom is greater than the radiation losses from the surface. For an 8-in. glass depth, the glass temperature at the floor indicates that the top face of the glass contact refractory is only $875^{\circ} \mathrm{C}$. Although this would ensure long refractory 1 ife, the low temperature at the bottom would almost certainly result in the buildup of a second phase. This would be a problem for a bottom drain but may not cause any real problem for the overflow type drain. For comparison a temperature profile within the glass and in the electrode is shown for a

\footnotetext{
* C. C. Chapman, Quarterly Progress Report, BNWL-1893, p. 11, February 1975. ** Assuming PW-4b waste, $41 \mathrm{~kg} /$ MTU as oxides and a frit to calcine ratio of 2.8 .
} 


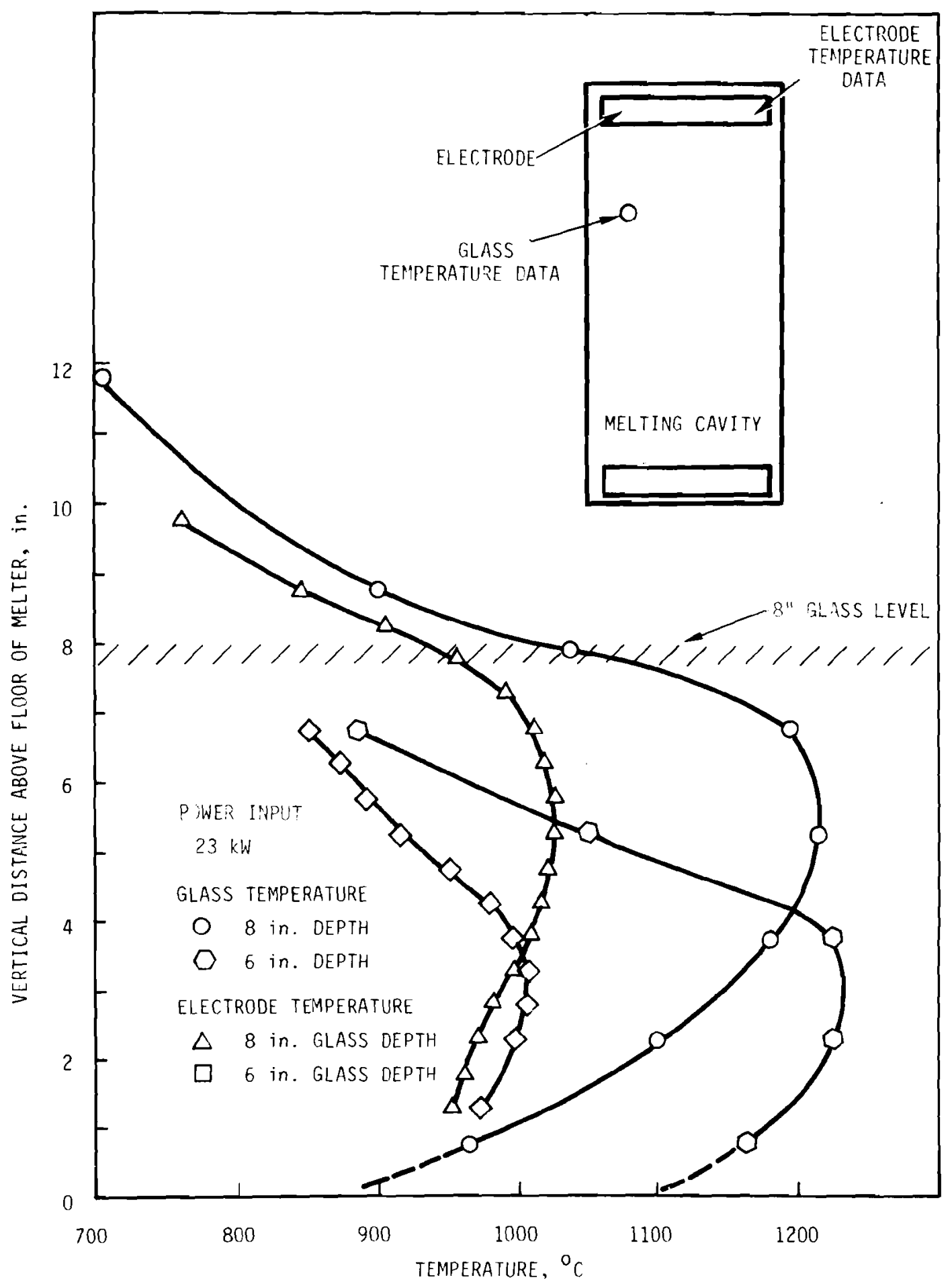

FIGURE 5. Temperatures in Melter While Idling 
6-in. glass depth. With this depth it seems likely that any second phase buildup could be put into solution by further increasing the power (temperature).

The temperatures within the electrode are of particular interest. The maximum temperature monitored in the electrode was nearly $200^{\circ} \mathrm{C}$ less than the maximum glass temperature. High temperatures within the electrode are reduced by the transfer of heat upward to the cooler region. The proximity of the water-cooled walls augments this cooling. Because the corrosion rate of the electrode material is strongly dependent upon temperature, lower operating temperatures would significantly increase electrode life. Figure 5 shows that a low electrode temperature exists while in the main pool the glass is at or above the desired melting temperature.

\section{Scouting Test}

A short run was executed to estimate the capacity of the melter and to test the operation of the overflow drain plunger. The melter was rapidiy filled with raw batch and allowed to cover the molten glass with approximately $6 \mathrm{in}$. of powder. Thereafter, batch was added intermittently to maintain a batch blanket until the supply was exhausted. In total 303 ib of batch was melted during the test. The elapsed time from initial batch addition to a fresh molten surface was $230 \mathrm{~min}$. This would indicate a gross melting rate of $80 \mathrm{lb} / \mathrm{hr}$. However, as the batch blanket thins at the end of melting, the melting rate slows rapidly. Therefore, a melting rate of $80 \mathrm{lb} / \mathrm{hr}$ should be taken as a lower bound on the melting rate. After 143 min, the batch blanket had completely melted except for a floating cone of powder $8 \mathrm{in}$. at its base. (Maximum estimated weight $10 \mathrm{lb}$ ). Using this information, the gross melting rate would be $120 \mathrm{lb} / \mathrm{hr}$.

An instantaneous melting rate can be estimated by taking an energy balance of the system during the melting operation. As shown in Figure 5 , the melter required $23 \mathrm{~kW}$ to maintain the glass temperature while idling. Water cooling of the sidewalls and floor removed $12 \mathrm{~kW}$ of this power. The balance of the power is lost from the surface of the glass to the lid of the melter, to air inleakage that sweeps into the meiter and from the bottom and sidewalls of the melter container. The energy that radiates 
from the surface of the molten glass during idling is useful energy when covered with batch. From temperature data of the cover lid it was estimated that at least $7 \mathrm{~kW}$ is radiated from the molten surface. Using this estimate, $16 \mathrm{~kW}$ are lost and are not usable in the melting of the glass batch.

Figure 6 shows the temperature/power history for the melter during this scouting test. From this data an estimate of the required melting energy per pound of batch can be obtained by integrating the power curve over the melting time. Table 5 gives the melting energy for this batch assuming $16 \mathrm{~kW}$ lost to cooling. The larger value presented assumes it took 230 min to melt the $303 \mathrm{lb}$ of batch. This should give an upper bound for the melting energy because it includes energy lost from the partially molten surface to the container lid during the last $90 \mathrm{~min}$. Using the estimated melting energy per pound and referring to Figure 6 , it is seen that the maximum instantaneous melting rate was from 140 to $180 \mathrm{lb} / \mathrm{hr}$ (9 to $12 \mathrm{MTU} /$ day reprocessing plant).* From 80 to $120 \mathrm{~min}$ into the test, the average melting rate was from 120 to $165 \mathrm{lb} / \mathrm{hr}$ ( 8 to $11 \mathrm{MTU} /$ day).* From this scouting test, it appears that this melter is more than adequate for a $5 \mathrm{MTU} /$ day reprocessing plant.

The discontinuities in the power versus time curve in Figure 6 are due to operator manipulation of the current control command signal. The initial smooth increases are due to the cooling effect of the batch on the molten pool. Smooth decreasing segments are attributed to a higher melting rate than draining rate. The smooth increases observed on the curve are due to a higher draining rate than melting rate. Review of the temperature history for this scouting test shows that the electrode remained relatively cool during the entire test, indicating that even greater capacity was attainable without adversely affecting the electrodes.

Two samples of the drained glass were taken during the test. The first was taken at an elapsed time of $40 \mathrm{~min}$ and the second was taken after 120 min. The densities and soxhlet leach test results for the two samples are given in Table 5 .

* Assuming PW-4b waste, $41 \mathrm{~kg} / \mathrm{MTU}$ as oxides and a frit to calcine ratio of 2.8 . 


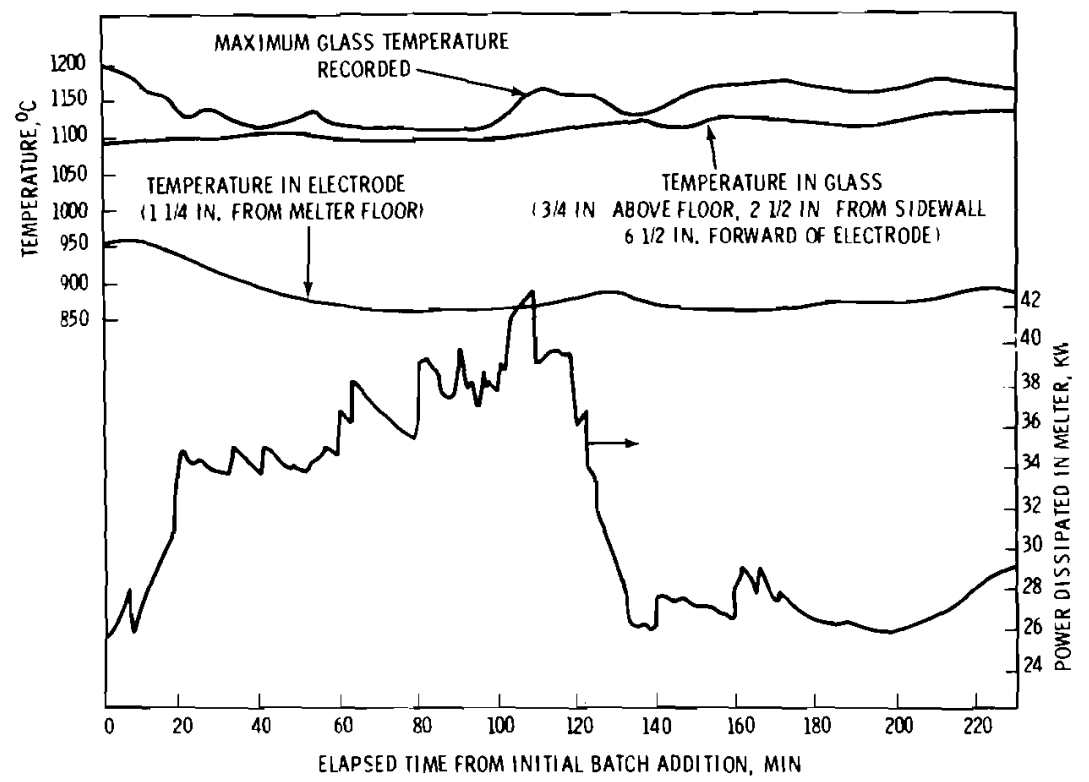

FIGURE 6. Temperature/Power History During Batch Melting

Because the results of this scouting test are preliminary and are for only a short production melting run, they should be reviewed as being indicative. Further testing will be required to verify the results. Nonetheless, the results were quite encouraging and point to the inherent capabilities of this type of melter. Future experiments will be run to obtain information over a longer time span and at steady state to better understand the operating characteristics of the system.

\section{TABLE 5. Test Results of Scouting Run}

\begin{tabular}{|c|c|c|c|c|c|}
\hline Calcine & \multicolumn{5}{|c|}{ PW-4b, Spray Calciner Run DSS-17 } \\
\hline Glass & \multicolumn{5}{|c|}{$72-68$} \\
\hline Frit/calcine ratio & \multicolumn{5}{|c|}{2.8} \\
\hline $\begin{array}{l}\text { Energy required to melt to } 1100^{\circ} \mathrm{C} \\
\text { (Estimated from Figure } 6 \text { ) }\end{array}$ & \multicolumn{5}{|c|}{$0.14-0.19 \mathrm{~kW}-\mathrm{hr} / 1 \mathrm{~b}$} \\
\hline $\begin{array}{l}\text { Melting rate } \\
\text { Maximum } \\
\text { Average over complete test }\end{array}$ & \multicolumn{5}{|c|}{$\begin{array}{l}140 \text { to } 180 \mathrm{lb} / \mathrm{hr} \\
80 \mathrm{lb} / \mathrm{hr}\end{array}$} \\
\hline Glass Sample, Time Obtained & Density & $24 \mathrm{hr}$ & $\underline{48 \mathrm{hr}}$ & $\underline{72 \mathrm{hr}}$ & Total \\
\hline $40 \min$ & 3.396 & 0.31 & 0.24 & 0.03 & 0.55 \\
\hline $120 \min$ & 3.304 & 0.23 & 0.31 & 0.10 & 0.63 \\
\hline
\end{tabular}


FLUIDIZED BED CALCINER - W. J. Bjorklund, M. S. Hanson, F. E. Haun

Fluidized bed calcination studies are designed to provide a system to convert high-level radioactive liquid waste to a dry solid product. The product will subsequently be converted to a glass form believed to be the most stable means of storing the waste.

Several significant runs were completed this period. They include 1) direct coupling the fluidized bed calciner to an in-can melter, 2) an 88-hr run using concentrated $\mathrm{PW}-7$ feed and 3) a 14-hr run testing the attrition-elutriation concept. The runs are summarized below:

Fluidized Bed Calciner Coupled to In-Can Melter

A 9-hr run in which the calciner was directly coupled to the in-can melter successfully produced $93 \mathrm{~kg}$ of waste glass product. Operation was extremely smooth, and no coupling problems were encountered. A photo of the calciner coupled to the in-can melter is shown in Figure 7.

PW-7 Calciner Run

An 88-hr run was completed in which concentrated $\mathrm{PW}-7$ feed was processed in the fluidized bed calciner. The objective was to produce quantities of typical calcine with full cesium level using a conventional overflowtype operation. A volume of 1570 liters of feed was processed, generating approximately $215 \mathrm{~kg}$ of calcine. Operating conditions for the run are shown in Table 6.

The desired operating mode of overflowing the material from the bed was not realized; instead all the product was elutriated from the bed and carried with the off-gas to the filter vessel. The initial starting bed was silica sand. For the first $60 \mathrm{hr}$ of operation unsuccessful attempts were made to grow a bed on this material or the calcine itself. Fines were recycled, temperatures were changed and replacement bed was added; however, the pattern of elutriating the fines and decreasing the bed level was consistent. No difference in operation was noted when the operating temperature was raised from $500^{\circ}$ to $600^{\circ}$. 


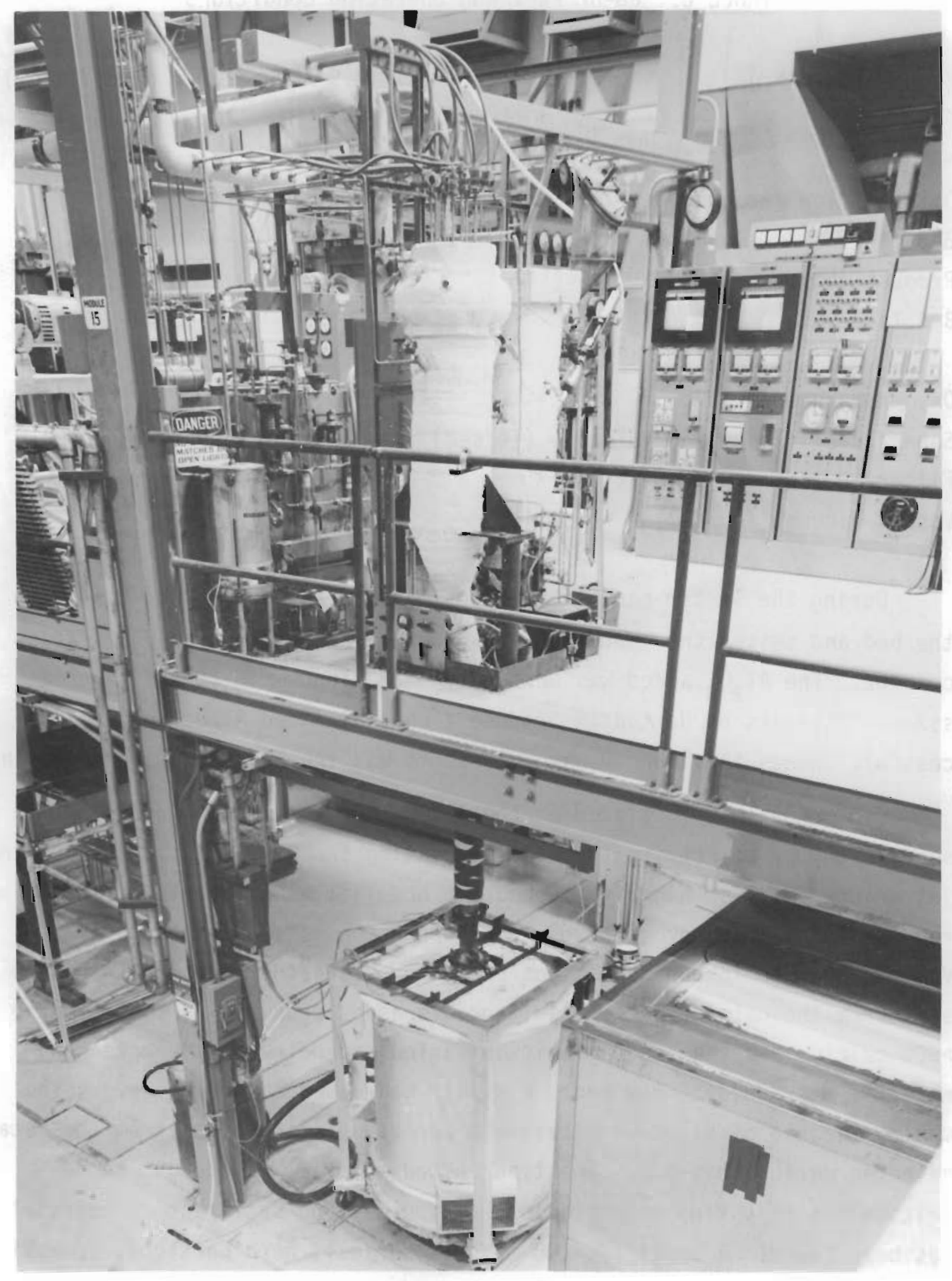

FIGURE 7. Fluidized Bed Calciner Coupled to the In-Can Melter 


\section{TABLE 6. 88-hr PW-7 Run Operating Conditions}

Feed rate $(\ell / h r)$

Feed

NAR

Off-gas flow (noncondensable) (scfm)

Bed material

Product $(\mathrm{kg})$

Bed Temperature $\left({ }^{\circ} \mathrm{C}\right)$

0xygen-kerosene ratio

Superficial fluidizing velocity ( $\mathrm{ft} / \mathrm{sec}$ )

Filter $\triangle P$ (in. $\mathrm{H}_{2} \mathrm{O}$ )

Vessel vacuum (in. $\mathrm{H}_{2} \mathrm{O}$ )
17.9 Avg. (138 g oxide/1iter)

PW-7, 378 थ/MTU, Sp. Gr. 1.2

$300-520$

12.3

$15 \mathrm{~kg} \mathrm{SiO} 2-$ Added $\mathrm{Al}_{2} \mathrm{O}_{3}$

213 (fines)

$500^{\circ}-43 \mathrm{hr}, 600^{\circ}-16 \mathrm{hr}$, $500^{\circ}-29 \mathrm{hr}$

2300

$0.9-1.2(5.4-7.8 \mathrm{scfm})$

$25-30$

$-5.5$

During the latter part of the run, $\mathrm{Al}_{2} \mathrm{O}_{3}$ was added to try to dilute the bed and switch the operation to an intentional attrition-elutriation concept. The $\mathrm{Al}_{2} \mathrm{O}_{3}$ added was Norton-type 38 alundum in 36 and 54 grit sizes. Attempts by Norton to produce a special sized $\mathrm{Al}_{2} \mathrm{O}_{3}$ were unsuccessful. Hence the alundum was used as it was the best "on hand" material.

Bed growth was initiated on the $\mathrm{Al}_{2} \mathrm{O}_{3}$, and a jet grinder was put in service to try to attrite the calcine coating from the $\mathrm{Al}_{2} \mathrm{O}_{3}$. Because the jet grinder was too high in the bed, it had little noticeable effect. The run data is plotted over the $88 \mathrm{hr}$ of operation as shown in Figure 8. Various changes in run conditions are noted along the bottom. As can be seen from the calcine percentage, the overheads product was consistently $>90 \%$ calcine and the bed composition varied depending on the rate new material was added to the bed. A dilute bed was attained; however, the maximum degree of dilution attainable cannot be ascertained from the data gathered during this run. The type of bed material is thought to be critical to this kind of operation, and to date no satisfactory material has been found. A small (30-100 mesh) spherical, hard particle, compatible with zinc borosilicate glass melts is preferred. 


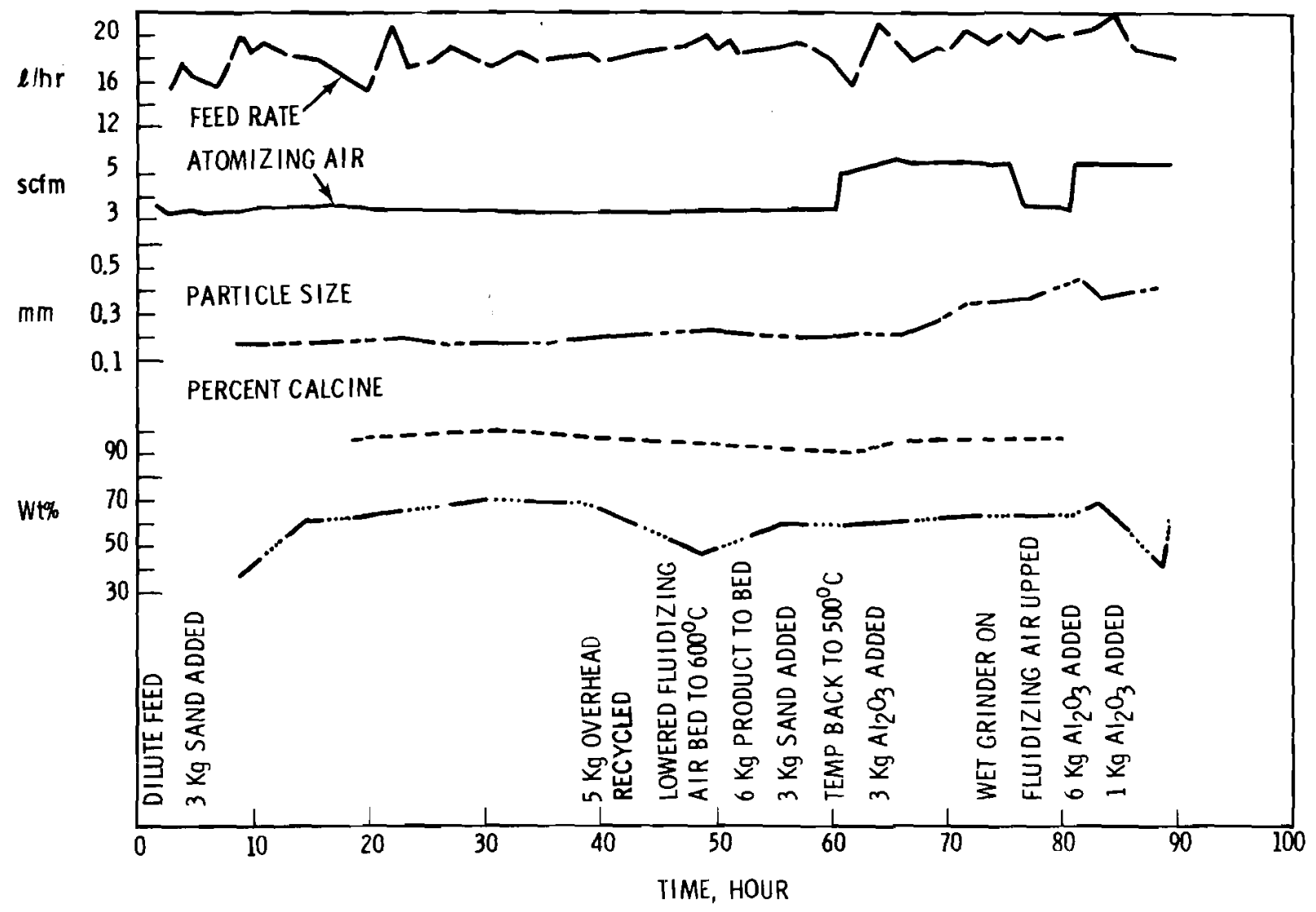

FIGURE 8. Run Data FBC-5

Characteristics of the bed material and overhead product produced are shown in Table 7 and Figure 9. The overhead fines were screened on a special sieving device and the results are sho:m in Table 8.

Cesium was found totally in the calcine, indicating no volatilization. The bed product and fines averaged $4.48 \mathrm{wt} \%$ cesium. Condensate and off-gas samples analyzed for cesium indicated $<1 \mathrm{ppm}$.

Off-gas samples were taken just downstream of sintered metal filters. The mass spectrometric gas analysis is shown in Table 9. Samples of offgas leaving the sintered metal filters were analyzed for solids loading and size using a cascade impactor test apparatus. The samples were taken at 8 and $12 \mathrm{hr}$ into the run and are shown in Table 10. 
TABLE 7. Bed and Overhead Characteristics

\begin{tabular}{|c|c|c|c|c|c|}
\hline \multirow[b]{2}{*}{$\begin{array}{l}\text { Bed Sample Time, } \\
\text { Run Hrib) }\end{array}$} & \multirow{2}{*}{$\begin{array}{l}\text { Density, } \\
\text { g/cc }\end{array}$} & \multirow[b]{2}{*}{$\begin{array}{l}\mathrm{NO}_{3} \\
\mathrm{mg} / \mathrm{g}\end{array}$} & \multicolumn{3}{|c|}{ Percent Weight Loss } \\
\hline & & & $100^{\circ} \mathrm{C}$ & $200^{\circ} \mathrm{C}$ & $380^{\circ} \mathrm{C}$ \\
\hline $14-60$ (Avg) & 2.11 & & & & \\
\hline $60-88$ (Avg) & 2.45 & & & & \\
\hline 14 & & 13.58 & 0.365 & 0.429 & 1.69 \\
\hline 37.5 & & 15.86 & 0.356 & 0.598 & 2.10 \\
\hline${ }_{55}(c)$ & & 2.58 & 0.220 & 0.305 & 0.63 \\
\hline 81 & & 18.3 & 0.260 & 0.350 & 2.16 \\
\hline
\end{tabular}

Overhead Sample

$$
\text { Time }
$$

$\begin{array}{ll}14-60 \text { (Avg) } & 2.20 \\ 65-88 \text { (Avg) } & 2.15\end{array}$

18

37.5

$49.5^{(c)}$

80

$\begin{array}{llll}26.42 & 0.290 & 0.441 & 3.15 \\ 28.97 & 0.204 & 0.372 & 2.99 \\ 20.87 & 0.350 & 0.504 & 2.31 \\ 28.69 & 0.310 & 0.560 & 3.20\end{array}$

Attrition Resistance of Samples Averaged less than 30 .

a. Tapped density in $10 \mathrm{ml}$ graduate.

b. See Figure 8 for conditions at time of sample (hours indicated are cumulative hours feed is on).

c. $600^{\circ} \mathrm{C}$ operation.

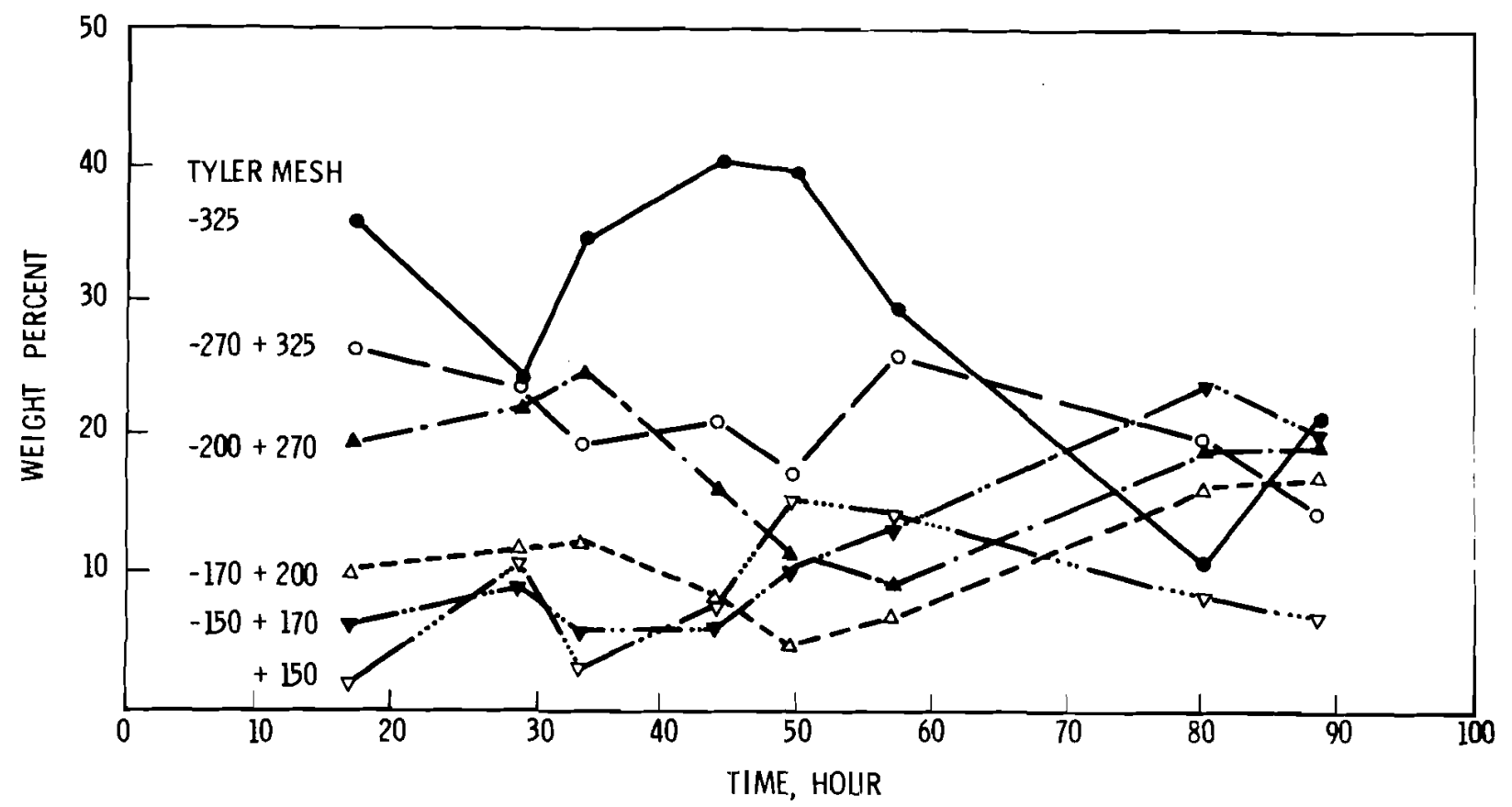

FIGURE 9. Distribution of Overhead Fines FBC-5 
TABLE 8. Overhead Fines Size Distribution

FBC -5

$\begin{array}{cr}\text { Size }(\mu) & \frac{W t \%}{} \\ 210 & 0.85 \\ 149 & 0.70 \\ 74 & 13.57 \\ 37 & 59.06 \\ 20 & 14.84 \\ 10 & 10.22 \\ <10 & 0.76\end{array}$

TABLE 9. FBC-5 Off-Gas Composition

\begin{tabular}{ccc} 
Component & $\begin{array}{c}\text { Mole } \% \\
(65 \mathrm{hr})\end{array}$ & $\begin{array}{c}\text { Mole } \% \\
\text { Co }\end{array}$ \\
\cline { 2 - 3 } $\mathrm{CO}_{2}$ & $94 \mathrm{hr})$ \\
$\mathrm{Ar}$ & 0.6 & 11.2 \\
$\mathrm{O}_{2}$ & 0.79 & 0.79 \\
$\mathrm{~N}_{2}$ & 22.7 & 21.7 \\
$\mathrm{CO}$ & 65.6 & 65.4 \\
$\mathrm{He}$ & $<0.1$ & $<0.1$ \\
$\mathrm{H}_{2}$ & $<0.01$ & $<0.01$ \\
$\mathrm{CH}_{4}$ & 0.04 & 0.06 \\
$\mathrm{~N}_{2} \mathrm{O}$ & $<0.01$ & $<0.01$ \\
$\mathrm{NO}_{\mathrm{NO}}$ & 0.51 & \\
& 0.81 & 0.87
\end{tabular}

TABLE 10. Particle Size and Concentration Fluidized Bed Calciner FBC-5

\begin{tabular}{|c|c|c|c|}
\hline Test Time & Sample Period & $\begin{array}{c}\text { Mass } \\
\text { Concentration } \\
\text { mg/scf(a) } \\
\end{array}$ & $\begin{array}{c}\text { Aerodynamic } \\
\text { Median Diameter } \\
\text { in Microns } \\
\end{array}$ \\
\hline $8 \mathrm{hr}$ & $1 \mathrm{hr}$ & $<0.004$ & -- \\
\hline $12 \mathrm{hr}$ & $1 \mathrm{hr}$ & 0.08 & 2.9 \\
\hline
\end{tabular}

a. Noncondensable off-gas. This represents a DF of $10^{4}$ to $10^{5}$ on solids. 
The 8-hr sample showed no particulated collected either visually or by weight. Since the sampling system was operating as expected, this can indicate one of two conclusions: 1) off-gas loading was extremely low and a representative sample was not being collected or 2) the particulate gas loading was below the detection limit of $0.004 \mathrm{mg} / \mathrm{scf}$ of gas for the $1 \mathrm{hr}$ sampling period.

Tests were made on the effect of changing pulse and cycle times for the sintered metal off-gas filters. In summary, very little difference was noted in the overall performance by changing time between pulses. Run criteria have been established to use the least amount of air to maintain a stable pressure drop. Pulses of $<0.2 \mathrm{sec}$ every 2 to $30 \mathrm{sec}$ on a $3-\mathrm{min}$ cycle are typical.

Few problems were encountered during the run. The feed during the first hours of operation was more dilute than anticipated. This meant that calcine was not being produced as fast as desired and the bed volume was dropping due to the high attrition rate. It is not known whether this had an effect on the ability to grow a bed or not, as bed growth with the $\mathrm{Al}_{2} \mathrm{O}_{3}$ particles was initiated at very low bed levels, as low as those in which no growth had previously been attained.

Restrictions in the feed line strainer occurred as the 10-mil screen periodically plugged with a green and white pasty material. The material was identified in the laboratory as predominantly $\mathrm{MnO}_{2}$ with some $\mathrm{MoO}_{3}$. Both $\mathrm{Mn}$ and Mo were added as oxides rather than nitrates and were difficult to get into solution. Feed flow was interrupted for about 5 min as the strainer was cleaned. In future runs, parallel strainers will be used so no downtime occurs, and manganous nitrate solution will be used in the feed makeup rather than $\mathrm{MnO}_{2}$.

No fuel nozzle restrictions were noted in this run. The only changes made since earlier runs were attempts to keep the vessel vacuum at -5 in. $\mathrm{H}_{2} \mathrm{O}$ whereas in earlier runs it reached -1 and -2 in. $\mathrm{H}_{2} \mathrm{O}$ and momentary pressurizations occurred during a filter blowback cycle.

The pressures at the fue 1 nozzle were 45 psig and 35 psig on the oxygen and kerosene, respectively. During earlier runs when the nozzle 
plugged, the pressures were $34 \mathrm{psig}$ and $17 \mathrm{psig}$ for the oxygen and kerosene. The supply pressures were similar for both runs, hence there must be differences in the nozzle makeup or perhaps an undetected leak in the oxygen connections.

\section{Attrition-Elutriation Run}

A run of $14 \mathrm{hr}$ was completed during which concentrated $\mathrm{PW}-7$ feed was processed.

The objective was to examine the effects of Cabosil ${ }^{\circledR}$ on the system and to further understand the attrition-elutriation mode of operation. Operating conditions for this run are shown in Table 11.

TABLE 11. Operating Conditions

Feed rate $(\ell / h r)$

Feed

NAR

Off-gas flow (noncondensable) (scfm)

Bed material

Bed temperature $\left({ }^{\circ} \mathrm{C}\right)$

oxygen-kerosene ratio

Superficial fluidizing velocity ( $\mathrm{ft} / \mathrm{sec}$ )

Filter $\Delta P$ (in. $\mathrm{H}_{2} \mathrm{O}$ )

Vesse1 vacuum (in. $\mathrm{H}_{2} \mathrm{O}$ )

\subsection{3}

PW-7, 378 l/MTU, Sp. Gr. $=1.2$ with Cabosil 2.5 wt\% $6.75 \mathrm{hr}, 1.2 \mathrm{wt} \%-7.25 \mathrm{hr}$ 375-620

12.6

$15 \mathrm{~kg} \mathrm{Al}_{2} \mathrm{O}_{3}$ (54 grit)

500

2255

$0.9-1.05$ ave $=0.957$

$20-32$

4.25

Cabosil ${ }^{\circledR}$ is a submicroscopic fire-dry fumed silica produced by Cabot Corporation. It has been used in a spray calciner pilot plant at Karlsruhe Research Center in Germany to minimize filter $\Delta \mathrm{P}$ problems. The material also aids the emulsification of liquids and the flowability of solids. Tests have shown that quantities $>4$ to $8 \%$ can jell waste feed solutions and give thixotropic properties. Cabosi ${ }^{\mathbb{R}}$ was added to the feed in the 
amounts of $2.5 \%$ (wt) for the first $6.75 \mathrm{hr}$ and $1.2 \%$ (wt) in the final $7.25 \mathrm{hr}$. The off-gas filters were washed in water and nitric acid prior to the run and initially gave low pressure drops, indicating they were clean. After running for $9 \mathrm{hr}$, at which time the pressure drop had come to equilibrium with the feed rate, essentially no differences could be detected between these $\Delta \mathrm{P}$ and previous $\Delta \mathrm{P}$ readings at similar operating conditions. At the given feed rate of approximately $15 \mathrm{l} / \mathrm{hr}$ an equilibrium filter $\Delta P$ of 30 in. of $\mathrm{H}_{2} \mathrm{O}$ was obtained.

Feed homogeneity was improved somewhat with the addition of Cabosil, ${ }^{\circledR}$ and particulate settling was reduced. Cabosil ${ }^{\circledR}$ appeared to have a deleterious effect on the feed nozzle, as more erratic pressure readings were noticed. Fewer problems occurred with feed line strainer plugging, which had hampered operation in the past. The material plugging the screen formed a more porous mass than usual and did not completely cut off flow.

Bed particle size increased immediately after feed was started and was difficult to control. The use of jet grinders produced a very fine product, but the attrition could not keep up with bed growth. Changes in fluidizing and atomizing air appeared to have minimal effects. The nozzle air ratio was taken as high as 620 in attempts to produce fines and slow bed growth. Bed growth was finally stabilized by feed rate adjustments and could be fairly well-controlled via this method. A rate of about $14 \mathrm{l} / \mathrm{hr}$ was required to maintain equilibrium compared to normal rates of 18 to $20 \mathrm{l} / \mathrm{hr}$ for conventional-type operation. Feed rate in the attritionelutriation mode may be limited by bed size and configuration unless an improved grinding method can be developed. The wear on the 310 stainless vessel from the jet grinder was much more severe than anticipated. The jet was directed at a vessel wall and considerable erosion was noted.

Some problems with the kerosene-oxygen fuel nozzle were encountered. Internal leaks in modified nozzles appear to be the cause of the problems. Popping noises were heard and fluctuations of the oxygen and kerosene flows were noted. Past investigations showed flame markings on the interior of the oxygen side of the nozzle, indicating internal burning. 
The particle size distribution of the overhead fines is shown in Table 12.

TABLE 12. Overhead Fines Distribution

\section{Tyler Screen Size}

+150
$-150+170$
$-170+200$
$-200+270$
$+170+325$
-325
a. The large portion of the product in the -325 mesh range is evidence of the effects of the jet grinders and the high NAR. Prior runs produced products typical1y $25 \%<325$ mesh.

Attrition indices on the bed material averaged 34 , compared to pure $\mathrm{Al}_{2} \mathrm{O}_{3}$ which was $\sim 58 \%$. These indices are lower than anticipated indicating large amounts of calcine coating the particles in the bed, which laboratory analysis of bed samples confirm. Results of laboratory analysis can be seen in Table 13.

TABLE 13. Bed and Overhead Product Characteristics

\begin{tabular}{|c|c|c|c|c|c|c|}
\hline $\begin{array}{l}\text { Bed Sample at } \\
\text { Cumulative } \mathrm{hr}(\mathrm{a})\end{array}$ & $\%$ Calcine (wt) & Bed, MMPD & $\% \operatorname{cs}(w t)$ & $\% \mathrm{Fe}(\mathrm{wt})$ & $\% \mathrm{H}_{2} \mathrm{O}(\mathrm{wt})$ & $\% \mathrm{NO} \mathrm{x}_{\text {(wt) }}$ \\
\hline 3.25 & 26.2 & 0.38 & 0.80 & 1.23 & 0.09 & 0.13 \\
\hline 6.00 & - & 0.36 & -- & -- & -- & -- \\
\hline 9.75 & 34.5 & 0.37 & 1.23 & 1.62 & 0.02 & 0.10 \\
\hline 14.00 & 40.0 & & 1.46 & 1.88 & 0.005 & 0.17 \\
\hline \multicolumn{7}{|l|}{$\begin{array}{l}\text { Overhead Product } \\
\text { at Cumulative hr } \\
\end{array}$} \\
\hline 3.33 & 61.7 & & 2.28 & 2.90 & 0.04 & 1.98 \\
\hline 9.75 & 97.2 & & 3.51 & 4.57 & 0.42 & 0.55 \\
\hline
\end{tabular}

a. Cumulative hours indicate hours feed has been on at time of sample. 
The rising percentage of calcine in the bed over the run is the cause of the growing bed and shows the insufficiency of the present jet grinder system. It is generally felt that small spherical particles rather than the irregularly* shaped ones now used will give better calcine attrition.

In general, attrition-elutriation is a feasible operating method but more development is required.

WIPED FILM EVAPORATOR - R. D. Dierks

The information being obtained in this study is intended to aid in developing design specifications for equipment to reduce high-level waste slurries to a solid borosilicate glass.

In several experiments completed during this and the preceding reporting period, a horizontal-type, wiped film evaporator was directly coupled to both a metallic-type melter and an "in-can" melting system to produce a borosilicate glass product directly from a simulated high-level waste slurry without an intermediate product.

The experiments with the evaporator coupled directly to the metallic melter were successful in that a glass product was made with such an arrangement, and the moist evaporator concentrate was dropped onto the molten glass in the melter without violent spattering or other explosive effects. However, the design coupling the two equipment pieces was only partially successful. The major problems were in the transfer of the evaporator product into the melter, and in the solids carry-over from the melter to the off-gas system. The evaporator discharged its product through a 5-in.long section of $3-i n$. pipe positioned on the underside of the horizontal barrel of the evaporator. The melter was positioned directly under this discharge nozzle with the upper end of the melter, which normally ran about $1200^{\circ} \mathrm{C}$, about $15 \mathrm{in}$. from the bottom of the discharge nozzle. The melter's radiant and conductive heat caused additional drying of the concentrate in the discharge nozzle and its eventual plugging.

Various configurations of the nozzle were tried. These included a 13-in.-long, 3-in. diam, boiling water cooled nozzle that almost filled

* Norton Type 38 alundum 
with concentrate dried by radiant heat from the melter walls, and an 18-in.-long, 1-in. diam, thin wal1, boiling water cooled nozzle that plugged with only a thin layer of calcined concentrate which very slowly covered the tip of the nozzle. Some nozzles were effective in transferring the concentrate into the melter when the solids content of the concentrate was 1 imited to 30 to $40 \mathrm{wt} \%$. But sustained operation was never realized when the solids content was in the 50 to $55 \mathrm{wt} \%$ range.

A second problem encountered was with the solids carry-over from the melter into the off-gas system, which appeared to be aggravated by highwater concentrations in the evaporator product charged to the melter. Several attempts were made to recycle the melter off-gas and its entrained solids back to the evaporator, including routing the off-gases back up through the evaporator concentrate discharge nozzle. This did little but hasten the plugging of the nozzle with dried concentrate. The most successful technique tried was to pump the melter off-gas with a steam ejector up through a Raschig ring packed column and into a condenser. The condensed steam and melter off-gases then dropped back down through the packed column, scrubbing the rising gases. The refluxed condensate, with its load of solids, then drained out of the scrubber unit and into the evaporator feed inlet nozzle.

Following these experiments, the melter was removed from under the evaporator and the facility was modified to enable the evaporator to drop its concentrate directly into a final storage-type receiving canister set in a full-length furnace on the floor below. The evaporator discharge nozzle was connected to the canister with a 10-ft-long, 8-in. diam tube that enabled the evaporator-canister system to operate at a negative pressure of $10 \mathrm{in}$. of water. The evaporator discharge nozzle was made so as to guide the concentrate to a single point as it issued from the evaporator and to drop it freely from this point directly into the receiving canister. The receiver was a section of $8-\mathrm{in}$. schedule $40,304 \mathrm{~L}$ stainless steel, fitted with internal stainless steel fins for increasing the heat transfer into the receiver. A glass former (73-1) was added to the receiver as a $-6+20 \mathrm{M}$ dry solid in a ratio of 2:1 (frit: feed oxide 
weight) from an external solids feeder. The receiver furnace was controlled to maintain the receiver at a maximum temperature of $1050^{\circ} \mathrm{C}$.

A simulated high-level waste slurry, PW-7-2, preheated in a she11 and tube heat exchanger, entered the evaporator a few degrees below its boiling point at an average rate of $26.5 \mathrm{l} / \mathrm{hr}$. The evaporator was operated with 30 psig steam in the heating jacket and discharged a product containing about $54 \mathrm{wt} \%$ condensable 1 iquids $\left(5 \mathrm{M} \mathrm{HNO}_{3}\right)$ to the hot receiving canister. The overall heat transfer coefficient for the evaporator under these conditions was about $210 \mathrm{Btu} / \mathrm{hr}-\mathrm{ft}^{2}-{ }^{\circ} \mathrm{F}$. About $80 \%$ of the condensable liquids in the feed solution were removed in the evaporator. The concentrate and frit were charged to the receiver to form glass at about $13 \mathrm{~kg} / \mathrm{hr}$. However, this appeared to be slightly above the capacity of the receiver/furnace configuration, as a cold cap slowly accumulated on the surface of the molten glass.

The melter off-gases were routed through the scrubber/separator described above and indicated a solids carry-over of about $50 \mathrm{~g} / \mathrm{hr}$. No problems were encountered with the evaporator discharge nozzle.

Further tests with the "in-can" melting system are planned to optimize the distance between the evaporator discharge nozzle and the furnace, to avoid plugging the discharge nozzle, and to minimize the splashing of the melt as the concentrate drops into the receiver. 


\section{WASTE FORM CHARACTERIZATION}

The purpose of waste form characterization is to measure the properties of candidate solidified products (solidified waste and canister) as a function of composition, processing parameters, and storage conditions. The measurements are used 1) to assure operability of the manufacturing processes and 2) to provide data for safety analyses of high-level waste management. The ultimate goal is to characterize the physical and chemical properties of the waste forms so thoroughly that when they are placed in retrievable storage, and later in ultimate disposal, full confidence can exist that their behavior is known and that any changes or any interactions with their environment which may occur are wholly predictable.

COMMERCIAL RADIOACTIVE WASTE COMPOSITIONS USED IN THE WASTE

\section{FIXATION PROGRAM - J. E. Mendel}

There is a continuing need to assure that the waste compositions being studied are relevant to projected commercial reprocessing plant practice. Therefore new waste compositions are added to the program as new information becomes avaizable.

Two new waste compositions have been defined, PW-7a and PW-7b. Their compositions are shown in Table 14. They represent a typical combination of intermediate-level waste (ILW) with the reference AGNS HLW, PW-7. The addition of ILW increases the sodium content to $0.586 \mathrm{M}$ in the combined ILW-HLW (PW-7a) when it is concentrated to $100 \mathrm{gal} / \mathrm{MTU}$. PW-7b is representative of combined AGNS ILW-HLW to which iron has been added in a ratio equimolar to the sodium present. The addition of iron aids in processing high sodium waste in a fluidized bed calciner. 
TABLE 14. Waste Compositions Used in Waste Fixation Program - Supplement No. 2(a)

\begin{tabular}{|c|c|c|c|c|c|c|c|}
\hline & & & & Kilograms & er MTU & & \\
\hline & & $\begin{array}{l}\text { PW-7, } \\
\text { as defined }\end{array}$ & $P W-7-1$ & $\begin{array}{l}P W-7 a, \\
\text { as defined }\end{array}$ & $P W-7 a-1$ & $\begin{array}{l}\text { PW-7b, } \\
\text { as defined }\end{array}$ & PW-7b-1 \\
\hline Inerts & $\mathrm{Na}_{2} \mathrm{O}$ & 0.117 & 0.117 & 6.872 & 6.872 & 6.872 & 6.872 \\
\hline & $\mathrm{Fe}_{2} \mathrm{O}_{3}$ & 3.022 & 3.022 & 3.022 & 3.022 & 17.711 & 17.71 \\
\hline & $\mathrm{Cr}_{2} \mathrm{O}_{3}$ & 0.345 & 0.345 & 0.345 & 0.345 & 0.345 & 0.345 \\
\hline & $\mathrm{NiO}$ & 0.141 & 0.141 & 0.141 & 0.141 & 0.141 & 0.141 \\
\hline & $\mathrm{P}_{2} \mathrm{O}_{5}$ & 2.686 & 2.686 & 6.339 & 6.339 & 6.339 & 6.339 \\
\hline & $\mathrm{Al}_{2} \mathrm{O}_{3}$ & - & - & - & - & - & - \\
\hline & $\mathrm{Gd}_{2} \mathrm{O}_{3}$ & 10.360 & 10.360 & 10.360 & 10.360 & 10.360 & 10.360 \\
\hline Fission & & & & & & & \\
\hline Products & $\mathrm{Rb}_{2} \mathrm{O}$ & 0.354 & 0.354 & 0.354 & 0.354 & 0.354 & 0.354 \\
\hline & sro & 1.059 & 1.059 & 1.059 & 1.059 & 1.059 & 1.059 \\
\hline & $\mathrm{Y}_{2} \mathrm{O}_{3}$ & 0.598 & $0.026(\mathrm{RE})^{(\mathrm{b}}$ & $, c\rangle_{0.598}$ & $0.026(\mathrm{RE})$ & 0.598 & $0.026(\mathrm{RE})$ \\
\hline & $\mathrm{ZrO}_{2}$ & 4.944 & 4.944 & 4.944 & 4.944 & 4.944 & 4.944 \\
\hline & $\mathrm{MoO}_{3}$ & 5.176 & 5.176 & 5.176 & 5.176 & 5.176 & 5.176 \\
\hline & $\mathrm{Tc}_{2} \mathrm{O}_{7}$ & 1.291 & $1.199\left(M_{0}\right)$ & 1.291 & 1.199 (Mo) & 1.291 & $1.199(\mathrm{Mo})$ \\
\hline & $\mathrm{RuO}_{2}$ & 2.972 & $1.783(\mathrm{Fe})$ & 2.972 & $1.783(\mathrm{Fe})$ & 2.972 & $1.783(\mathrm{Fe})$ \\
\hline & $\mathrm{Rh}_{2} \mathrm{O}_{3}$ & 0.480 & $0.304\left(\mathrm{C}_{0}\right)$ & 0.480 & $0.304(\mathrm{Co})$ & 0.480 & $0.304\left(C_{0}\right)$ \\
\hline & PdO & 1.483 & $0.905(\mathrm{Ni})$ & 1.483 & $0.905(\mathrm{Ni})$ & 1.483 & $0.905(\mathrm{Ni})$ \\
\hline & $\mathrm{Ag}_{2} \mathrm{O}$ & 0.088 & 0.088 & 0.088 & 0.088 & 0.088 & 0.088 \\
\hline & $\mathrm{CdO}$ & 0.097 & 0.097 & 0.097 & 0.097 & 0.097 & 0.097 \\
\hline & $\mathrm{TeO}_{2}$ & 0.725 & 0.725 & 0.725 & 0.725 & 0.725 & 0.725 \\
\hline & $\mathrm{Cs}_{2} \mathrm{O}$ & 2.880 & 2.880 & 2.880 & 2.880 & 2.880 & 2.880 \\
\hline & $\mathrm{BaO}$ & 1.567 & 1.567 & 1.567 & 1.567 & 1.567 & 1.567 \\
\hline & $\mathrm{La}_{2} \mathrm{O}_{3}$ & 1.480 & 3.207 (RE) & 1.480 & 3.207 (RE) & 1.480 & $3.207(\mathrm{RE})$ \\
\hline & $\mathrm{CeO}_{2}$ & 3.323 & $6.385(\mathrm{RE})$ & 3.323 & $6.385(\mathrm{RE})$ & 3.323 & 6.385 (RE) \\
\hline & $\operatorname{Pr}_{6}{ }^{2} 11$ & 1.482 & $0.644(\mathrm{RE})$ & 1.482 & 0.644 (RE) & 1.482 & 0.644 (RE) \\
\hline & $\mathrm{Nd}_{2} \mathrm{O}_{3}$ & 4.522 & $2.293(\mathrm{RE})$ & 4.522 & $2.293(\mathrm{RE})$ & 4.522 & $2.293(\mathrm{RE})$ \\
\hline & $\mathrm{Pm}_{2} \mathrm{O}_{3}$ & 0.123 & - & 0.123 & - & 0.123 & - \\
\hline & $\mathrm{Sm}_{2} \mathrm{O}_{3}$ & 0.924 & 0.396 (RE) & 0.924 & 0.396 (RE) & 0.924 & 0.396 (RE) \\
\hline & $\mathrm{Eu}_{2} \mathrm{O}_{3}$ & 0.200 & 0.133 (RE) & 0.200 & 0.133 (RE) & 0.200 & 0.133 (RE) \\
\hline & $\mathrm{Gd}_{2} \mathrm{O}_{3}$ & 0.137 & $0.274(\mathrm{RE})$ & 0.137 & 0.274 (RE) & 0.137 & $0.274(R E)$ \\
\hline Actinides & $\mathrm{U}_{3} \mathrm{O}_{8}$ & 11.689 & 11.689 & 11.689 & 11.689 & 11.689 & 11.689 \\
\hline & $\mathrm{NpO}_{2}$ & 0.865 & $0.903(U)$ & 0.865 & $0.903(U)$ & 0.865 & $0.903(U)$ \\
\hline & $\mathrm{PuO}_{2}$ & 0.103 & $0.106(U)$ & 0.103 & $0.106(\mathrm{U})$ & 0.103 & $0.106(U)$ \\
\hline & $\mathrm{Am}_{2} \mathrm{O}_{3}$ & 0.181 & 0.115 (RE) & 0.181 & 0.115 (RE) & 0.181 & 0.115 (RE) \\
\hline & $\mathrm{Cm}_{2} \mathrm{O}_{3}$ & 0.040 & $0.026(R E)$ & 0.040 & 0.026 (RE) & 0.040 & 0.026 (RE) \\
\hline & & 65.454 & 53.949 & 75.862 & 74.357 & 90.551 & 89.046 \\
\hline
\end{tabular}

a. See also p. 28, BNWL-1841 and p. 23 , BNWL-1871.

b. Where used, chemical substitutes are shown in parentheses.

c. $\mathrm{RE}=$ a commercial rare mixture nominally containing wt\% $0.2 \mathrm{Y}_{2} \mathrm{O}_{3}, 24.0 \mathrm{La}_{2} \mathrm{O}_{3}$, $48.0 \mathrm{CeO}_{2}, 5.0 \mathrm{Pr}_{6} \mathrm{O}_{11}, 17.0 \mathrm{Nd}_{2} \mathrm{O}_{3}, 3.0 \mathrm{Sm}_{2} \mathrm{O}_{3}, 0.8 \mathrm{Eu}_{2} \mathrm{O}_{3}$ and $2.0 \mathrm{Gd}_{2} \mathrm{O}_{3}$. 


\section{GLASS COMPOSITION DEVELOPMENT - J. E. Mende 1}

The objective of this work is to optimize glass compositions for the immobilization of commercial $H L W$ and other wastes, such as alpha wastes, which require equivalent long-term immobilization.

A series of laboratory-scale melts were prepared to characterize zinc borosilicate glass containing AGNS-type waste. Emphasis was on in-canister low-melting process glass with maximum fission product loading. The effect of combining ILW with HLW was included in the evaluation. Calcining combined ILW-HLW by fluidized bed calcination requires an additive to accelerate decomposition of the $\mathrm{NaNO}_{3}$. Iron added in a ratio equimolar to the sodium has been reported to be a satisfactory additive for this purpose. Therefore ILW-HLW with iron was included in the evaluation.

Maximum fission product loading in the glasses containing HLW, combined ILW-HLW, and combined ILW-HLW plus iron, melted for $3 \mathrm{hr}$ at $1000^{\circ} \mathrm{C}$, was about 16, 18, and 15 wt\%, respectively. Factors limiting fission product loading to these approximate values were 1) molybdate salt phase separation and 2) slow reaction rates which left excessive porosity.

\section{Experimental Procedure}

The melts were prepared on a $40-\mathrm{g}$ scale in platinum crucibles. Three waste compositions were used, PW-7-1, PW-7a-1, and PW-7b-1. PW-7-1 corresponds to AGNS-type HLW; PW-7a-1 corresponds to combined ILW-HLW; and PW-7b-1 corresponds to combined ILW-HLW plus the iron required for fluidized bed calcination. The waste solutions were batch calcined in the laboratory at $500^{\circ} \mathrm{C}$ and ground to pass a 20 -mesh screen.

The melt batches were made by mixing the required amounts of calcine and zinc borosilicate glass frit No. 73-1 (composition given p. 29, BNWL-1841) and holding in a preheated furnace at $1000^{\circ} \mathrm{C}$ for $3 \mathrm{hr}$.

$\underline{\text { Results }}$

The melt compositions and experimental observations are shown in Table 15. As the waste content of the glasses increased, the homogeneity of the glasses decreased. All of the $\mathrm{PW}-7 \mathrm{~b}-1$ glasses were poorly melted in 


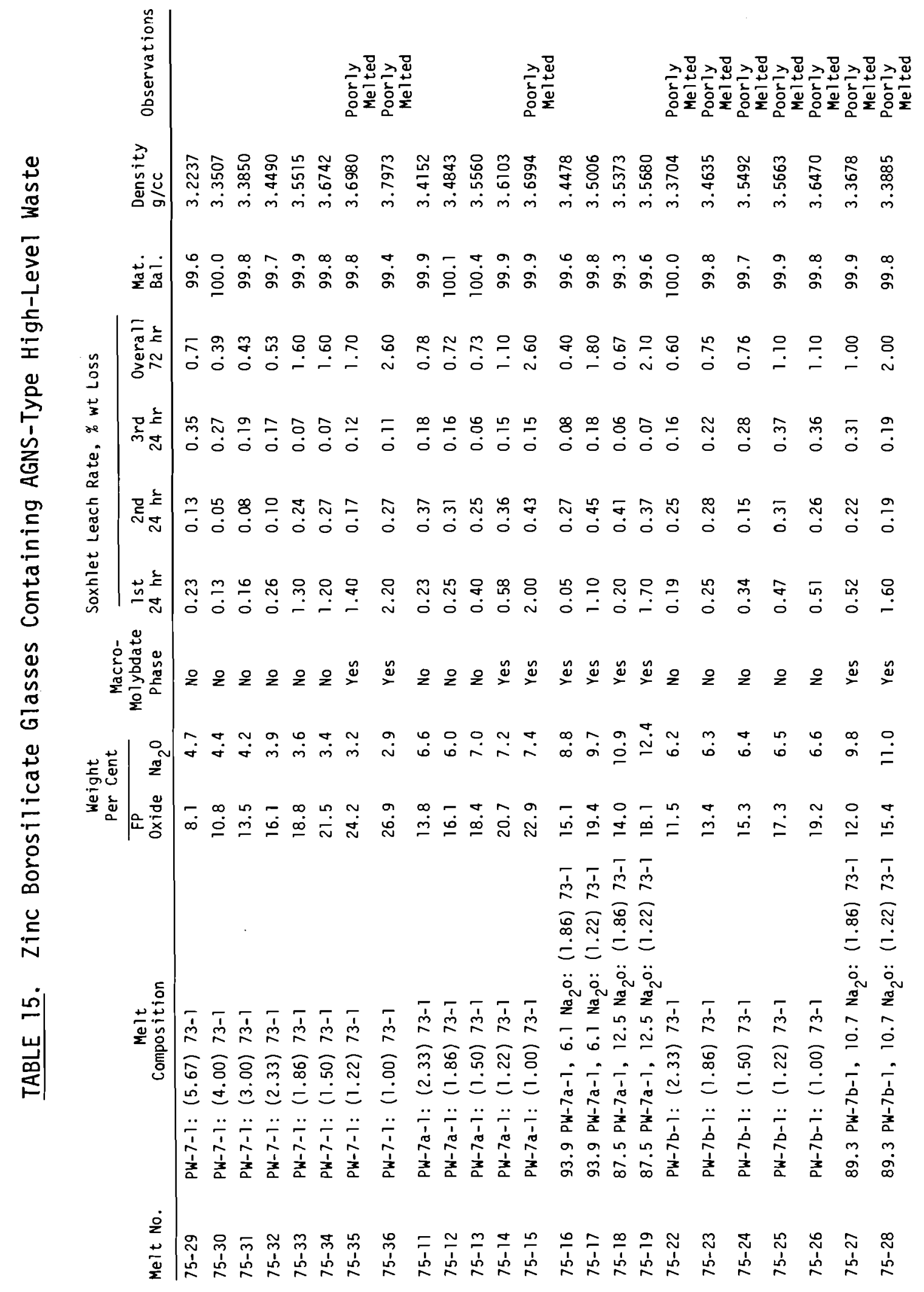


$3 \mathrm{hr}$ at $1000^{\circ} \mathrm{C}$. Indications are that a longer time or higher temperature is required to achieve homogeneous glasses with this waste composition. In Figure 10 the viscosity of a PW-7b-l glass is compared with that of PW-7-1 and PW-7a-1 glasses, each containing the same proportion of frit. The viscosities were measured with a Brookfield viscometer on glass specimens preheated to $1150^{\circ} \mathrm{C}$. When this was done, the iron-containing PW- $7 \mathrm{~b}-1$ glass was homogeneous and had a viscosity comparable to the $\mathrm{PW}-7-1$ and PW-7a-1 glasses.

The leach rates obtained with the AGNS-type wastes (Table 15) are quite comparable with those obtained previously with PW-4b waste, except at higher waste loadings where the molybdenum second phase is present. This phase is water-soluble. The data indicate, however, that once the soluble molybdenum second phase is leached from the sample the residual glass is just as nonleachable as that with lower waste loading.

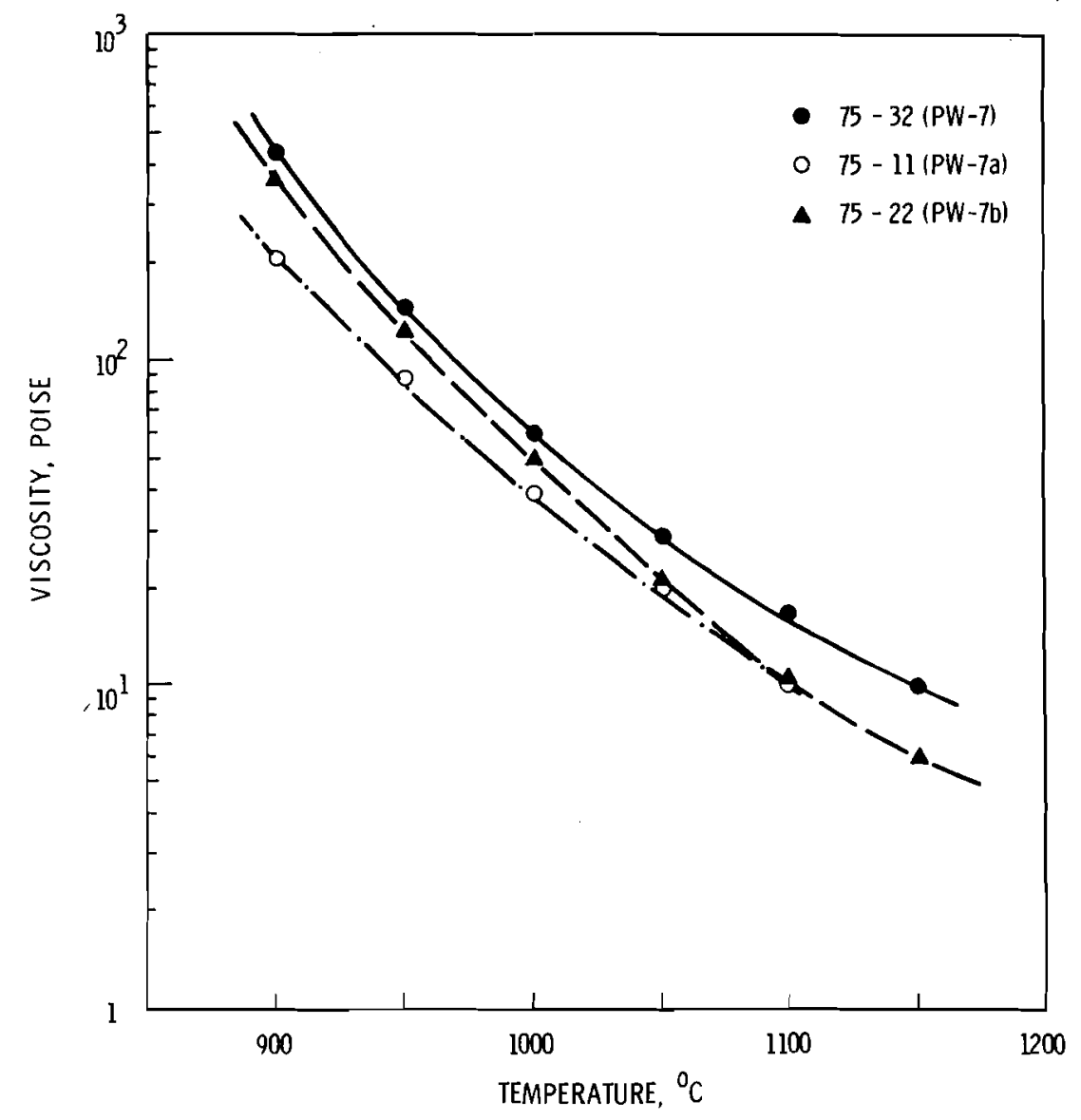

FIGURE 10. Viscosity of Zinc Borosilicate Glasses Containing AGNS-Type High-Level Waste 
The leachates were analyzed for strontium, cesium and molybdenum after one series of Soxhlet leach tests. In Table 16 the leach rates calculated from analyses for individual elements are compared to leach rates calculated from the overall weight loss. All three elements are preferentially leached. The leaching behavior of cesium and molybdenum corresponds closely; both exhibit a greater preferential leachability than strontium. of the melts in Table 16, only 75-14 and 15 exhibited a macro-molybdate second phase. The results in Table 16 show that the second phases were almost completely dissolved in the first $24 \mathrm{hr}$ Soxhlet leaching contact.

The presence of the molybdate second phase is a function of both fission product and sodium content of the glass. As shown in Figure 11, it is desirable to minimize sodium content to obtain maximum fission product loading without the presence of the molybdate second phase. Methods to eliminate the molybdate second phase problem are being investigated.

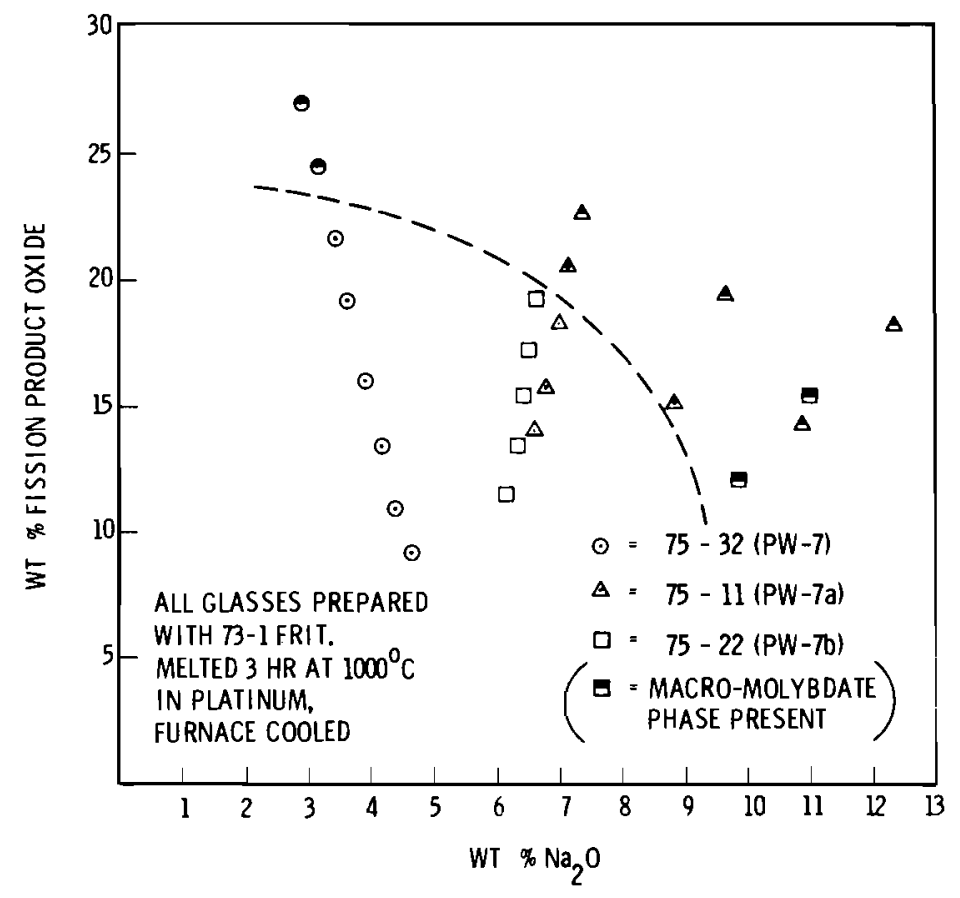

FIGURE 11. Effect of Fission Product and Sodium Content on Molybdenum Phase Separation 
TABLE 16. Leach Rate of Zinc Borosilicate Glasses Soxhlet
Leach Rate, (a) $\mathrm{g}$ Glass Dissolved $/ \mathrm{cm}^{2}$ Day $(\mathrm{b})$

Constituent

Analyzed:

Cesium
Strontium
Molybdenuin
Overall Weight Loss

$$
\text { Leach Rate, (a) g Glass Dissolved/cm² Day }(b)
$$

\begin{tabular}{|c|c|c|c|c|c|}
\hline & & & nd $24 \mathrm{Hr}$ & & \\
\hline & $75-11$ & $75-12$ & $75-13$ & $75-14$ & $75-15$ \\
\hline Cesium & $3.8 \times 10^{-5}$ & $3.5 \times 10^{-5}$ & $2.0 \times 10^{-5}$ & $5.3 \times 10^{-5}$ & $9.0 \times 10^{-5}$ \\
\hline Strontium & $2.7 \times 10^{-5}$ & $2.3 \times 10^{-5}$ & $1.3 \times 10^{-5}$ & $4.1 \times 10^{-5}$ & $2.7 \times 10^{-5}$ \\
\hline Molybdenum & $4.4 \times 10^{-5}$ & $3.4 \times 10^{-5}$ & $2.0 \times 10^{-5}$ & $6.2 \times 10^{-5}$ & $5.3 \times 10^{-5}$ \\
\hline Overall Weight Loss & $1.8 \times 10^{-5}$ & $1.6 \times 10^{-5}$ & $1.3 \times 10^{-5}$ & $1.8 \times 10^{-5}$ & $2.2 \times 10^{-5}$ \\
\hline & & & ard $24 \mathrm{Hr}$ & & \\
\hline & $75-11$ & $75-12$ & $75-13$ & $75-14$ & $75-15$ \\
\hline Cesium & $6.8 \times 10^{-5}$ & $3.9 \times 10^{-5}$ & $2.1 \times 10^{-5}$ & $3.0 \times 10^{-5}$ & $3.0 \times 10^{-5}$ \\
\hline Strontium & $1.9 \times 10^{-5}$ & $2.4 \times 10^{-5}$ & $i .5 \times 10^{-5}$ & $2.5 \times 10^{-5}$ & $2.3 \times 10^{-5}$ \\
\hline Molybdenum & $3.6 \times 10^{-5}$ & $3.1 \times 10^{-5}$ & $1.7 \times 10^{-5}$ & $3.6 \times 10^{-5}$ & $4.1 \times 10^{-5}$ \\
\hline Overall Weight Loss & $9.0 \times 10^{-6}$ & $8.0 \times 10^{-6}$ & $3.0 \times 10^{-6}$ & $7.5 \times 10^{-6}$ & $7.5 \times 10^{-6}$ \\
\hline
\end{tabular}

a. Soxhlet leach test procedure described in BNWL-1741.

b. Calculated from $\frac{a_{1}}{A_{0}}\left(\frac{W}{S t_{n}}\right)$, where:

$a_{1}=$ amount of constituent leached in $t_{n}$ days.

$A_{0}=$ amount of constituent present in sample specimen.

$W=$ weight of sample specimen $(1 \mathrm{~g})$.

$S=$ surface area of sample specimen (not measured, estimated $200 \mathrm{~cm}^{2}$ ).

$t_{n}=$ duration of leaching contact ( 1 day). 


\section{STORED ENERGY MEASUREMENTS - F. P. Roberts}

The objectives of the task are to experimentally determine the buildup of radiation-induced stored energy in solidified high-level wastes as a function of the storage time and storage temperatures, and to characterize the thermal behavior of the solidified waste when the stored energy is released. The results of the study are to be used to establish whether or not stored energy constitutes a hazard in waste storage.

Experiments were carried out to observe the effect of the storage temperature of the solidified waste on the stored energy behavior. A specimen of ${ }^{244} \mathrm{Cm}$-doped melt 72-68 was allowed to accumulate an alpha dose of $4 \times 10^{17}$ alpha/g while stored at $23^{\circ} \mathrm{C}$. Portions of the specimen were held at various fixed temperatures $\left(100\right.$ to $250^{\circ} \mathrm{C}$ ) for a minimum of three weeks. The stored energy release was measured by differential scanning calorimeter (DSC) each week. Determining the energy release each week showed that the stored energy had reached a constant value within the experimental uncertainties in less than one week. The results of these measurements, given in Figure 12, show the relationship between the total amount of stored energy and the temperature at which the solidified waste is stored. The quantity of energy is inversely proportional to the storage temperatures and therefore can be limited to some extent by maintaining the solidified waste at a slightly elevated temperature.

In earlier experiments it had been observed that the rate of release of stored energy became appreciable only at temperatures significantly above the temperature at which the test specimen was stored. This phenomenon was further evaluated in the current experiment by estimating temperature at which the onset of energy release occurred. The data, shown in Figure 13, indicate that the energy release begins $100^{\circ} \mathrm{C}$ above the storage temperature. This is significant because small temperature excursions of less than $100^{\circ} \mathrm{C}$ above ambient storage conditions will not trigger the release of stored energy. 


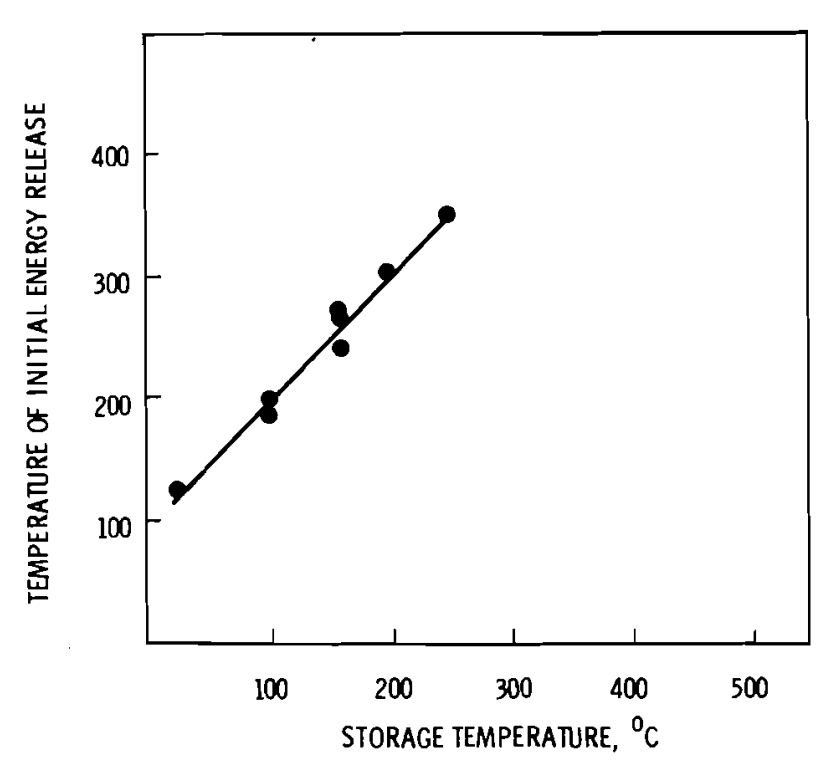

FIGURE 12. Onset Temperature of Energy Release

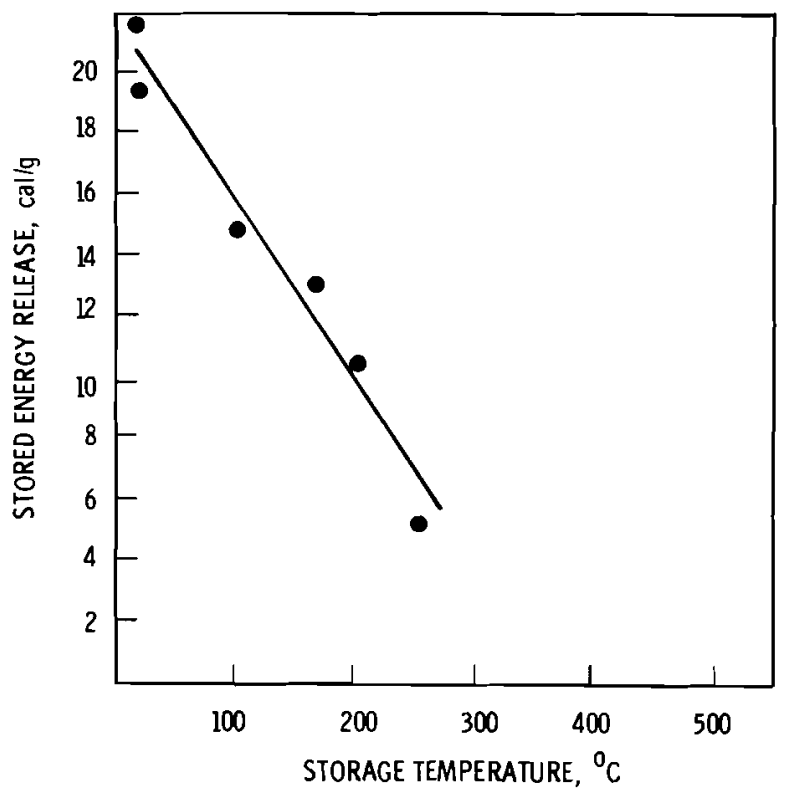

FIGURE 13. Quantity of Stored Energy Released as Function of Storage Temperature

\section{HELIUM IN GLASS - R. P. Turcotte}

The objective of this study is the determination of helium diffusion coefficients in simulated waste glass. To assess radiation domage effects and to provide a relatively high helium content, samples doped with ${ }^{244} \mathrm{~cm}$ are being examined. Helium release is being measured from thin discs as a function of time and temperature by manometric and mass spectrometer methods.

Work in the last quarter included preliminary runs and calibrations with the new mass spectrometer as well as isothermal release measurements on two samples. At variance with the earlier manometric runs, for short times a diffusion coefficient in the $10^{-8} \mathrm{~cm}^{2} / \mathrm{sec}$ range was obtained at $350^{\circ} \mathrm{C}$. An activation energy for diffusion of $\sim 15 \mathrm{kcal}$ was obtained for samples annealed at $525^{\circ} \mathrm{C}$. The samples studied had ingrown helium for 170 days at ambient temperatures containing, by calculation, 0.038 cc of 
helium (STP) per cc glass. The experimental procedure involved isothermal heating with direct coupling to the mass spectrometer. To increase sensitivity, the pumping system was throttled back to maintain pressures at $\sim 5 \times 10^{-6}$ Torr with gases released from the sample continuously pumped past the quadrupole head at this pressure. A calibrated standard leak $\left(6.6 \times 10^{-8} \mathrm{cc} / \mathrm{sec}\right)$ was used to periodically calibrate the mass spectrometer during the course of the runs. The repeatability was $\simeq \pm 2 \%$.

The results of three isothermal runs extending over several days of continuous release are given in Figure 14, with the sequence of runs being from low to high temperature (168 days, sample A-23-1). The data are plotted as $\mathrm{cc} / \mathrm{sec}$ versus time so that the area under each curve is directly proportional to the total helium released. The areas were determined by weighing graphed strips, with the results obtained plotted in Figure 15 as cc (at STP) of helium versus time. For this $0.94 \mathrm{cc}$ disc, the calculated inventory was $0.035 \mathrm{cc}$, which suggests that the run at $526^{\circ} \mathrm{C}$ was approaching full release, although a large rate decrease is not apparent. The long time release rates at $351^{\circ} \mathrm{C}$ and $426^{\circ} \mathrm{C}$ are lower than at the higher temperatures, as expected.

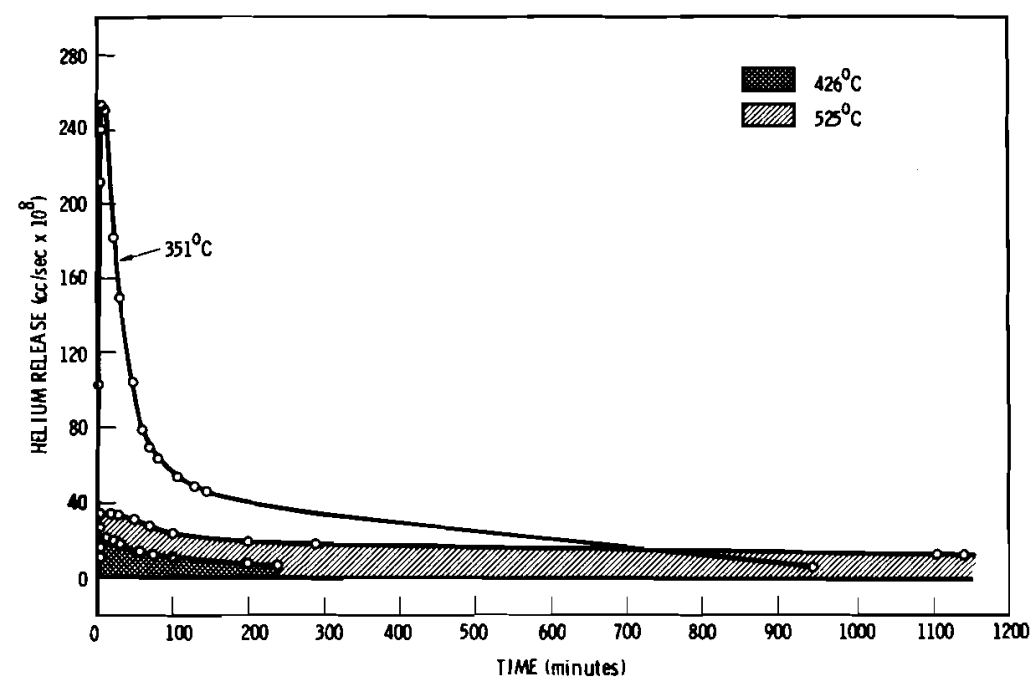

FIGURE 14. Isothermal Helium Release After 168 Days' Ingrowth for Sample A-23-1, Plotted as cc/sec Versus Time 


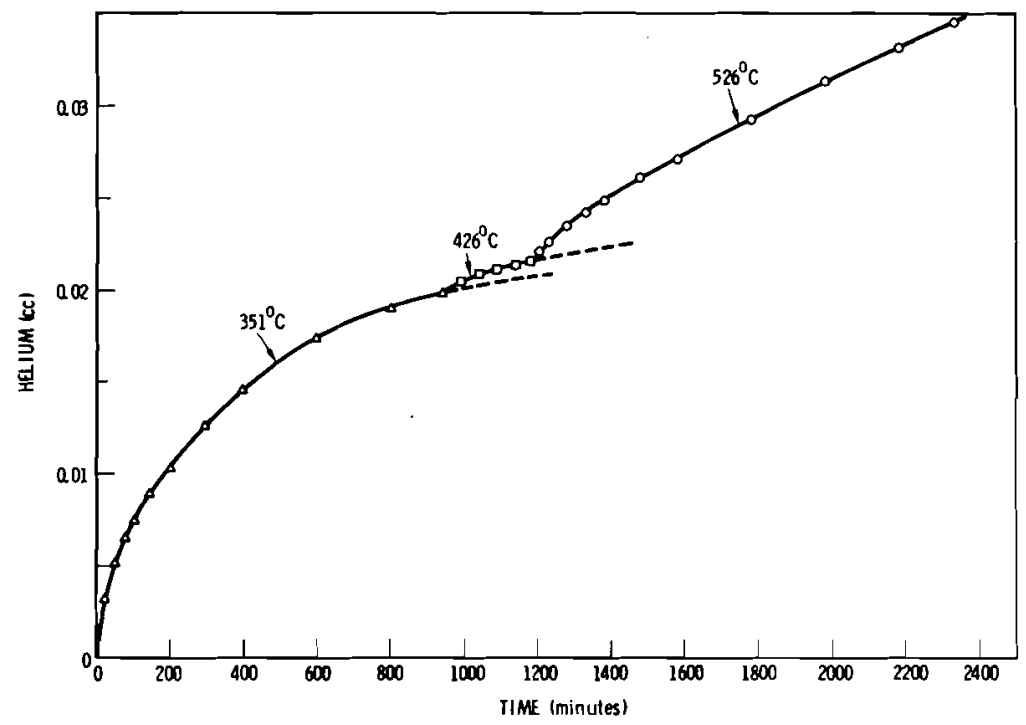

FIGURE 15. Data Replotted as Total cc of Helium (STP) Versus Time

The Fick's law solution for the disc geometry employed, where $F$ is the fractional gas release, is given by:

$$
F=1-\frac{8}{\pi^{2}} \sum_{m=0}^{\infty} \frac{1}{(2 m+1)^{2}} \exp \left[-D(2 m+1)^{2} \pi^{2} t / l^{2}\right]
$$

where $D$ is in units $\mathrm{cm}^{2} / \mathrm{sec}, t$ is time in seconds, and $\ell$ is the slab thickness $(\mathrm{cm})$. Based on the $0.035 \mathrm{cc}$ calculated inventory, the $351^{\circ} \mathrm{C}$ data are shown plotted as fractional release versus time in Figure 16. A good fit to the above equation can be obtained for any given time segment of the release curve, but the change to smaller $D$ with increasing time (or release fraction) is clear, with the slope for $t>800 \mathrm{~min}$, suggesting $D<1.0 \times 10^{-8} \mathrm{~cm}^{2} / \mathrm{sec}$. For the first few hours, $D \sim 3 \times 10^{-8} \mathrm{~cm}^{2} / \mathrm{sec}$ gives a reasonable fit, but with an increasing difference the longer the time. 


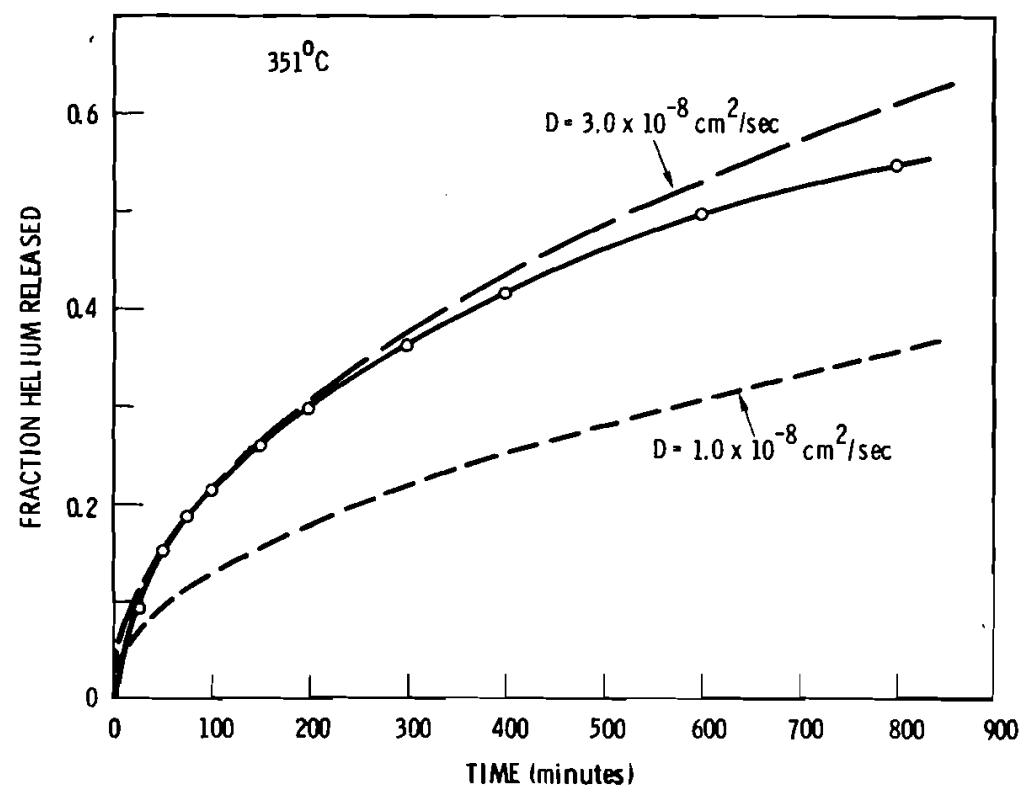

FIGURE 16. Isotherm at $351^{\circ} \mathrm{C}$ Plotted as Fractional Release Versus Time and Compared to Theoretical Curves

The mass spectrometer results agree poorly with the manometer data obtained last quarter. Those data suggested a very high short time $D$ of $21 \times 10^{-6} \mathrm{~cm}^{2} / \mathrm{sec}$, falling off to values in the $10^{-8} \mathrm{~cm}^{2} / \mathrm{sec}$ range only at long times. Since the samples were stored in a high-humidity glove box, it now seems probable that significant hydration occurs, perhaps erihanced by the high radiation field, and that the short time release measured with the manometer reflects water release rather than helium. A small effort will continue toward a resolution of this discrepancy, since there are other explanations and since the release of any gas is of potential importance.

The activation energy for diffusion was determined from two samples after $\sim 2$ days heating at $525^{\circ} \mathrm{C}$. Release rates are shown in Figure 17, plotted as $1 n$ (rate) versus $1 / T$. The release rate for a given ( $\sim$ constant) fraction release is directly proportional to $D_{T}$ at long times. If a single 
diffusion mechanism is operative, the plot given should be linear with slope $-E / R$. The two sets of data are in reasonable agreement, giving $E=16.0 \mathrm{kcal}$ and $13.9 \mathrm{kcal}$ for samples A-23-1 and A-25-3, respectively. The mean diffusion coefficient is thus given as

$$
\mathrm{D}_{\mathrm{T}}=\mathrm{D}_{\mathrm{O}} \exp [-7500 / \mathrm{T}]
$$

which al though somewhat high in $E$, is comparable to values reported for other glasses. Since the complication of radiation damage is present, the activation energy may vary with the extent of damage. The present result is, therefore, specific to the case of $\sim 2$ days annealing at $525^{\circ} \mathrm{C}$, after self-damage ingrowth of 168 days. Since the experimental method is now established and relatively easy, determination of $E$ for other recovery fractions will be made during the next quarter. Several samples are being stored at $300^{\circ} \mathrm{C}$ to determine the importantce of storage temperature on release behavior.

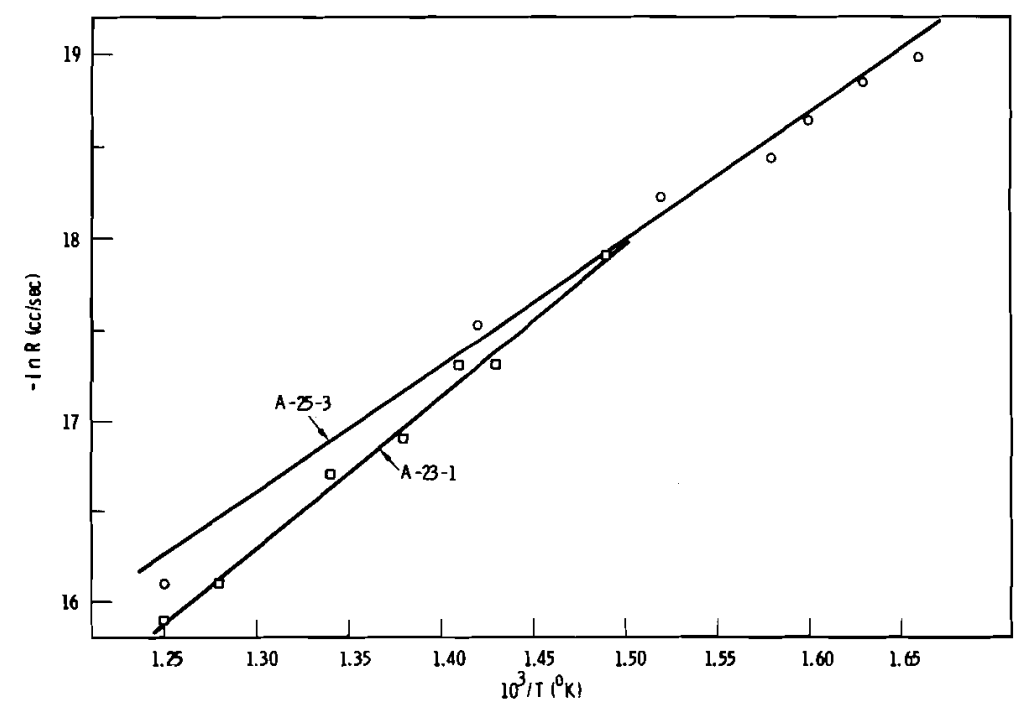

FIGURE 17. Release Rates Plotted as In R Versus $1 / T$ for Two Samples, Following Anneals at $525^{\circ} \mathrm{C}$ 
RADIOLYTIC GAS GENERATION - G. L. Tingey and W. D. FeTix

In this task the stability of calcined nuclear waste products in a radiation environment is being investigated because of the potential pressure buildup of evolved gases in a waste container.

As part of the task to characterize calcined waste, we are studying the surface properties, particularly the surface area and gas sorption properties of calcined waste materials. Micrographs have shown considerable void volume with connecting cracks.* Thus we would expect the material to have considerable surface area available for gas sorption. Surface areas are reported* to be about $1.5 \mathrm{~m}^{2} / \mathrm{g}$ for $\mathrm{PW}-7$ waste particles in the size range from 125 to $175 \mu \mathrm{m}$.

The sorption of $\mathrm{N}_{2}, \mathrm{O}_{2}, \mathrm{H}_{2}$, and $\mathrm{CO}_{2}$ has been measured for $\mathrm{PW}-7$ calcined waste. Nitrogen sorbed in the normal manner at $-195^{\circ} \mathrm{C}$, and the data were used in conjunction with the BET equation to calculate the surface area. However, no measurable sorption was found at $25^{\circ} \mathrm{C}$. Likewise, oxygen sorption was barely detectable at $-90^{\circ} \mathrm{C}$ and none was detectable at $25^{\circ} \mathrm{C}$. Hydrogen appeared to be much more strongly sorbed by the waste, but the sorption was more strongly a function of time than of hydrogen pressure and increased with increasing temperature rather than with decreasing temperature as expected. These results suggest that the hydrogen may be reacting chemically with the waste material rather than merely adsorbing on the surface.

Carbon dioxide sorption isotherms were more reliable and, therefore, were studied more thoroughly. Figure 18 shows the $\mathrm{CO}_{2}$ sorption isotherms at temperatures up to $700^{\circ} \mathrm{C}$, with $\mathrm{CO}_{2}$ sorption increasing as a function of pressure at all temperatures, but does not show the expected decreasing sorption with temperature. The sorption increases with temperatures up to $500^{\circ} \mathrm{C}$ and decreases at higher temperatures. This may be due to chemical

* Quarterly Progress Report, BNWL-1893, February 1975. 
reaction of the gas with the waste material or to surface changes which occur slowly during high temperature heating.

Under most conditions, the quantity sorbed is about $0.03 \mathrm{wt} \%$ and the maximum sorption observed $\left(500^{\circ} \mathrm{C}\right.$ and $1 \mathrm{~atm} \mathrm{CO}_{2}$ pressure) was $0.06 \mathrm{wt} \%$. This small quantity of $\mathrm{CO}_{2}$ is not sufficient to cause much gas generation in the waste during transport or storage. At higher pressures more sorption may occur, but the isotherms are clearly flattening as the pressure increases. Thus a substantial increase even at very high pressures is not likely. Although the quantity sorbed is of little consequence to pressurization, it is essential in studies of the radiolygis reaction to know accurately the quantity of the product sorbed on the surface. These experiments are continuing to more accurately characterize the surface properties of the various waste forms.

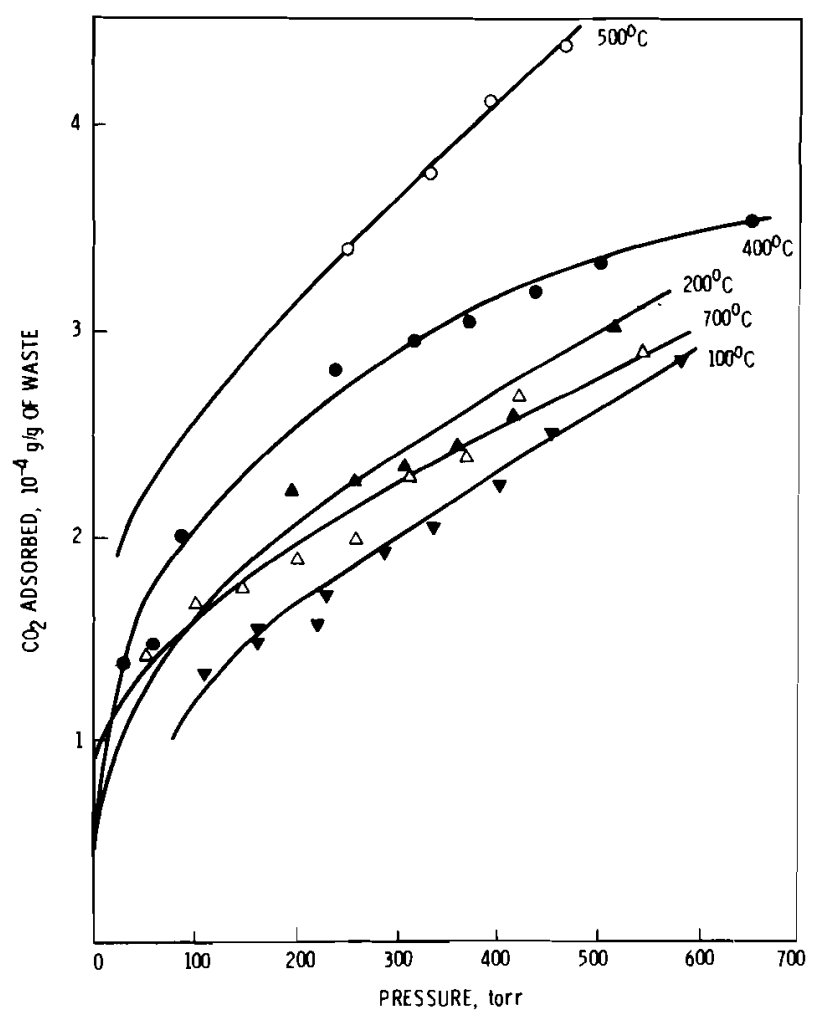

FIGURE 18. $\quad \mathrm{CO}_{2}$ Adsorption of PW-7 Nuclear Waste 
FULL-LEVEL RADIOACTIVE TESTS - Y. B. Katayama

Fully radioactive waste glass specimens wilz be prepared on a laboratory scale. Analysis of the off-gas wizl be made during melting of the radioactive glasses. Characteristics of the fully radioactive glass specimens will be compared with nonradioactive glasses of similar chemical composition as a function of storage conditions.

Approximately $2 \mathrm{~kg}$ of irradiated $\mathrm{UO}_{2}$ power reactor fuel pellets (55,000 MWD/MTU, 1 1/2 years out-of-reactor) have arrived at PNL. Reprocessing will begin in April. The in-cell glass making equipment is being modified to facilitate remote handling, especially the melting chamber closure design.

SS-9 CANISTER EVALUATION STATUS - Y. B. Katayama, C. E. Bigelow

The objective is to determine the mechanism of containment penetration and supply reference data for future canister material selections.

The lower portion of canister 36 has been covered with an overpack. This overpack was TIG welded, manually with a manipulator, while the canister was suspended vertically. The $3 / 8 \mathrm{in}$.-thick $304 \mathrm{~L}$ stainless steel overpack was tack welded and then sequence welded. Some undercutting of the canister metal, top of weld, was observed during welding. The overpack closure was helium leak checked after the glass product was vacuum dried. The canister has been returned to the SSETF water test pod.

A Huey corrosion test of 310 and $304 \mathrm{~L}$ stainless steel samples indicated the samples were fully sensitized. The samples have weight losses representing a uniform penetration rate greater than $40 \mathrm{mils}$ per month. The 310 stainless stee 1 sample was trepanned from canister 36 of run SS-9, and the 304L sample was trepanned from the canister of run PC-8.

Five trepanned samples from canister 36 were sectioned, mounted, and polished in the 327 Building hot cells. These samples were examined on a metallograph, after etching, at various magnifications. Microcracking was observed in the samples taken from macrocracked areas, but no signs of microcracking were evident in the samples taken from areas free of macrocracks. 


\section{IMPACT TESTING OF VITREOUS SIMULATED HIGH-LEVEL WASTE IN CANISTERS -}

T. H. Smith, W. A. Ross, S. L. Sutter

The objective of this work segment is to investigate the amount of waste glass breakup, in both glassy and devitrified forms, in impacted test canisters.

Quantities determined have included fractional breakup, size distribution of particles and geometric surface area produced. The final report has been written and is to be released shortly (BNWL-1903).

THERMAL PROPERTIES OF WASTE FORMS - W. A. ROSS, F. P. Roberts

The thermal property data of waste materials are necessary to allow calculations of the time-temperature relationships in processing and storage of these materials.

Therma 1 Conductivity of Glass

The thermal conductivity of a $72-68[\mathrm{PW}-4 \mathrm{~b}-2(3.0) \cdot 73-1] \mathrm{g}$ lass was determined by the unsteady-state method described previously.* The sample was prepared by sintering glass powder at $700^{\circ} \mathrm{C}$ around the heater and thermocouple wires. The sample was then heated in a furnace to the test temperatures. The data is shown in Table 17.

TABLE 17. Thermal Conductivity of Glass

$\begin{array}{cc}\text { Temperature, }{ }^{\circ} \mathrm{C} & \begin{array}{c}\text { Thermal Conductivity, } \\ \text { Watts } / \mathrm{M}^{\circ} \mathrm{K}\end{array} \\ 25 & 0.84 \\ 211 & 1.05 \\ 403 & 1.21\end{array}$

\footnotetext{
* W. A. Ross, "Thermal Conductivity of Calcine," Quarterly Progress Report, BNWL-1893, February 1975.
} 


\section{Heat Capacity}

A differential scanning calorimeter which is part of the DuPont No. 990 thermal analysis system was used to measure seven samples of 72-68[PW-4b-4:(2-8)73-1] glass and one sample of PW-4b-2 fluid bed calcine. The data shown in Figure 19 for the $72-68$ glass is the average of the seven values. The values had a standard deviation of about $10 \%$. The heat capacity data for the calcine is shown in Figure 20.

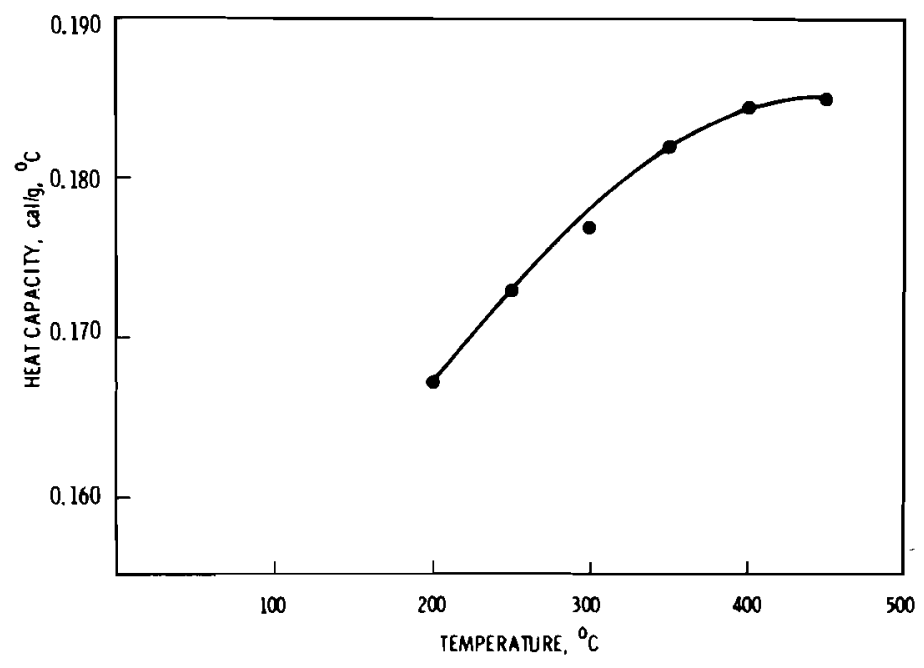

FIGURE 19. Heat Capacity of 72-68 Glass

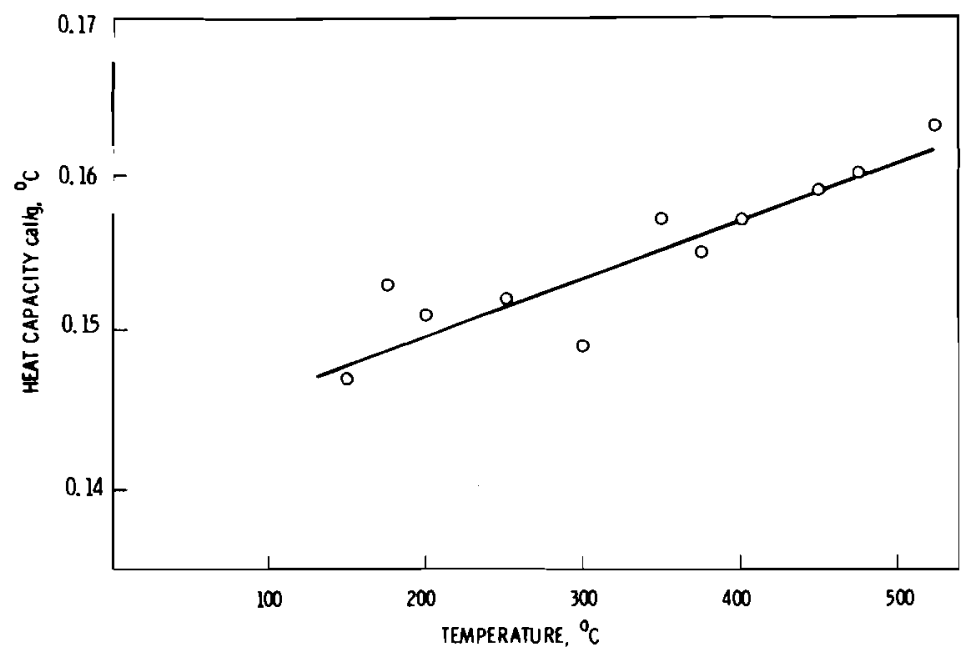

FIGURE 20. Heat Capacity of PW-4b-2 Calcine 


\section{ALTERNATIVE WASTE FIXATION PROCESSES}

The goal of this task is to develop alternative waste fixation processes and evaluate their waste form products to assure that viable processes will be available for containment of high-level wastes. The alternative processes and products are to be compared for cost and safety to the current reference process and product, silicate glass castings in large metal canisters. Alternative processes are now being developed on the Zaboratory scale. After the most promising concept(s) are selected, further engineering-scale development will be undertaken.

\section{GLASS SINTERING - W. A. RosS}

This study is to determine the feasibility of sintering a calcine-frit mixture as part of a waste fixation process.

A major advantage of a pellet form appears to be its ability to be coated with various inert materials. Tests this month have included pellet forming method, pellet characterization, and preliminary coating tests.

\section{Pellet Formation}

Preliminary evaluations of pellet requirements indicate that two size ranges should be considered. The largest pellets will be of about 1 in. diam and may be suitable for coating by rolling, spraying, dipping, or other methods. The smaller pellets will be in the $1 \mathrm{~mm}$ diam range, appropriate for Chemical Vapor Deposition (CVD) coating methods in a fluid bed. The large diameter pellets probably can be formed successfully by cold pressing. But the small pellets will require another method because of the volume of material to be handled. Some tests with agglomeration techniques have successfully produced some pellets, but binders must be found that significantly increase green strength. Additional pellet forming methods will be tested later. 
An SEM (scanning electron microscope) examination of calcine-rich areas in a poorly reacted glass suggested that a modification to 73-1 frit should be made. The new frit, $75-10$, contains $47 \mathrm{wt} \% \mathrm{SiO}_{2}, 16 \% \mathrm{~B}_{2} \mathrm{O}_{3}$, $15 \% \mathrm{ZnO}, 7.5 \% \mathrm{CaO}, 6 \% \mathrm{Na}_{2} \mathrm{O}, 6 \% \mathrm{~K}_{2} \mathrm{O}$ and $2.5 \% \mathrm{Mg} 0$. Comparison of the two frits has shown 75-10 to be less leachable than 73-1 when mixed with high concentrations of calcine. To test the effect of calcine concentration, a test with PW-4b-2 was made where calcine concentration was varied between 60 and $85 \%$. The pellets were cold pressed from well mixed -325 mesh powders and sintered $2 \mathrm{hr}$ at $875^{\circ} \mathrm{C}$. The pellet densities and leach rate were determined and are shown in Figure 21. This test shows that a pellet with about $65 \mathrm{wt} \%$ calcine is optimum for these sintering conditions. Further tests have shown that the sintered density of the $65 \mathrm{wt} \%$ calcine pellets can be increased to $3.22 \mathrm{~g} / \mathrm{cc}$ by sintering at $900^{\circ} \mathrm{C}$.

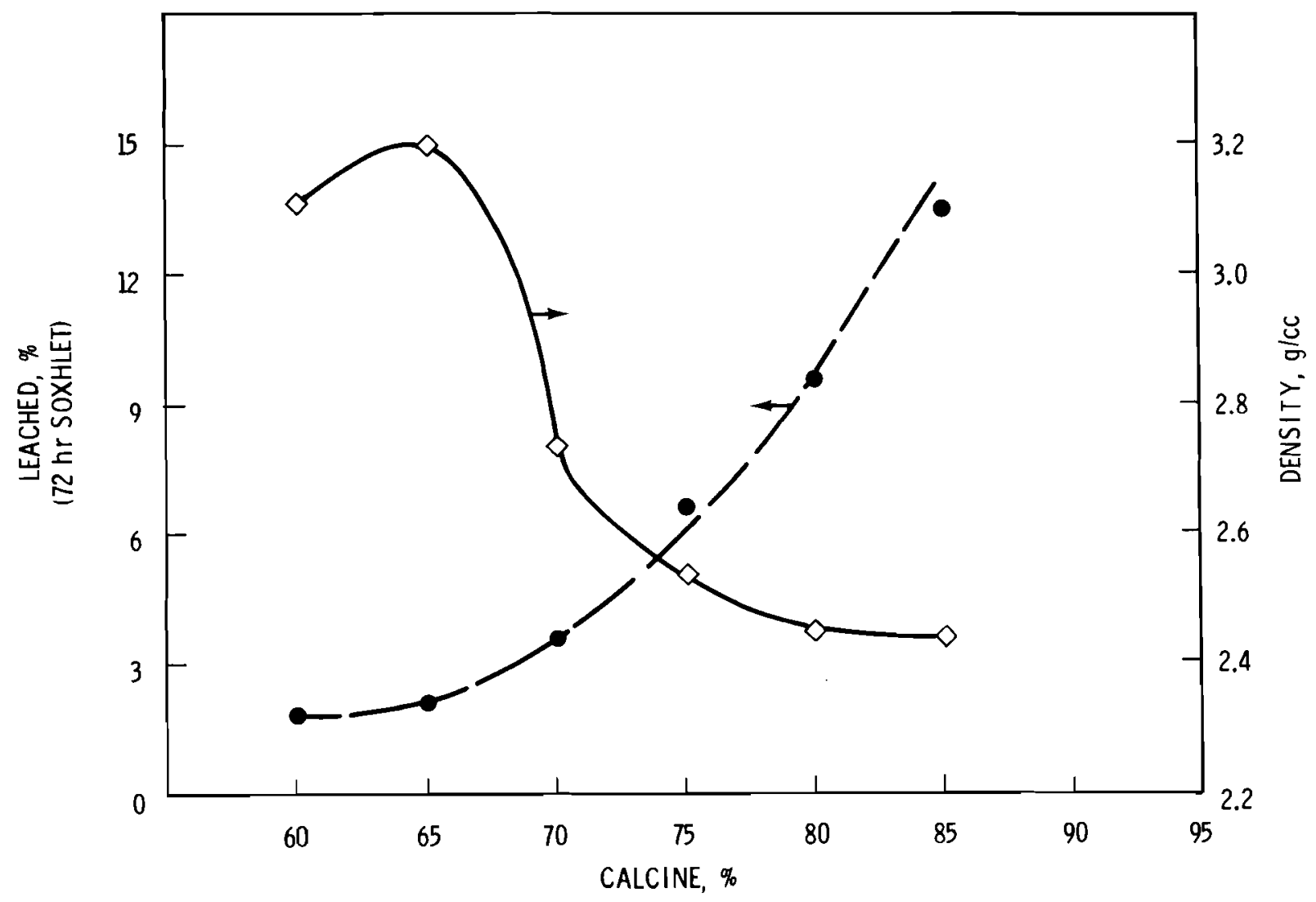

FIGURE 21. Characteristics of High-Calcine Content Pellets Formed with PW-4b-2 Calcine and $75-10$ Frit at $875^{\circ} \mathrm{C}$ 


\section{Pel let Characterization}

The pellets sintered at $900^{\circ} \mathrm{C}$ have been examined with optical and electron microscopes. Figure 22, an optical micrograph, shows considerable porosity in the $\sim 75 \mu$ range. It is estimated from both a calculated calcine density and from comparison to known microstructures that the porosity is about 20 vol \%. This is much higher than desired, but indications are that much of the porosity is still closed. The SEM micrograph (Figure 23) shows some additional porosity in the $3 \mu$ range. The majority of the structure does not appear to be crystalline, but several crystals are present, and spot analysis indicates that they are a $(\mathrm{Sr}, \mathrm{Ca}) \mathrm{MoO}_{4}$. These crystals have been observed previously in heat treated calcines.* Pel let Coating

Inert coatings on pel lets can provide very significant improvement in leach resistance of radioactive elements. For example, if a $1.25-\mathrm{mm}$ coating of nonradioactive glass such as 73-1 frit with a leach rate of $10^{-6} \mathrm{~g} / \mathrm{cm}^{2}$ day were applied to a body, it would require 1000 years of continuous leaching to remove the coating and begin leaching radioactive species.

Preliminary tests of simulated waste particles coated with frit have shown that coatings can be applied and that they are impact resistant. It was also noted that pellet surfaces must be uniform for complete coatings to be applied. Considerable work will be required to successfully develop remote coating methods.

PLASMA SPRAY SYSTEM - J. J. Rasmussen, J. L. Bates

The purpose of this study is to develop spray refractory and protecvive coatings for various applications in the nuclear waste fixation program. Present studies include refractory coatings of metals and ceramics, coating of waste forms, and simultaneous spraying of ceramic and waste.

* G. J. McCarthy and M. T. Davidson, "Phases Formed on Firing a Simplified PW-4b Calcine," WFP Quarterly Progress Report, October-December 1974, BNWL-1893, p. 59, February 1975. 


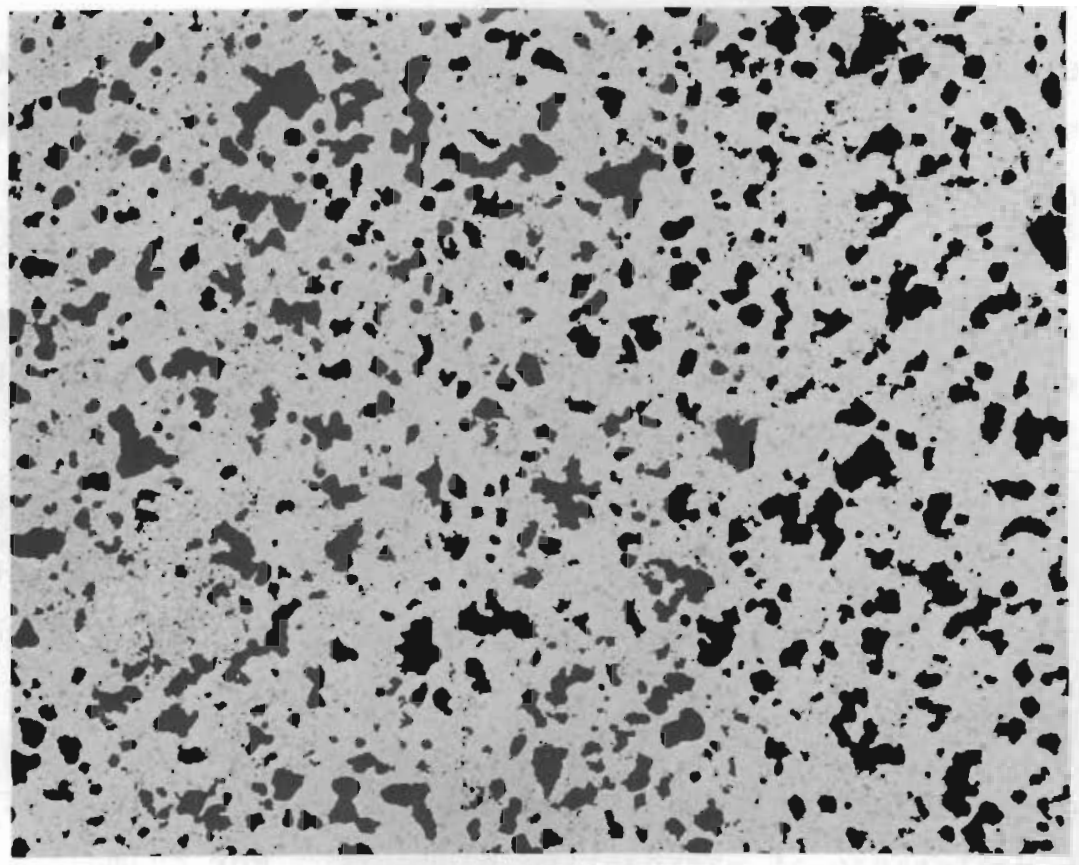

FIGURE 22. 50X Photomicrograph of Pellet of 65 wt $\%$ PW-4b-2 Calcine and 35 wt\% $75-10$ Frit Sintered at $900^{\circ} \mathrm{C}$ for $2 \mathrm{hr}$

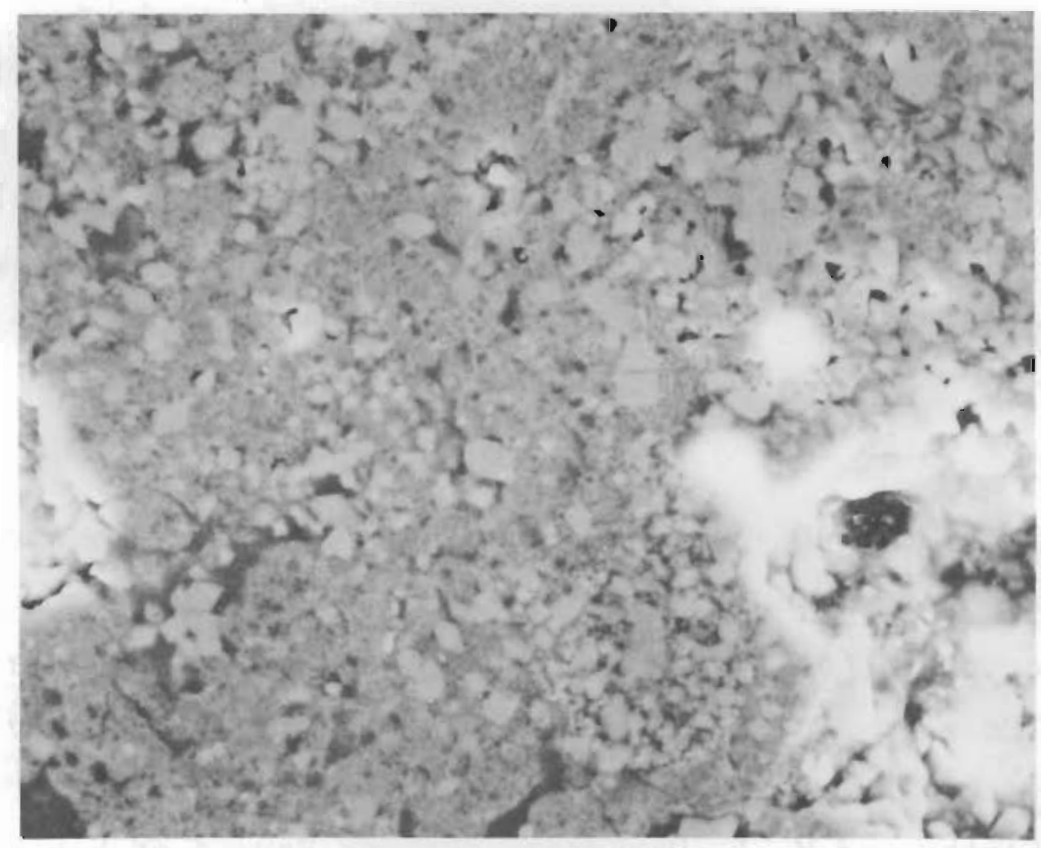

FIGURE 23. 1000X SEM Micrograph of Above Pellet 
The plasma spray system has been installed and checked out by the factory service engineer. Coatings of stabilized zirconium oxide, molybdenum, and polypropylene have been sprayed onto copper and stainless steel. The plasma spray system is a versatile unit capable of spraying coatings of materials from the plastics to highly refractory carbides. The system will first be used to produce protective oxides, carbides, nitrides, borides, or plastic coatings on metals or ceramics of interest to the waste fixation program. The system has been designed with two separate feed hoppers for simultaneously spraying two different materials. This also allows the spray unit to be used to study the potential processes of simultaneously spraying waste and inert oxides to form an inert waste product, and for coating of waste forms.

An oxidation-resistant spray coating of $\mathrm{ZrO}_{2}$ was made directly on 304 stainless steel coupons. The coupons were inserted into an electrically heated furnace and fired to $1100^{\circ} \mathrm{C}$ in air. One sample was removed from the furnace at $1100^{\circ} \mathrm{C}$ and quenched in water. The second sample was removed at $1100^{\circ} \mathrm{C}$ and cooled in air. The $\mathrm{ZrO}_{2}$ coating cracked badly upon cooling on both coupons, but the stainless steel was not oxidized. An uncoated sample of 304 stainless steel was substantially oxidized in the same test. The failure of the coating was attributed to inadequate coating bonding with the metal. To obtain an adherent coating, an intermediate coating of $\mathrm{Ni} / \mathrm{Cr}$ alloy will be applied before coating with $\mathrm{ZrO}_{2}$.

A $\mathrm{ZrO}_{2}$ coating was also applied on several thermocouple protection tubes to learn if this would assist in reducing the corrosion rate of the tubes in glass compositions.

An estimate made of the cost to apply a protective coating to a stainless steel canister for containing waste uses the following relationship:

$\cos t /$ pound $=\frac{(\text { spray rate } x \text { material cost })+\text { labor, overhead, and equipment costs }}{\text { spray rate } x \text { deposit efficiency }}$ 
The following assumptions were made: $75 \%$ deposit efficiency and labor, overhead, and equipment charges of $\$ 25 / \mathrm{hr}$. The costs given in Table 18 are those required to spray a coating of $0.05-i n$. thickness on the inside and outside surfaces of a canister $12 \mathrm{in.} \mathrm{diam} \mathrm{by} 24 \mathrm{in.} \mathrm{high.}$

\section{TABLE 18. Costs to Spray Coat Waste Containers}

\section{Spray Rate (1b/hr) $\$ / 1 \mathrm{~b}$ of Spray Fed $\$ /$ Container}

A. $\mathrm{Al}_{2} \mathrm{O}_{3}$, density $3.98 \mathrm{~g} / \mathrm{cm}^{3}$, cost $\$ 8 / 1 \mathrm{~b}$

$\begin{array}{lrr}0.264 & 136.93 & 2,230 \\ 2.64 & 23.29 & 380 \\ 26.4 & 11.93 & 194\end{array}$

B. $\mathrm{Cr}_{3} \mathrm{C}_{2} / \mathrm{NiCr}$, density $6.15 \mathrm{~g} / \mathrm{cm}^{3}$, cost $\$ 10 / 1 \mathrm{~b}$
0.396
97.51
3.96
21.75
39.6
14.18
2,450
547
356

ADVANCED PRODUCT FORMS RESEARCH AND DEVELOPMENT (PENNSYLVANIA STATE UNIVERSITY) - G. J. McCarthy

The materials Research Laboratory at Pennsylvanie State University, University Park, $P A$, is operating under a subcontract to investigate advanced solidified waste forms, e.g., forms other than melt-formed glasses or glass-ceramics. Overall objectives of the program are to develop fundamental understanding of the crystal chemistry of calcined high-level waste and to use this understanding to develop solidified waste forms with enhanced chemical and thermal stability. Near-term objectives are 1) to complete a laboratory-scale study on the use of hot-pressing techniques for high-level waste fixation and 2) to develop a "super calcine" formulation, prepared by chemically mixing specially chosen additives to the waste solution so that all of the individual radioactive atoms will be isolated in inert phases when the waste is calcined. 
SILICA MATRIX ISOLATION BY HOT PRESSING - G. J. McCarthy and M. T. Davidson

The concept, formulations and processing parameters have been outlined in previous quarterly reports. Compositions and product characterization for selected runs are outlined in Table 19 and summarized below.

TABLE 19. Composition and Product Characterization for Selected HP Runs

\begin{tabular}{|c|c|c|c|c|c|c|}
\hline Run No. & $\begin{array}{c}\text { Formulation } \\
\text { wt\% }\end{array}$ & $\begin{array}{l}\text { HP Temp. } \\
{ }^{\circ} \mathrm{C} \\
\end{array}$ & $\mathrm{H}$ & $S G$ & $\begin{array}{c}\text { Leachability } \\
\text { (72-hr Soxhlet) } \\
\text { (wt\% lost) } \\
\end{array}$ & $\begin{array}{c}\text { Porosity and } \\
\text { Average Size } \\
\text { (SEM) }\end{array}$ \\
\hline HP-41 & $\begin{array}{c}30 \text { PW-4b } \\
63 \text { Quartz } \\
7 \text { PBS }\end{array}$ & 1200 & > SS & 3.1 & 1.0 & $0.7 \%-1.7 \mu \mathrm{m}$ \\
\hline$H P-43$ & " & 1100 & > >SS & 3.1 & 1.6 & $1.2 \%-1.6 \mu m$ \\
\hline $\mathrm{HP}-49$ & " & 1000 & $<\mathrm{SS}$ & 3.0 & 2.7 & $4.9 \%-1.3 \mu m$ \\
\hline$H P-53$ & $\begin{array}{l}25 \text { PW-4b } \\
67.5 \text { Quartz } \\
7.5 \text { PBS }\end{array}$ & 1200 & >>SS & 3.0 & 0.92 & - \\
\hline HP-55 & $\begin{array}{l}20 \text { PW-4b } \\
72 \text { Quartz } \\
8 \text { PBS }\end{array}$ & 1200 & $\gg$ >SS & 3.0 & 0.81 & - \\
\hline
\end{tabular}

- Microstructure. HP-41, $-43,-49$ were examined; porosity increases with decreasing temperature; the largest visible grains are quartz, 40 um or smaller; the waste is very fine grained; lead borosilicate (PBS) glass gives the appearance of having "flowed" in HP-4l, but distinct PBS "grains" are more obvious in the lower temperature run HP-49. Scanning electron photomicrographs of HP-41 are shown in Figure 24. Figure $24 a$ shows that the composite is not strictly homogeneous. Figure 24b. shows a waste region (1ight grey and white) surrounded by 

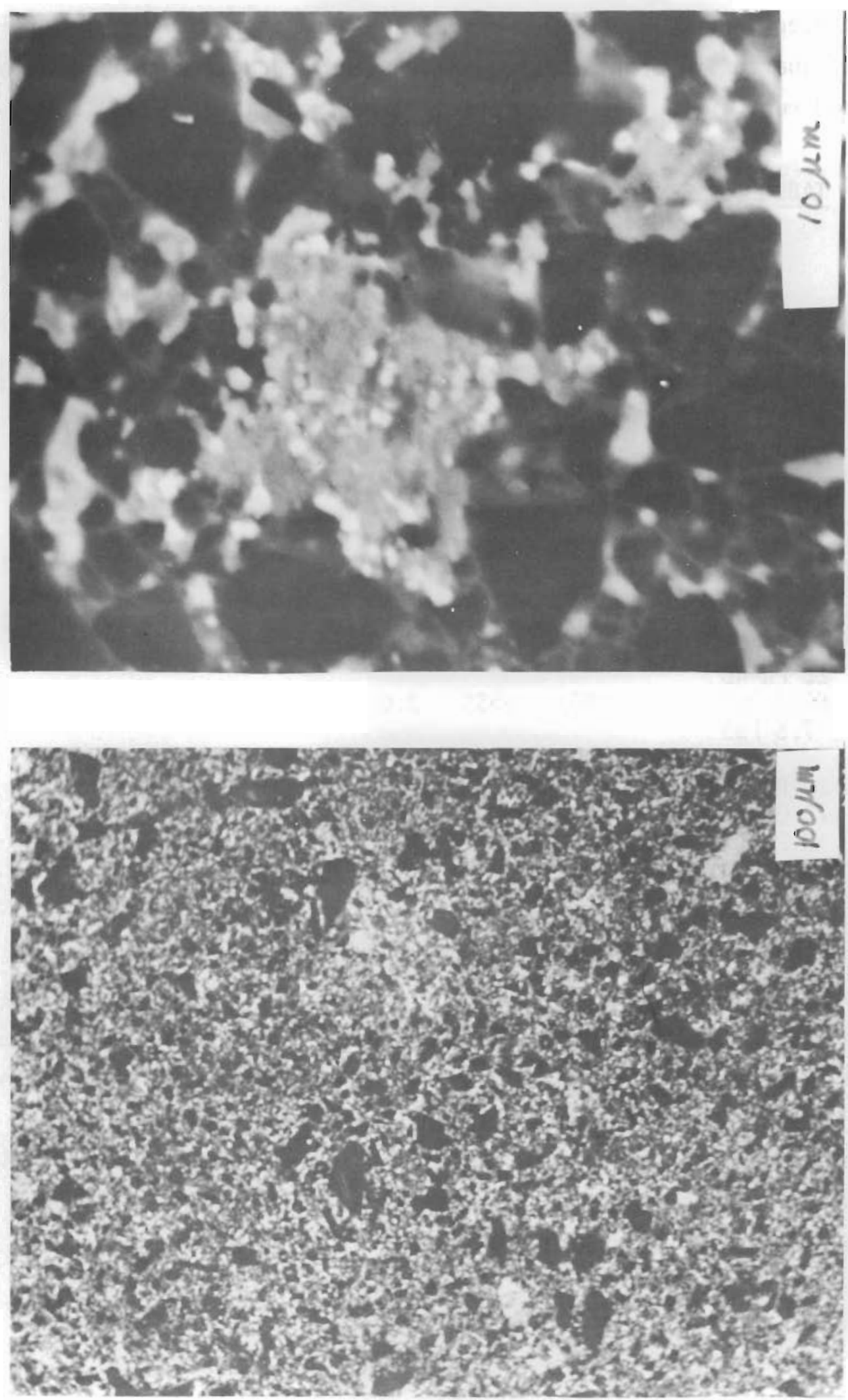

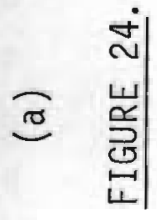


quartz grains (dark) which are bonded together by glass (chiefly PBS). The waste region is not actually "isolated" by a continuous shield of quartz grains alone, and thus the integrity of the composite depends both on the quartz grains and the bonding glass.

- $X$-Ray Phase Analysis of HP-41. Major phases are the polymorphs of $\mathrm{SiO}_{2}, \sim 90 \% \alpha$-quartz and the balance cristobalite (i.e., some of the original quartz was transformed to cristobalite during $1200^{\circ} \mathrm{C}$ processing). The phases from the waste included two fluorite structure solid solutions (SS), one rich in $\mathrm{CeO}_{2}$, the other in $\mathrm{ZrO}_{2}$, a scheelite structure SS rich in $\mathrm{SrMOO}_{4}, \mathrm{RuO}_{2}$, and a spinel structure SS rich in $\mathrm{NiFe}_{2} \mathrm{O}_{4}$. In a survey of all formulations the scheelite structure SS always had a larger unit cell when PBS glass rather than Pyrex glass was used. This implies that there is some $\mathrm{PbMoO}_{4}$ solid solution in $(\mathrm{Ba}, \mathrm{Sr}) \mathrm{MoO}_{4}$. In runs with high PBS glass additions, microscopic orange $\mathrm{PbMoO}_{4}$ regions were visible.

- Leaching of HP-41. Nine separate determinations of leachability of this waste form by the soxhlet accelerated method gave an average weight loss value of $1.19 \%$ with a standard deviation of $0.15 \mathrm{wt} \%$. Chemical analysis of the leaching solutions by atomic absorption spectrometry indicates that 6 to $12 \%$ of the Cs present in this waste form is removed by soxhlet leach testing in $72 \mathrm{hr}$.

Leaching of HP-41 was continued for 10 days. Weight lost after that duration was $1.9 \%$, and Cs analysis of the leaching solutions showed that $\sim 17 \%$ of the $C s$ in the waste form was removed by the leaching. Extrapolation of graphs of these losses as a function of time implied that they would level off at about twice these values after 20 to 40 days of 1 eaching.

- X-Ray Phase Analysis After Leaching. Phase assemblage was identical. The only change is a broad maximum peak near the strongest reflection of cristobalite. This implies that some of the quartz has been converted to amorphous silica by the hot water leaching. 
- Thermal Stability. Long-term tests on the thermal stability of the HP-41 product were made at the following temperatures chosen in relation to RSSF type storage:

$1050^{\circ} \mathrm{C}$ : "cooling accident"

$900^{\circ} \mathrm{C}$ : early model for maximum storage centerline temperature

$800^{\circ} \mathrm{C}$ : current model of centerline temperature

Four particle sizes were studied: $<150 \mu \mathrm{m}, 250-350 \mu \mathrm{m},>500 \mu \mathrm{m}$ and fragments weighing about $1 \mathrm{~g}$. Weight loss due to volatilization was a function of temperature, time and surface area:

1. $1050^{\circ} \mathrm{C}$ : after one week weight loss of the finest grains had leveled off at $\sim 13 \%$ and the coarsest at $\sim 6 \%$.

2. $900^{\circ} \mathrm{C}$ : the spread of weight losses after one week was smaller here and ranged from $0.8 \%$ to $2.4 \%$ depending on particle size.

3. $800^{\circ} \mathrm{C}$ : only smal1 losses were recorded at this temperature for even the finest grains $(<150 \mu \mathrm{m})$; after 14 days the loss was only $0.59 \%$.

The species lost to volatilization are being determined at PNL, but previous experience would indicate that these will be chiefly the oxides of $\mathrm{Cs}, \mathrm{Rb}, \mathrm{Ru}$ and Te from the waste and probably $\mathrm{Pb}$ from the matrix. From the rapid decrease in weight loss with temperature demonstrated in these measurements, we can project that as long as the waste form remains monolithic there should be no problem with volatilization.

- X-Ray Phase Analysis of HP-41 After Heat Treatment

After seven days at $1050^{\circ} \mathrm{C}$ most of the quartz in the matrix had been transformed to cristobalite. The relative intensities of the waste phases were somewhat different and the reflections were sharper, but the major phases remained the same. $\mathrm{RuO}_{2}$ was gone. There was no change in phase assemblage when HP-41 was heated at 900 or $800^{\circ} \mathrm{C}$ for up to 14 days. 
- PW-7 Type Wastes. Several reconnaissance runs using simplified versions of $\mathrm{PW}-7 \mathrm{a}$ (high $\mathrm{Na}$ ) and $\mathrm{PW}-7 \mathrm{~b}$ (high $\mathrm{Na}+\mathrm{Fe}$ ) were carried out. Because of the high alkali content of each waste, it was expected that an alkali-silicate-rich liquid would form during processing and thus lower processing temperatures could be used. With a $90 \%$ quartz - 10\% PBS matrix and 30\% waste loading at a hot pressing temperature of $1000^{\circ} \mathrm{C}$ a dense, hard but obviously nonhomogeneous product was produced in each case. There were macroscopic regions of red-brown waste in a light colored (probably sodium-silicate-rich) matrix. The products were clearly unsatisfactory, and no further characterization was performed.

It was apparent that because of the radical differences in the waste compositions compared to $\mathrm{PW}-4 \mathrm{~b}$ that a considerable number of runs might have to be made in order to optimize formulations, processing parameters and product properties. If work using these waste formulations is to be resumed, we recommend that an aluminosilicate rather than a simple silicate matrix be used since sodium silicates are known to have considerable solubility.

\section{SUPERCALCINE - G. J. McCarthy}

"Supercalcine" is a term for a crystalline ceramic waste form prepared by modifying with selected additives the composition of the liquid waste stream from the reprocessing of high-level commercial power reactor spent fuel so that when it is dried, calcined and given additional heat treatment a series of thermodynamically stable, refractory, and leach-resistant crystalline phases will be formed.

Work on development of supercalcine continues in two tasks. First, phases suitable for fixation of Cs are being examined separately, and, second, supercalcine formulations for a somewhat simplified 10-component version of $\mathrm{PW}-4 \mathrm{~b}$ are being tested. 
CS FIXATION - G. J. McCarthy and S. A. Gallagher

The objective is to look for and characterize phases which could fix $\mathrm{Cs}$ and which are refractory (stable to $\sim 1050^{\circ} \mathrm{C}$ in air) and leach resistant. Because of the size of $\mathrm{Cs}$, one is largely limited to oxide structure types which can contain very large cations, such as the perovskite and scheelite families, and the framework aluminosilicates with large stuffing sites. The following phases have been or are being studied:

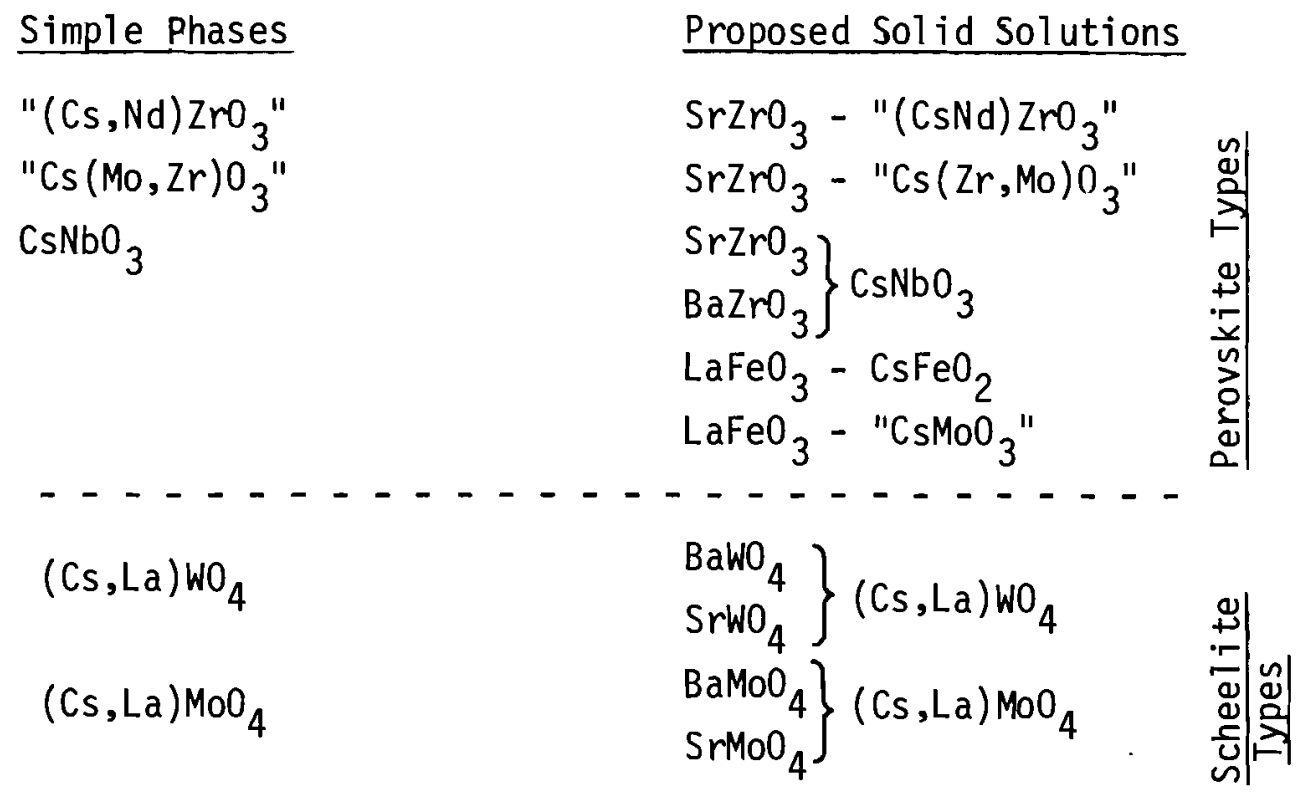

So far, not one of the above phases has been successful in completely preventing $\mathrm{Cs}$ volatilization at $1050^{\circ} \mathrm{C}$. (Cs,La)WO 4 is sufficiently refractory at $\sim 950^{\circ} \mathrm{C}$, but near $1050^{\circ} \mathrm{C}$ it melts and vaporizes. Phases with the normal $\mathrm{PW}-4 \mathrm{~b}$ distribution of rare earths rather than just La are somewhat more refractory and are under investigation. (Cs, La) $\mathrm{MoO}_{4}$ is less refractory than $(\mathrm{Cs}, \mathrm{La}) \mathrm{WO}_{4}$. Neither of these phases has the simple scheelite structure type, and their detailed structure is stil1 unknown. Attempts to solid solution stabilize them with or in the $\mathrm{Ba}$ and $\mathrm{Sr}$ molybdates and tungstates which do have the simple scheelite structure have been made, but preliminary results indicate that no significant solid solutions in any of the end members are formed at $1050^{\circ} \mathrm{C}$.

Emphasis in Cs fixation research has shifted to the framework a luminosilicates. 
FORMULATIONS - G. J. McCarthy, D. E. Pfoertsch and C. A. Smith

The procedure for designing supercalcine formulations based on a series of crystal chemical hypotheses was described in the last two Quarterly Reports (BNWL-1871 and 1893). We continue to use a 10-cation component version of $\mathrm{PW}-4 \mathrm{~b}$ consisting of ( $\mathrm{Nd}, \mathrm{Ce}, \mathrm{Zr}, \mathrm{Mo}, \mathrm{Cs}, \mathrm{Sr}, \mathrm{Ba}, \mathrm{Fe}$, $\mathrm{Ni}, \mathrm{Cr}$ ) in our screening tests. Ten formulations were studied which made use of the following additives and proposed phase formations:

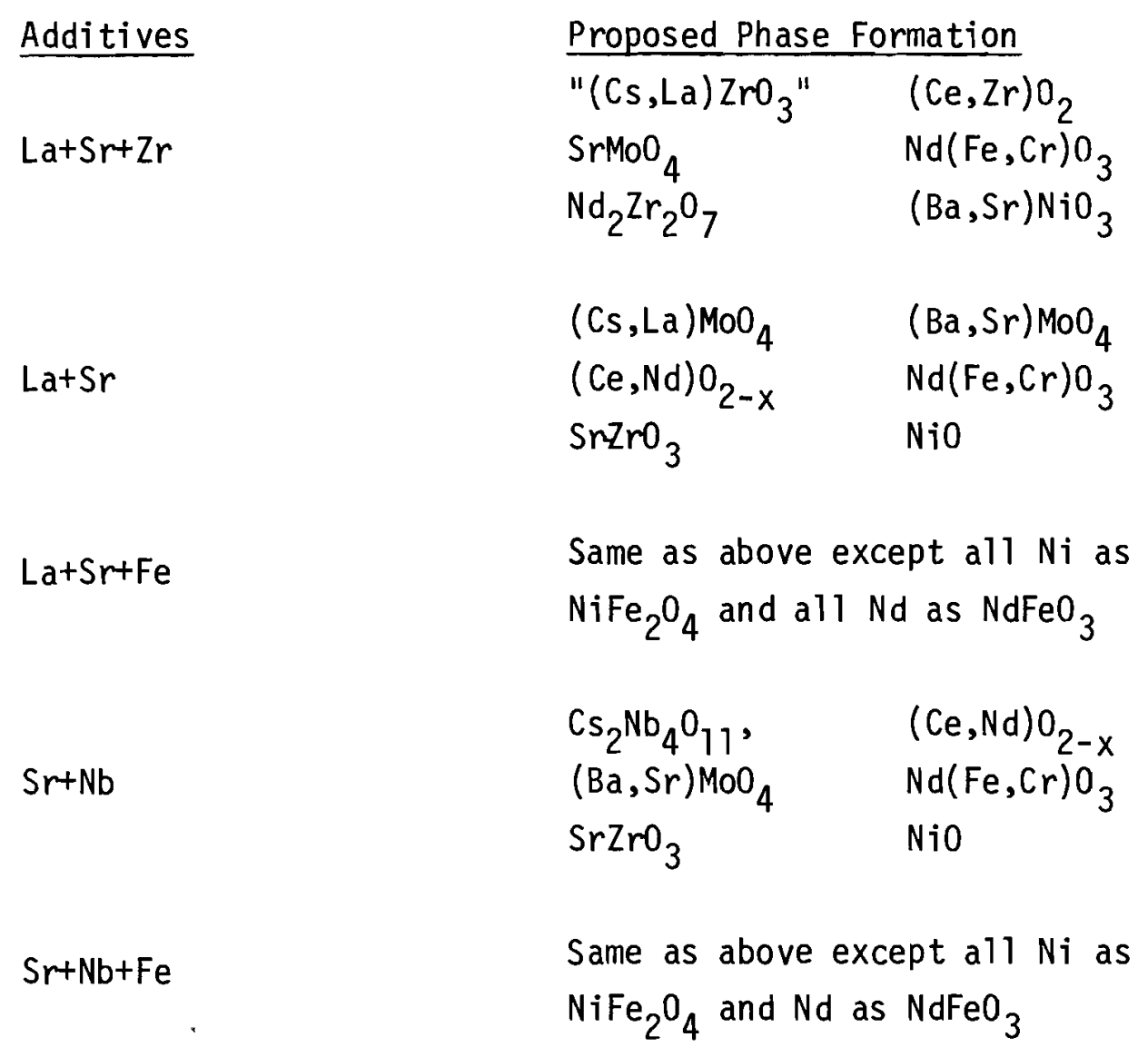

We noted in the last report that Cs was the major problem among the 10 components of $\mathrm{PW}-4 \mathrm{~b}$ being considered because it vaporizes during the firing step $\left(1050^{\circ} \mathrm{C}\right.$ for $\left.6 \mathrm{hr}\right)$. In the most recent 10 formulations none of the cations added to promote Cs fixation succeeded. This was shown 
by weight loss on firing and by the 1 ack of Cs phases in the product. Another simple test for Cs loss on firing was devised whereby a pellet of the formulation is placed inside a silica glass tube inside a furnace at $1050^{\circ} \mathrm{C}$. If $\mathrm{Cs}$ is vaporized, it immediately attacks and clouds the adjacent glass, forming Cs silicate glass. If the glass is clear, Cs has been retained by the pellet. Any other oxide species vaporizing will collect on the water-cooled outer end of the tube.

It is not surprising now that " $(\mathrm{Cs}, \mathrm{La}) \mathrm{ZrO}_{3}$ " and $(\mathrm{Cs}, \mathrm{La}) \mathrm{MoO}_{4}$ did not fix Cs during the $1050^{\circ} \mathrm{C}$ firing since we later showed that the former did not exist and that the latter melted and vaporized below $1050^{\circ} \mathrm{C}$. However, $\mathrm{Cs}_{2} \mathrm{Nb}_{4} \mathrm{~N}_{11}$ is a well characterized refractory phase of $\mathrm{Cs}$, and yet several formulations with varying amounts of $\mathrm{Nb}_{2} \mathrm{O}_{5}$ added still lost $\mathrm{Cs}$ when fired. The answer lies in the preference of $\mathrm{Nb}$ to substitute in the octahedral site in perovskite type structures. These phases were especially prominent in the $X$-ray phase assemblages whenever $\mathrm{Nb}$ was added.

Our hypotheses on phase formation for the other nine cations are generally valid since the proposed phases are usually observed in the products, although never as the pure end-member compositions 1 isted above. There is no evidence for significant vaporization on firing of any of these components. However, a brown stain often observed near the Pt crucible support brick implies that a small amount of Fe is carried off with Cs when it vaporizes. The most important finding to date is that $\mathrm{MoO}_{3}$, potentially one of the greatest vaporization problems, has an affinity for Sro to form the refractory phase, $\mathrm{SrMoO}_{4}$. Future supercalcine formulations will doubtless include $\mathrm{Sr}$ as an additive for Mo fixation.

The six most recent formulations prepared used $\mathrm{Si}$ or $(\mathrm{Si}+\mathrm{A} 1)$ as Cs fixation additives. Although analysis of the products is incomplete, the results look promising. The weight losses are much lower than are usually observed. There is still some Cs loss on firing, as evidenced by the silica tube experiments. Our emphasis has now shifted to aluminosilicates for Cs fixation. 


\section{SYSTEMS EVALUATION}

The purpose of the Systems Evaluation Task is to define and investigate waste management systems in relation to the containment, immobizization, and isolation of the wastes and to evaluate the risk and cost implications of these systems. Currently, the likelihood and consequences (risk) of potential release incidents are being estimated for a reference system for the management of high-level waste that includes liquid storage through retrievable surface storage operations. *

\section{SUMMARY}

Computer codes were written to evaluate the probability of previously identified failure sequences, release fractions, and ordered risk measures of the sequences. The codes will be used in evaluating the large fault trees developed for the reference systell. Distribution coefficients (Kd values) for the movement of selected radionuclides through a "typical" saturated southeastern United States subsoil in contact with "typical" groundwater were estimated. Estimates were made of the surface distribution of material deposited downwind of an accidental release.

FAULT TREE EVALUATION METHODOLOGY - T. H. Smith, P. J. Pelto, G. D. Seybold, W. L. Purce11

The objective of this effort is to develop a suitable automated methodology for evaluating large fault trees representative of complex waste management facilities and operations. The approach is to develop a computer code system capable of importance-screening very large numbers of failure sequences (cut sets). The screening is to be based on a crude measure of risk rather than on probability or consequences individually. Cut sets so identified as constituting relatively high risk wizl be retained for more detailed analysis.

* The reference system is described in previous WFP Quarterly Progress Reports, BNWL-1761, BNWL-1809, and BNWL-1826. 
A code has been written to evaluate the probability of previously identified cut sets. Repairable and nonrepairable components, mixed cut sets, inhibit conditions, on-line and standby components, detection, repair, maintenance and testing, and allowed outage times can all be accommodated. The code has been checked out on a small but complex fault tree.

A code has been written to evaluate release fractions and ordered risk measures of cut sets. Checkout was performed on a small but complex fautt tree.

Work is continuing on a high-capacity, high-efficiency code for identifying cut sets and for performing a preliminary screen. All of the codes will be checked out on the large fault tree representing water bas in storage waste. Basic event failure probabilities and release fractions are being derived for that tree.

TRANSPORTATION OF SOL IDIFIED HIGH-LEVEL WASTE - E. S. Murphy

The purpose of this activity is to estimate the risk in shipment of solidified high-level waste by rail transportation from a reprocessing plant to an interim storage facility (RSSF).

The fault tree for identifying failure modes and failure sequences which could result in a release of radioactivity to the environment during rail transportation was redrawn to permit quantitative evaluation using the computer codes developed during the quarter. Figure 25 shows the top levels of the fault tree. One branch in the tree describes the release of radioactive material to the environment as a result of cask and canister failure initiated by a collision accident (gate A-12). The use of inhibit gates for probabilistic description of cask and canister failure associated with a collision accident is shown in Figure 26. The conditional probability of containment failure resulting from any given collision accident is obtained by forming the product of the probability that a collision accident occurs, the fraction of collision accidents which result in accident environments of given severity, and the fraction of severe accident environments which result in containment failure. For each conditional probability, an associated release fraction is then assigned based on the severity of the accident environment and on the 


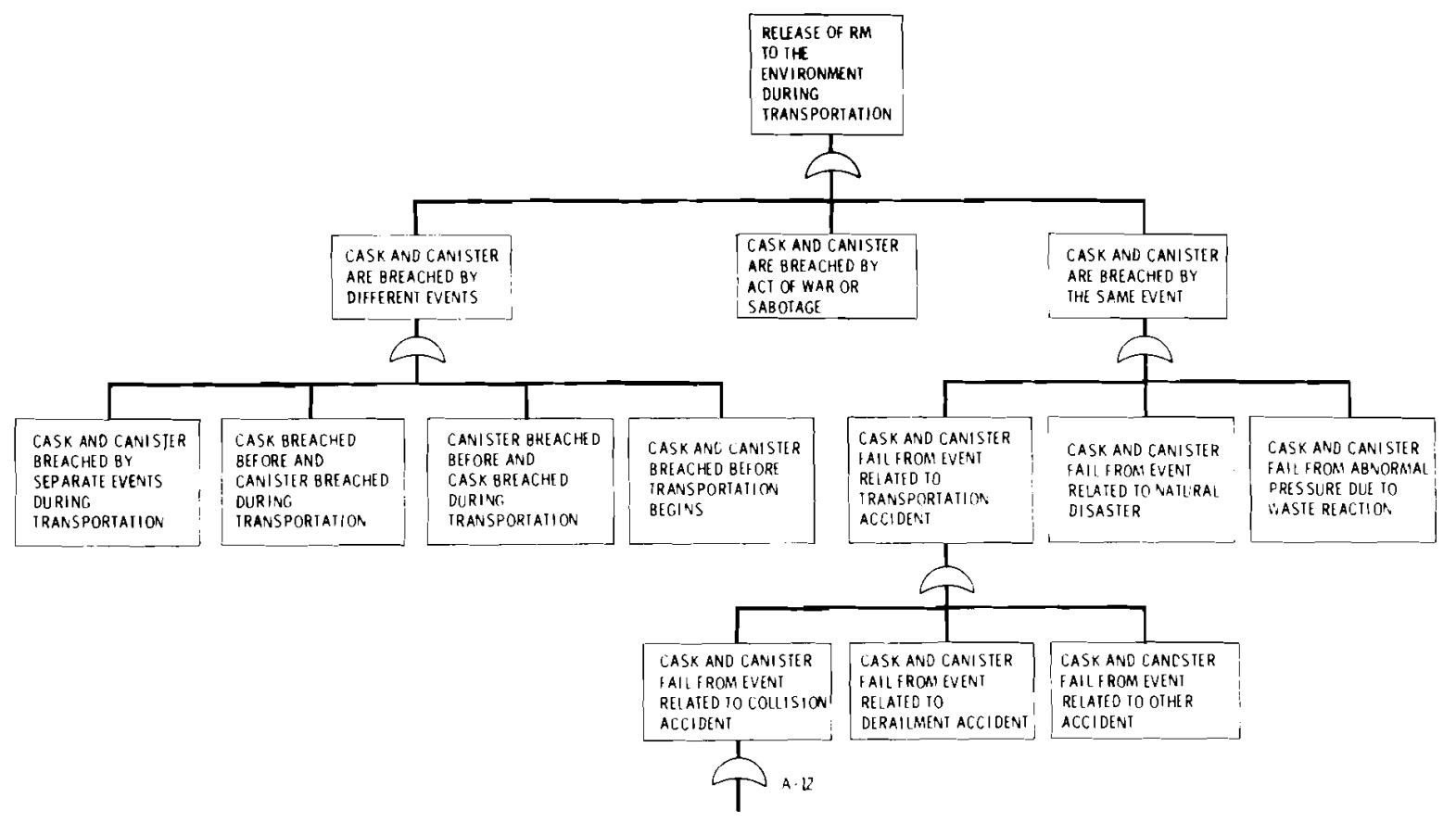

FIGURE 25. Top Levels of the Rail Transportation Fault Tree

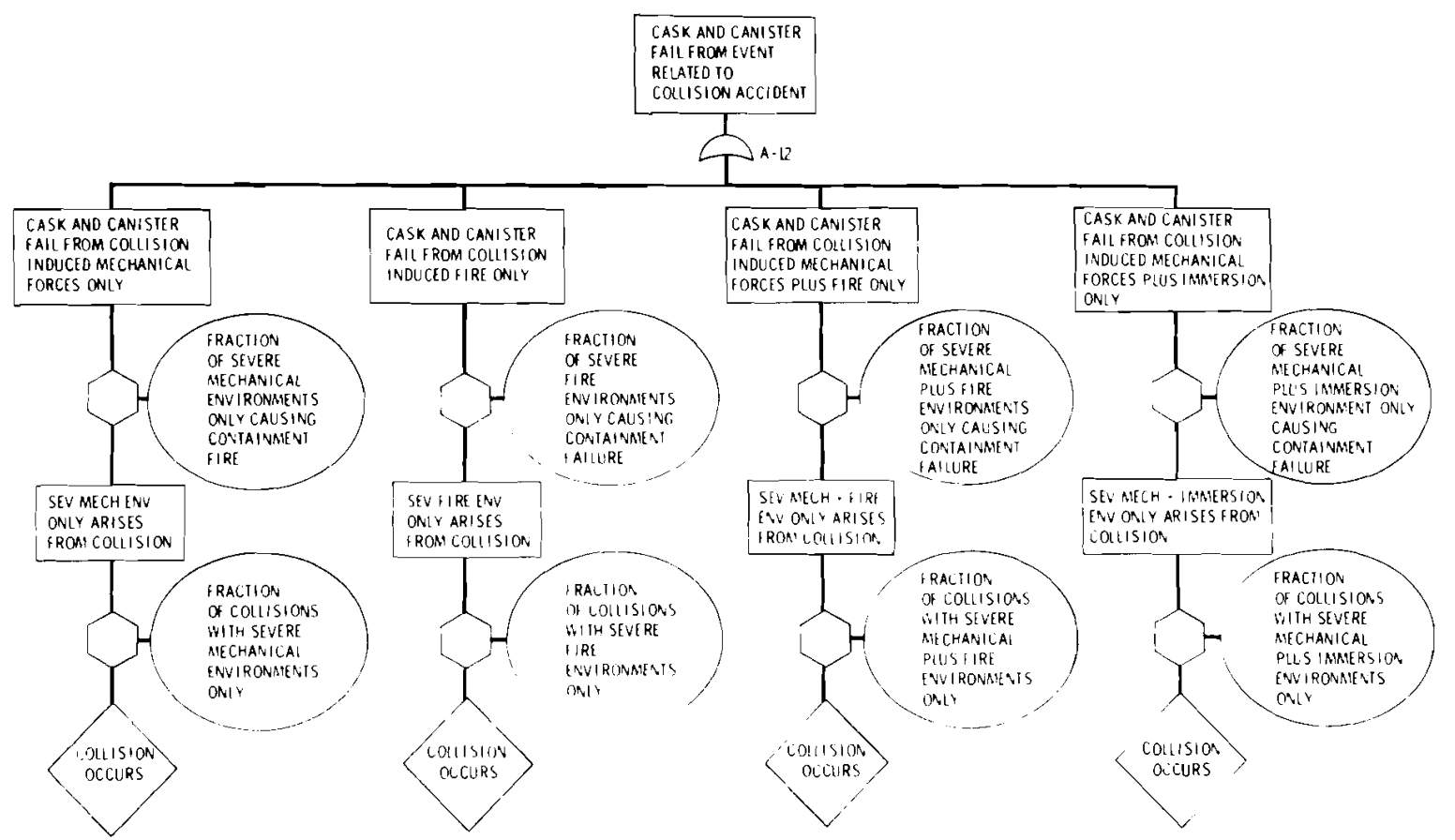

FIGURE 26. Example of the Use of Inhibit Gates in the Rail Transportation Fault Tree 
prior integrity of the containment system. Evaluation of the rail transportation fault tree using the procedure outlined above will be carried out during the next reporting period.

\section{LIQUID STORAGE AND TRANSFER - J. M. Taylor}

The purpose of this activity is to estimate the risk associated with storage and transfer of high-level liquid waste.

The top level of the fault tree developed to identify failure sequences is shown in Figure 27. The tree is based on a system that includes storage in tanks housed in stainless steel-lined underground concrete vaults and transfer via steam jets. Piping for liquid transfers is also installed in stee $7-1$ ined concrete vaults.

Probability and release data are being compiled, and during the next report period the fault tree will be evaluated using the recently developed computer codes.

\section{MIGRATION OF RADIOACTIVE ELEMENTS THROUGH SUBBSOILS - R. C. Routson}

The objective of this task is to develop information for use in estimating the extent of migration of radionuclide chains through various U.S. subsoils.

Distribution coefficients and retardation factors (Table 20) for the movement of selected radioactive elements through a "typical" saturated southeastern United States subsoil in contact with "typical" groundwater (Table 21) were estimated during the quarter. Because of the generally lower $\mathrm{pH}$ and mineralogy typical of the southeast, the distribution coefficients (Kd values) are generally lower than those previously estimated for a "typical western desert soil.* The values will be used to estimate the extent of migration of radionuclide chains through subsoils, providing a gross comparison of the inherent confinement characteristics of the two soil types.

* K. J. Schneider and A. M. Platt, Editors, High-Level Radioactive Waste Management Alternatives, Section 3, "Evaluation Methodology," BNWL-1900, vol. 1, Battelle, Pacific Northwest Laboratories, Richland, Washington, May 1974. 

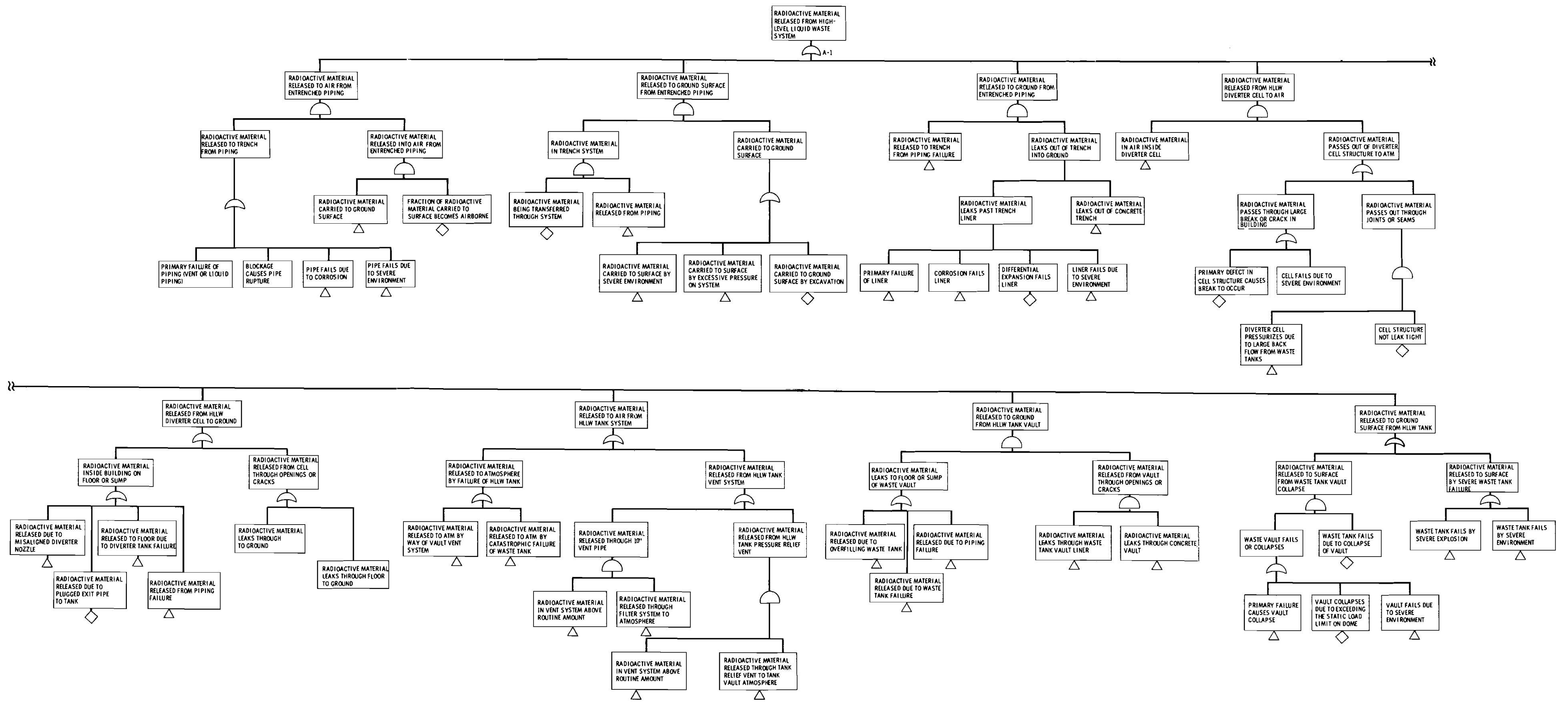


\section{TABLE 20. Estimated Distribution Coefficients for Trace Radionuclides in Southeastern United States Soil}

Atomic No.

Element

Tritium

Beryllium

Carbon

Sodium

Chlorine

Argon

Potassium

Calcium

Iron

Cobalt

Nickel

*Selenium

Krypton

Rubidium

Strontium

Yttrium

Zirconium

Niobium

*Molybdenum

Technetium

*Pal 7 adium

Cadmium

Tin

Antimony

Iodine

Cesium

Promethium

Samarium

Europium

Holmium

Thallium

Lead

*Bismuth

*Polonium

Astatine

Radon

Francium

Radium

*Actinium

Therium

*Protactinium

Uranium

Neptunium

Plutonium

Americium

Curium

*Berkel ium
$\underline{K d(m l / g)}$

$\underline{V i / V w}$

1

0.03

1

0.07

1

0.02

0.1

20

2

2

3

0

75

10

2,000

2,000

2,000

500

0

250

2,000

250

0

0

100

12

12

12

12

- 20

4,000

1

30

0

0

100

25
75

15,000

150

15
0.8

150

75

75

75
0.8

0.02

0.2

0.2

0.1

1

0.005

0.04

0.0002

0.0002

0.0002

0.0008

0.002

0.0002

0.002

1

1

0.004

0.03

0.03

0.03

0.03

0.02

0.0001

0.3

0.01

1

1

0.004

0.01

0.005

0.00002

0.002

0.02

0.3

0.002

0.005

0.005

0.005

* Poorly known - based on analogues 
TABLE 21. Estimated Composition of Groundwater Below a Typical Southeastern United States Area

$\mathrm{pH} \quad \underline{\mathrm{SO}}_{4}=\quad \underline{\mathrm{NO}}_{3}^{-} \quad \underline{\mathrm{Cl}^{-}} \quad \underline{\mathrm{HCO}}_{3-}^{-} \quad \underline{\mathrm{Na}^{+}}+\underline{\mathrm{K}}^{+} \quad \underline{\mathrm{Ca}^{++}} \quad \mathrm{Mg}_{-}^{++}$

$\begin{array}{llllllll}5-5.5 & 11 & 1 & 2 & 12 & 4 & 6 & 1\end{array}$

CONSEQUENCES OF RESUSPENSION OF AN AIRBORNE RELEASE - T. W. Horst

Materials accidentally released to the environment can present an airborne hazard in two ways. First, the original release may result in an airborne plume. Further, since the material in this original plume may deposit on the ground, there is an additional potential airborne hazard due to the resuspension and atmospheric transport of the deposited matemal. The objective of this study is to investigate the relative hazard of the resuspended material compared with that of the original plume.

The probable distribution of the original plume, as well as the resulting deposition to the ground, was calculated during the quarter. These computations were made for the case of no deposition, for $v_{d} / u=10^{-2}$, and $v_{d} / u=10^{-3}$. These latter values for the ratio of deposition velocity to windspeed correspond to particles with a specific gravity of 3 and diameters of $10 \mu$ and $1 \mu$, respectively. In order to test the sensitivity of the results to the choice of deposition model, both the surface depletion and source depletion mode were used.

Using the surface distribution established as the source for resuspension, air concentrations are currently being calculated for case studies of resuspension during specified meteorological conditions. In order to assess the relative importance of resuspension to the evaluation of the airborne hazard, the exposure (the time integral of the air concentration) due to resuspension will then be compared to the exposure due to the original plume during similar meteorological conditions. 
No. of

Copies

OFFSITE

UNITED STATES

1 ERDA Chicago Patent Group 9800 South Cass Avenue Argorine, IL 60439

A. A. Churm

2 NRC Directorate of Licensing

for Fuels and Materials

4915 St. Elmo Avenue

Bethesda, MD 20014

Deputy Director for Fuels and Materials

S. H. Smiley

Chief, Technical Support Branch for Fuels and Materials

R. B. Chitwood

1 ERDA Division of Biomedical and Environmental Research Earth Sciences Branch Washington, DC 20545

W. G. Belter

1 ERDA Division of Production and Materials Management

Washington, DC 20545

F. P. Baranowski

2 ERDA Division of Reactor Research and Development Washington, DC 20545

Assistant Director for Reactor Technology

E. E. Sinclair

Chief, Fuel Recycle Branch

W. H. McVey
No. of

Copies

7 ERDA Division of Waste Management and Transportation Washington, DC 20545

G. H. Daly

W. K. Eister

0 . P. Gormley

A. F. Perge

F. K. Pittman

R. W. Ramsey

R. D. Walton

1 ERDA Idaho Operations Office P. 0. Box 2108 Idaho Falls, ID 83401

K. K. Kennedy

1 ERDA 0ak Ridge Operations 0ffice P. 0. BoX X

Oak Ridge, TN 37830

E. H. Hardison

1 ERDA Savannah River Operations Office P. 0. Box A

Aiken, SC 29801

R. L. Chandler

215 ERDA Technical Information Center

5 Allied Chemical Corporation 550 - 2nd Street Idaho Falls, ID 83401

J. A. Buckham

B. R. Dickey

E. W. Rhodes

C. M. Slansky

B. R. Wheeler

3 Allied-Gulf Nuclear Services P. 0. Box 847 Barnwell, SC 29812

B. M. Legler

G. R. Bray

A. Schneider 
No. of

Copies

1 Bechte1 Corporation

50 Beale Street

San Francisco, CA 94119

1 Brookhaven National Laboratory

Research Library, Reference Section

Information Division

Upton, Long Island, NY 11973

M. Steinberg

1 C-E Refractories

Box 828

Valley Forge, PA 19482

Alfred W. Allen

1 Ceramic Engineering

University of Il1inois

Urbana, IL 61801

Dr. Dennis O'Boyle

1 Combustion Engineering, Inc. Combustion Division

Windsor, CT 06095

Jack Parry

1 Corning Glass Works

Technical Staff's Division

Corning, NY 14830

M. G. Britton

1 Desert Research Institute

University of Nevada System

Reno, NV 89507

P. Senske

1 Dow Chemical Company (ERDA)

Rocky Flats Division

P. 0. Box 888

Golden, CO 8040]

D. L. Ziegler
No. of

Copies

4 duPont Company, Aiken (ERDA)

E. I. duPont DeNemours and Co.

Savannah River Laboratory

Aiken, SC 29801

C. H. Ice

A. S. Jennings

L. H. Meyer

R. W. Wallace

1 duPont Company, Wilmington (ERDA)

E. I. duPont DeNemours and Co.

Wilmington, DE 19898

A. A. Johnson

1 Environmental Protection Agency

Technology Assessment Div. (AW-559)

Office of Radiation Programs

U.S. Environmenta 1 Agency

Washington, DC 20460

G. L. Meyer

1 Environmental Protection Agency P. 0. Box 15027

Las Vegas, NV 89114

B. Mann

1 Environmental Protection Agency 5555 Ridge Avenue

Cincinnati, $\mathrm{OH} 45213$

R. E. Landreth

1 E. R. Johnson Associated, Inc. Suite 317 910 17th N.W.

Washington, DC 20006

J. P. McBride

2 Exxon

RichTand, WA 99352

S. J. Beard

L. T. Lakey 
No. of

Copies

1 General Electric Company

175 Curtner Avenue (M/C 160)

San Jose, CA 95125

R. G. Barnes

1 General Electric Company

Midwest Fuel Recovery Plant Route 1, Box 219-B

Morris, IL 60450

R. Lambert

2 General Electric Company

Vallecitos Nuclear Center

Vallecitos Road

Pleasanton, CA 94566

W. H. Reas

1 Gibbs and Hi11, Inc. 393 Seventh Avenue

New York, NW 10001

P. P. DeRienzo

3 General Atomic Co.

P. 0. Box 81608

San Diego, CA 92138

L. H. Brooks

J. J. Shefcik

M. E. Spaeth

4 Holifield National Laboratory (ERDA)

Central Research Library

Document Reference Section

Central Research Library, HNL

Laboratory Records Dept., HNL

Laboratory Records Dept., HNL-RC

P. 0. Box X

Oak Ridge, TN 37830
No. of

Copies

1 Los Alamos Scientific Laboratory (ERDA)

P. 0. Box 1663

Los Alamos, NM 87544

C. W. Christenson

1 National Academy of Sciences Committee of Radioactive Waste Management

2101 Constitution Avenue NW Washington, DC 20418

D. Cyrus Klingsberg,

Technical Secretary

1 National Lead Company

111 Broadway

New York, NY 10006

Stephen Brown

2 Nuclear Fuel Services, Inc. P. 0. Box 124 West Valley, NY 14171

J. P. Duckworth,

Plant Manager

6000 Executive Blvd., Suite 600

Rockville, MD 20852

E. D. North, Director of

Technical Administration

1 Nuclear Safety Associates

5101 River Road

Bethesda, MD 20016

W. A. Rodger

1 Nuclear Water and Waste

Technology

P. 0 . Box 6406

San Jose, CA 95150

W. L. Pearl 
No. of

Copies

1 Numen

609 Warren Avenue

Apol1o, PA 15613

C. R. Woods

1 NYS Atomic and Space

Development Authority

230 Park Avenue, Room 2425

New York, NY 10017

J. G. Cline, General Manager

1 Penberthy Electromelt

631 S. 96th Street

Seattle, WA 98108

L. Penberthy

1 Pennsylvania State University

Materials Research Laboratory

University Park, PA 16802

G. J. McCarthy

3 Sandia Laboratories

A7buquerque, NM 87107

R. L. Hagengruber

R. W. Lynch

A. C. Zuppero

3 Union Carbide Corporation (HNL) Chemical Technology Division P. 0. Box $Y$

Oak Ridge, TN 37830

J. 0. Blomeke

F. Gera

H. W. Godbee

1 University of California

Los Angeles

6532 Boelter $\mathrm{Ha} 11$

Los Angeles, CA 90024

John D. MacKenzie
No. of

Copies

FOREIGN

1 Atomic Energy of Canada Ltd. W.N.R.E. Pinawa, Manitoba, ROE 1LO

CANADA

$$
\text { P. J. Dyne }
$$

1 Atomic Energy Research

Establishment

Harwe11, Didcot, Berks.

ENGLAND

K. D. B. Johnson

1 United Kingdom Atomic Energy

Authority

RisTey, ENGLAND

D. W. Clelland

2 Centre de Marcoule

Boite Postale 106

30 - Bagnols S/Ceze

FRANCE

R. Bonniaud

3 Centre d'Etudes Nucleaires de Fontenay-aux-Roses

Boite Postale 6

92 - Fontenay-aux-Roses

FRANCE

J. Sauteron

Y. J. Sousselier

R. Villard

1 Bundesministerium für Bildung und Wessenschaft

D53 Bonn 12

Postfach 120124

GERMANY

R. P. Rand 1 
No. of

Copies

1 Hahn-Meitner-Institut

1 Berlin 39

Glienickerstr. 100

GERMANY

Hans W. Levi

2 Institut für Chemische

Technologie

Kernforschungsanloge Julich

GmbH

D517 Julich

Postfach 365

GERMANY

E. R. Merz

K. H. Rattay

1 Laboratorio di Ingegneria

Sanitaria

Via Anguîi 1larese km $1+300$

Roma, ITALY

Willy Bocola

2 International Atomic Energy Agency

Kartner Ring 11

P. 0. Box 590

A-1011, Vienna, Austria

1 MGH/GWK/Wiederac ifurbe itung Santage/WAK

Karlsruhe, GERMANY

W. A. Isse1

2 Nuclear Research Center

Waste Management Department

D75 Karlsruhe

Weberstr. 5

GERMANY

W. Krause

1 NUKEM

6450 Hanau

P. 0. BOX 869

W. GERMANY

Dr. Hartmut Witte
No. of

Copies

1 Dr. H. F. Ramdohr

c/o Friedrich Uhde Gmbh

46 Durtmund

Deggingstre 10-12

GERMANY

1 Government of India

Bhabha Atomic Research Center

Hal1 No. 5

Trombay

Bombay 85, INDIA

N. S. Sunder Rajah

ONSITE

2 ERDA Richland Operations Office Production and Waste Management Programs Division

0. J. Elgert

R. B. Goranson

1 ERDA Richland Operations Office

Safety and Quality Assurance Division

J. H. Straub, Director

11 Atlantic Richfield Hanford Co.

H. Babad

L. E. Brownel1

R. E. Isaacson

D. C. Nelson

R. C. Roal

H. P. Shaw

W. W. Shultz/M. J. Kupfer

R. J. Thompson

J. H. Warren

D. D. Wodrich

File Copy

2 United Nuclear Industries, Inc.

2 Westinghouse Hanford Company

C. R. Cooley

G. L. Richardson 
No. of

Copies

52 Battelle-Northwest
E. L. Alpen
R. J. Bashor
J. W. Bartlett
J. L. Bates
W. J. Bjork1 und
H. T. Blair
W. F. Bonner
D. J. Bradley
J. R. Carrel1
N. E. Carter
C. C. Chapman
T. D. Chikalla
G. M. Dalen
R. D. Dierks
J. W. Finnigan
T. A. Golding
J. N. Hartley
J. D. Kaser
R. P. Marsha 11

No. of

Copies
J. L. McEl roy (10)

J. E. Mendel

D. F. Newman

R. E. Nightingale

D. E. Olesen

P. J. Pelto

A. M. Platt

J. Posakony

F. P. Roberts

W. A. Ross

K. J. Schneider

D. H. Siemens

T. H. Smith

R. P. Turcotte

L. D. Williams/R. J. Hal1

W. K. Winegardner

Technical Information (5)

Technical Publications (3) 